INTERNATIONAL MONETARY FUND
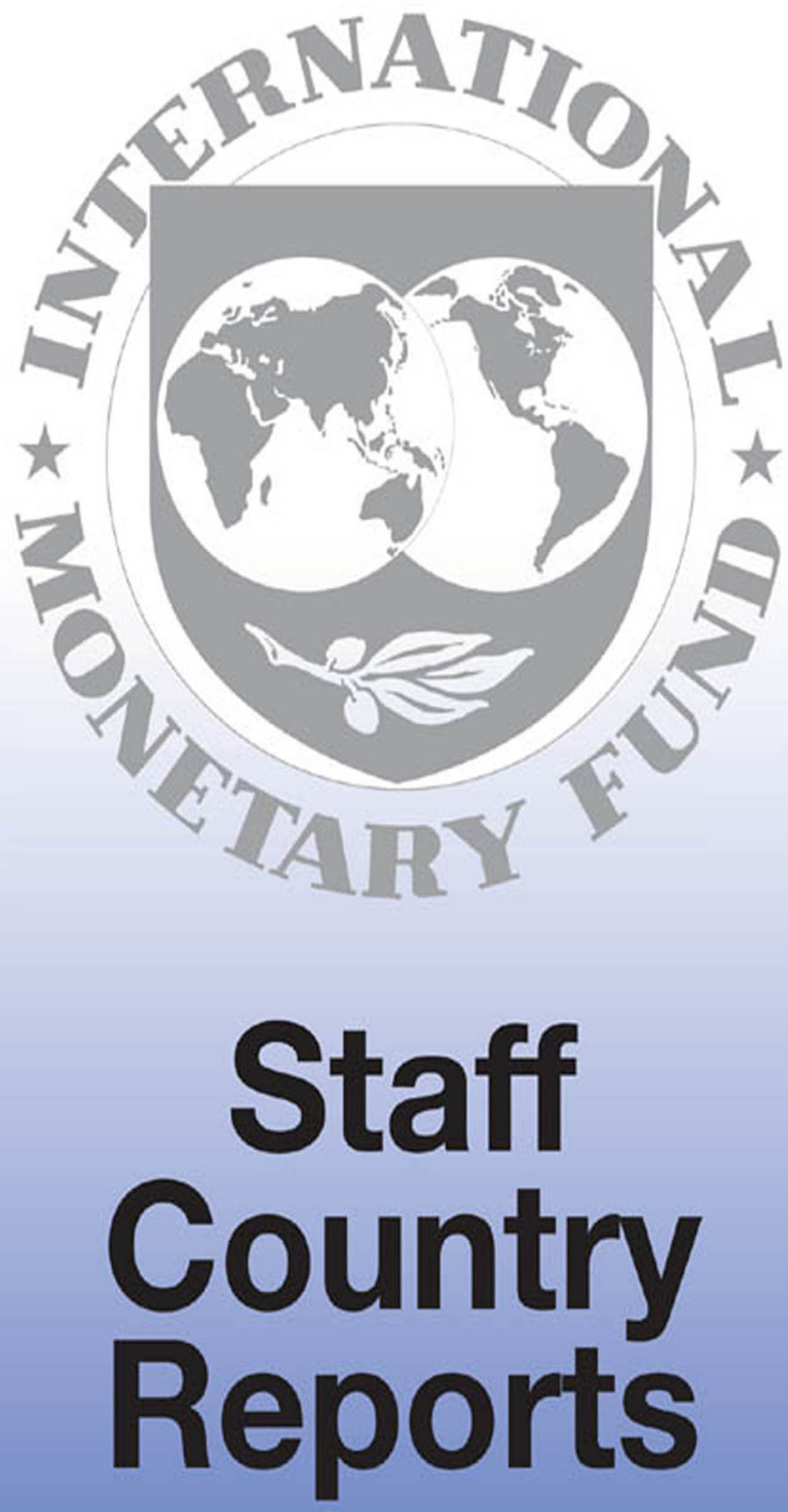


\section{Kyrgyz Republic: Medium-Term Development Program- Poverty Reduction Strategy Paper}

Poverty Reduction Strategy Papers are prepared by member countries in broad consultation with stakeholders and development partners, including the staffs of the World Bank and the IMF. Updated every three years with annual progress reports, they describe the country's macroeconomic, structural, and social policies in support of growth and poverty reduction, as well as associated external financing needs and major sources of financing. This country document for the Kyrgyz Republic, dated April 2012, is being made available on the IMF website by agreement with the member country as a service to users of the IMF website.

Copies of this report are available to the public from

International Monetary Fund • Publication Services

$70019^{\text {th }}$ Street, N.W. • Washington, D.C. 20431

Telephone: (202) 623-7430 • Telefax: (202) 623-7201

E-mail: publications@imf.org Internet: http://www.imf.org

\section{International Monetary Fund Washington, D.C.}


This page intentionally left blank 


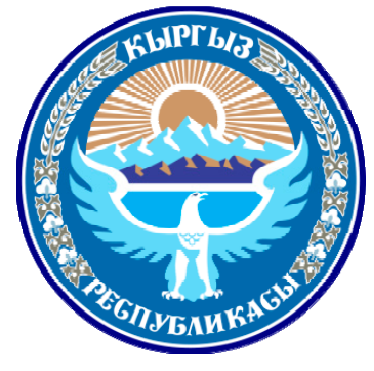

\section{MEDIUM TERM DEVELOPMENT PROGRAM OF THE KYRGYZ REPUBLIC FOR 2012-14}

Approved by

Government of the Kyrgyz Republic

Decree \#239

from April 12, 2012 


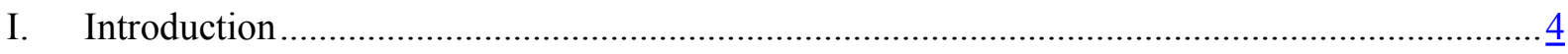

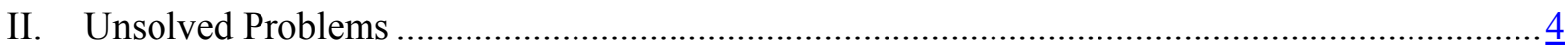

III. Post-Conflict Regulation....................................................................................... 5

IV. Goals and Objectives of the Country's Development ................................................... $\underline{6}$

V. Development of the Economy............................................................................................

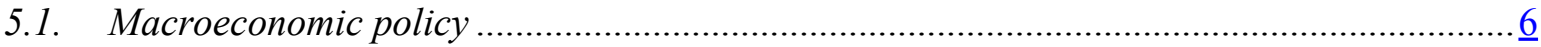

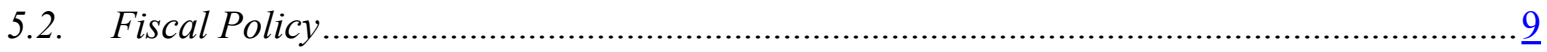

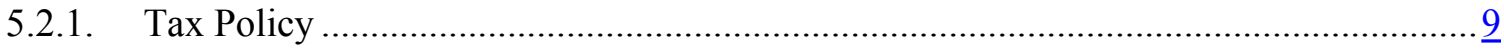

5.2.2. Public finance management and budgetary policy ............................................ 10

5.3. State debt administration strategy ............................................................................... 11

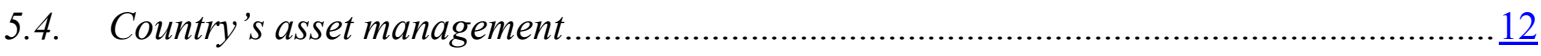

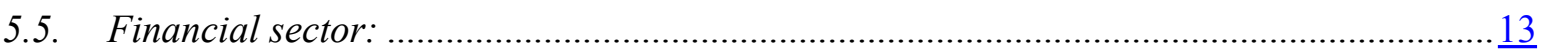

5.5.1. Banking and non-banking sector................................................................. 13

5.5.2. Stock/security and insurance market........................................................... 14

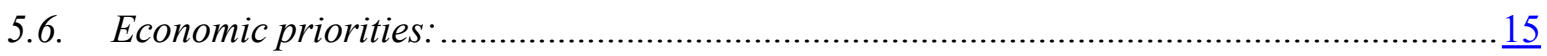

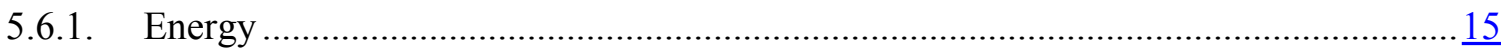

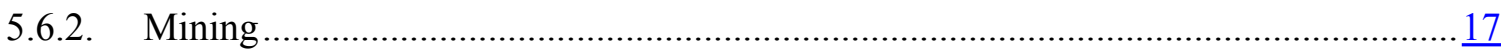

5.6.3. Agricultural sector and processing of the agricultural products ............................. 18

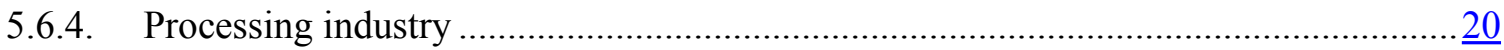

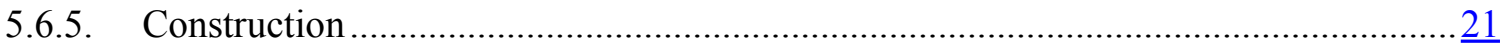

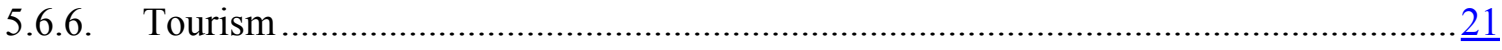

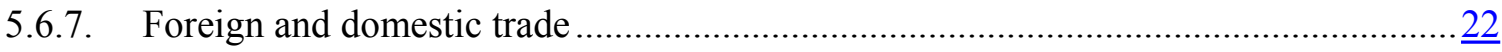

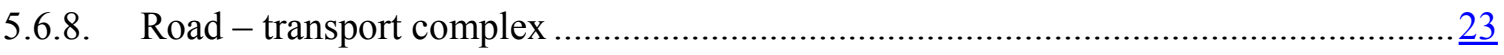

5.6.9. Communication and Information ................................................................... 24

5.6.10. Foreign Economic Policy ............................................................................. 25

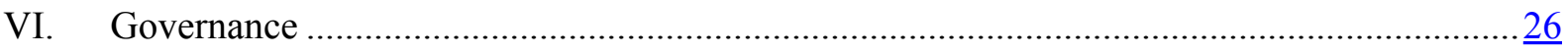

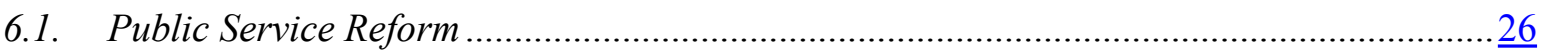

6.1.1. Assessment of effectiveness of the government institutions activity ........................ 26

6.1.2. Reform of working conditions of the public servants.......................................... 27

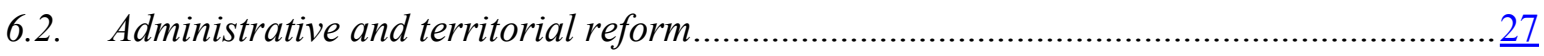

6.3. Combating corruption ............................................................................................. 27

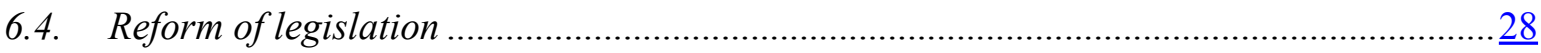

VII. Improvement of development environment ............................................................... 29

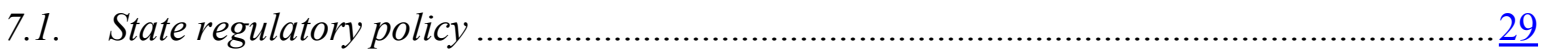

VIII. Social development and poverty reduction strategy................................................. $\underline{30}$

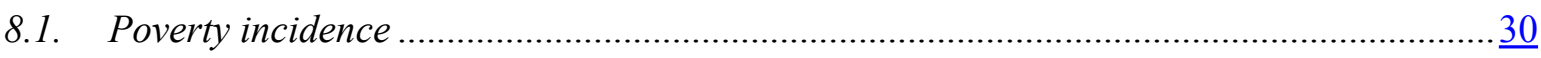

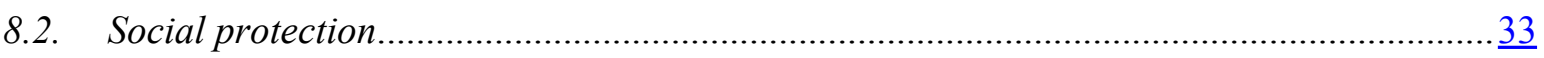




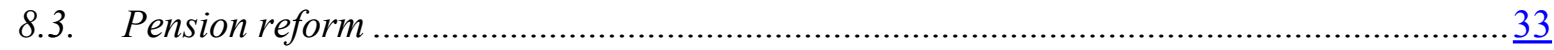

8.4. Development of the system of education ...................................................................... 34

8.5. Health system development ....................................................................................... 36

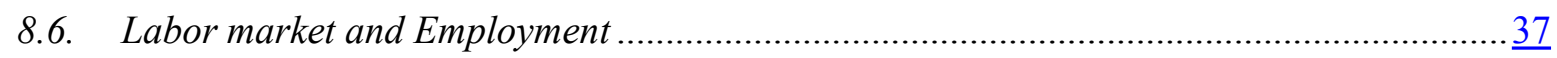

8.7. Culture and religious aspects ............................................................................

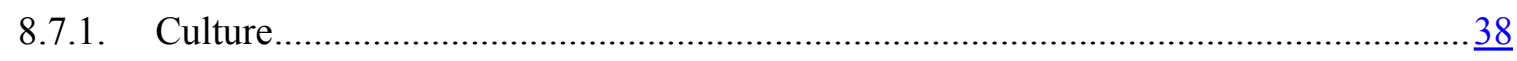

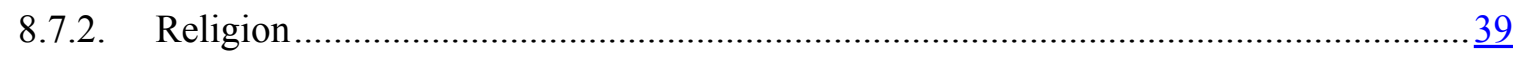

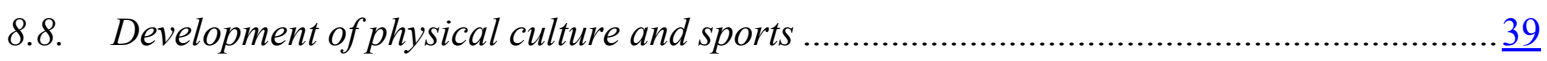

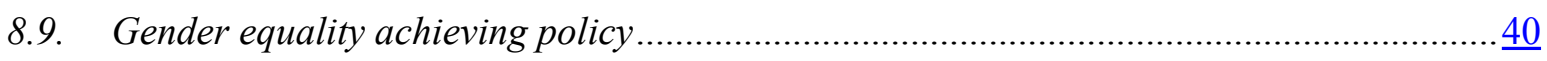

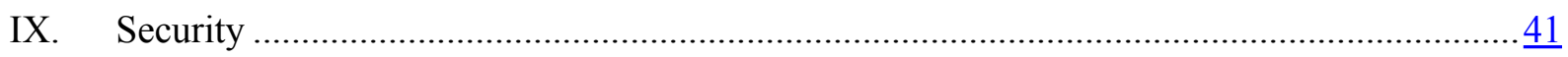

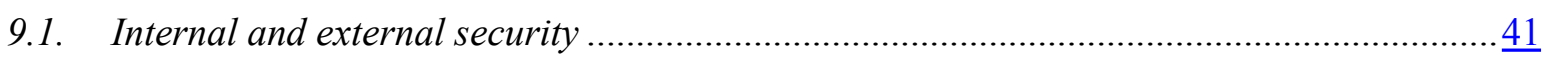

9.1.1. Establishing the rule of law and ensuring security of the citizens ........................... 41

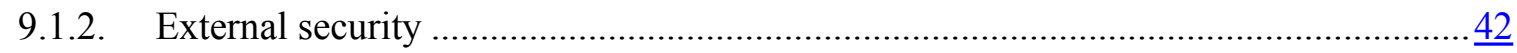

9.2. Reform of the judiciary and guaranteeing of property rights ........................................ $\underline{42}$

9.3. Ensuring environmental safety .................................................................................. 43

9.4. Ensuring comprehensive safety of the population and the territory from natural disasters

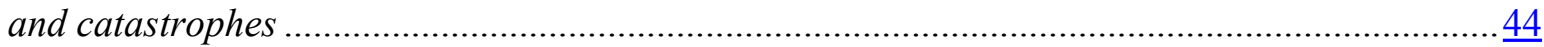

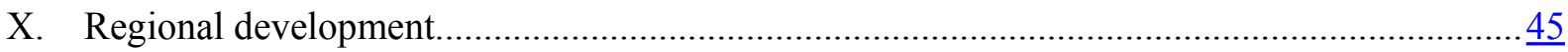

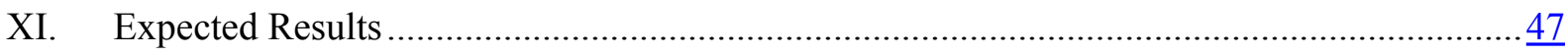

XII. Conclusion ..................................................................................................

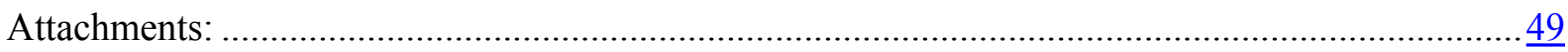




\section{Introduction}

1. This document reveals prospective and mid-term priorities of development of the Kyrgyz Republic for the years 2012-2014.

2. After April 2010 events, drastic changes took place in the government system of the Kyrgyz Republic. The parliamentary form of ruling was introduced in the country. Ensuring security of the society became a key topic in agenda of the Parliament of the Kyrgyz Republic. The President of the Kyrgyz Republic (hereinafter - ("President"), Jogorku Kenesh of the Kyrgyz Republic (hereinafter - "Jogorku Kenesh"), and the Government of the Kyrgyz Republic (hereinafter "Government") were able to prevent crisis events and direct life of the country towards stable and constructive dimension.

3. Last years, the power and criminal have being merging. Post-revolutionary period was accompanied with activation of the criminal elements. Therefore, the Government undertook decisive measures on decriminalization of the society and economy. Today, the most influential figures of the criminal world are either in prisons or hidden abroad.

4. After April 2010 events, practice of auction and tender holding without fixed price was eliminated. Such practice allowed implementing insider transactions and selling objects by understated prices. Actions of the Government regarding privatization of the state property are carried out based on principles of transparency and accountability of processes to the Parliament and civil society. Composition of the privatization commission was revised - the members of the Parliament, representatives of the law-enforcement and supervisory bodies and non-governmental and non-commercial organizations are the members of this commission. In order to restore property interests of the republic, 47 objects were nationalized, which have being illegally privatized under the previous political regime.

5. The Government was able to prevent economy from deep decline. Because of increasing poverty level, the social policy focused on solution of urgent problems of the population. Salary of the teachers and health workers was increased in two times and even more. Pensions were increased by $30 \%$.

6. Aim of the Medium-Term Program is to put economy of the country into sustainable vector of development and improve the budget status in order to prevent social effects, increase living standard and reduce poverty in the country. This document focuses on following areas of development: (i) reform of the governance system and combat against corruption; (ii) faster promotion of economic priorities through startup and implementation of the big national projects; (iii) renew the policy of state asset management; (iv) increase effectiveness of the policy of social development and poverty alleviation.

7. Implementation of the reforms anticipated by the Program will help to reduce deficit of the state budget, enhance fight against corruption, improve living standard and decrease social tension in the society. Business environment will be oriented towards recovery and strengthening of good investment climate in the country, state regulation free form bureaucratization and provision of economic freedom to the economic entities.

\section{Unsolved Problems}

8. The Government did not manage to address all problems inherited from the previous leaders of the country. During twenty years, numerous unsolved problems have being accumulated. Structure of economy became obsolete and noncompetitive by many positions compare to the foreign producers. Labor productivity is law; outflow of the most qualified labor from the country is observed today; becomes worse. Attractive investment climate was destroyed in the country; flight of capital is observed. Not only obsolete assets are degrading, but the social and housing infrastructure. 
9. The countries - main trading partners of Kyrgyzstan switch themselves to new technological structure of economy, which ensures their development in future. Maintenance of existing trend will lead to regress and transformation of our country into a periphery of the global as well as the regional economy. There will emerge a risk to become a country of raw material and consumption; therefore, the Government intends to prepare the country to further changes through cardinal reforms in the economy.

10. It is necessary to carry out reforms in the social sphere as well. Consequences of the world economic crisis of 2009 and events in 2010 led to decrease of living standard, and poverty level was increased from $31.7 \%$ to $33.7 \%$. Today, the state distributes limited resources of the budget inefficiently; social support is not provided in targeted way. As a result, state support of that category of people who are in urgent need, is insufficient. It is necessary to define clearly the objects of the state protection and provide actual social support and protection, and not declarative one.

11. Delay of the judicial system reform is a constraint for the country's progress.

12. Existing structure of the governance is inadequate to goals of the country and it hampers development. State institutions became cumbrous and inflexible because they undertook superfluous functions. Today, the existing system of the governance does not facilitate development of economy and improvement in social development, and hampers development of the market principles.

13. Thus, it was impossible to ensure development of Kyrgyzstan based on outmoded principles of the public governance.

\section{Post-Conflict Regulation}

14. More than 100 ethnic groups live in the country - they have their own history, language and cultural characteristics. Last years, issues of interethnic, inter-tribal and regional relations have more political influence and used by some politicians as element of pressure on the state power to achieve specific goals. This factor became more significant because of rising of social-economic problems. Unfortunately, all these circumstances led to tragic events in the south of the country under sharp political struggle of 2010.

15. Setting up the Commission on assessment of damage in the south of the country is one of the first steps of the Government in post-conflict regulation area. The State Direction especially formed to restore Osh city and Jalal-Abad city carried out practical work on restoration of destroyed houses, infrastructure and social objects.

16. The Concept of Ethnical Policy and Consolidation of the Society of the Kyrgyz Republic till 2015, defining strategic approaches aimed to consolidate the society and form balanced policy in a sphere of interethnic relations, was approved by the Decree of the President of the Kyrgyz Republic in order maintain unity and reconciliation in the south of the country.

17. The President of the Kyrgyz Republic declared 2012 as a Year of Family, Peace, Harmony and Mutual Forgiveness to ensure stable development and prosperity of the country, creation of decent conditions for the citizens and ensuring peace and concord among the people.

18. Main areas of the Government's policy on post-conflict rehabilitation and reconciliation in the south of the country till 2014 will be: (i) extension of form of participation of the civil society in the governance; (ii) ensure equal access for the representation from the ethnic groups in political, economic and public life.

19. The Government will ensure actual involvement of all ethnic groups in the economic and social life through use of non-discriminatory approach in sphere of employment and business and through adoption of measures on training and re-training of the staff.

20. The state administrations and local self-governance bodies will ensure equal access for all citizens to the natural, financial, informational and other resources through transparent and controlled procedures. 


\section{Goals and Objectives of the Country's Development}

21. Main goal of the reforms declared by the Government in this document is to increase living standard of the population and poverty alleviation based on economic growth, improvement of business environment and development of the efficient governance system.

22. This goal will be achieved through addressing the following objectives: (i) reform in the public administration and formation of the compact government; (ii) reduction of the public expenditures and increasing of revenues; (iii) accelerated development of the economy through startup of new national projects; (iv) effective public asset management; (v) reform of the licensepermitting and control-supervisory systems; (vi) reform in the social sphere; reform in the security sphere; (vii) reform in the judicial system.

\section{Development of the Economy}

\subsection{Macroeconomic policy}

23. By assessment of the Government, inertial development of the country under maintenance of trends observed in 2011 and stability of external factors will lead to aggravation of problem associated with budget deficit (Table 1). Therefore, the Government acts with initiative of new course of the economy development and improvement of the business environment.

\begin{tabular}{|l|c|c|c|c|}
\hline \multicolumn{5}{|c|}{ Table 1. Main macroeconomic indicators of inertial development } \\
\hline \multicolumn{1}{|c|}{ Billion soms } & $\mathbf{2 0 1 1}$ & $\mathbf{2 0 1 2}$ & $\mathbf{2 0 1 3}$ & $\mathbf{2 0 1 4}$ \\
\hline GDP & $\mathbf{2 7 3 . 1}$ & $\mathbf{3 1 3 . 7}$ & $\mathbf{3 6 3 . 2}$ & $\mathbf{4 1 6 . 4}$ \\
\hline Growth of GDP & $5.7 \%$ & $6.6 \%$ & $5.8 \%$ & $6.0 \%$ \\
\hline State budget revenues & 77.3 & 82.6 & 84.0 & 85.2 \\
\hline State budget expenditures & 90.9 & 100.6 & 107.6 & 110.9 \\
\hline State budget deficit & $\mathbf{- 1 3 . 5}$ & $\mathbf{- 1 8 . 0}$ & $\mathbf{- 2 3 . 6}$ & $\mathbf{- 2 5 . 7}$ \\
\hline $\begin{array}{c}\text { State budget deficit, \% of } \\
\text { GDP }\end{array}$ & $\mathbf{- 5 . 0 \%}$ & $\mathbf{- 5 . 7 \%}$ & $-6.5 \%$ & $-6.2 \%$ \\
\hline
\end{tabular}

24. The reforms indicated within this Program, will allow achieving ambitious goals - on real GDP growth (in average by 7.5\% annually), revenue increasing (more than 28 billion soms in 2014 compare to 2011) and significant decrease of the budget deficit (to 2.6\% of GDP in 2014). In case of successful reforms and implementation of measures stipulated in the Program, the economy of the country will be characterized by following macroeconomic parameters: 


\begin{tabular}{|l|c|c|c|c|}
\hline \multicolumn{5}{|c|}{ Table 2.Main macroeconomic indicators with consideration of the Program } \\
implementation
\end{tabular}

25. Macroeconomic policy will be directed towards restoration and ensuring of macroeconomic stability. Coherent fiscal, budget and tax policies will be aimed to retain level of inflation not higher than 10\% in 2012-2014. Achieving balance between needs of the economy in liquidity and needs to hold back inflation will be one of key areas of the fiscal policy.

26. To keep inflation at controlled level it is required to: (i) develop new monetary instruments on sterilization of excessive monetary aggregates; (ii) develop mechanism of non-monetary impact on the market of grain and bakery products through the state regulation / intervention to hold back the price growth; (iii) develop and introduce the state instrument of price restraints for inflation "booms" period (not more than 3 months); (iv) carry out reform of the state tariff policy on utilities services to prevent their drastic growth.

27. Policy of floating exchange rate will be continued. Sharp fluctuation of exchange rate will be smoothed out by instruments of the fiscal policy including interventions on the inter-banking currency market.

28. Restoration and maintaining of the favorable investment climate, flexible regulatory policy in the entrepreneurship area, predictability and stability of the legislation will facilitate economic growth, which is forecasted as $7.5 \%$ in average per annum...

29. Macroeconomic conditions and preconditions of development can be divided into favorable and unfavorable for economy of the country:

External favorable preconditions and conditions: (i) growth of the world economy by $2.5 \%$, and the countries, main trading partners (Russia and Kazakhstan) - from 4\% to 7\%; (ii) forecasted growth of the gold price - 1700-2000 USD per 1 troy ounce; (iii) controlled indexes of inflation rate $(5 \%-8 \%)$ in the countries, main trading partners of the Kyrgyz Republic (Russia and Kazakhstan).

External unfavorable factors / risk: (i) growth of the world prices on food products; (ii) high world prices on crude oil (over $100 \mathrm{USD} /$ barrel) against the background of tense political situation in the Middle East and North Africa countries; (iii) reduction of re-export and restriction of goods export from Kyrgyzstan because of entering into force terms and conditions of the Customs Union.

30. Besides external conditions and preconditions, the country's economy will depend on internal factors:

- internal favorable preconditions and conditions: (i) optimization of the governance system; (ii) restoration of favorable trade infrastructure in the affected south regions; (iii) creation of enabling business environment; (iv) attraction of direct foreign investment in the big national projects; 
- internal unfavorable factors / risk: (i) risk of outflow of the capital and labor resources from the country; (ii) risk of growth of the shadow economy; (iii) risk, associated with the food security because of growth of the world prices on food, which can be significantly enhanced in case of internal social-political tension; (iv) natural and climate factor can negatively affect on development of the agriculture.

31. The Government and the National Bank of the Kyrgyz Republic will elaborate the Anti-crisis Program taking into account these conditions and preconditions, which is aimed to mitigate potential shocks on economy. These shocks are related to deterioration of the world trends of development.

32. From production side, growth of economy will be supported by all sectors of the real economy forming GDP of the country. Maximum input is forecasted form the service entities (3.4 percentage points). Real input of industrial production and agriculture will be moderate, 1.1 and 0.7 percentage points, correspondingly. Input of the construction sector, in spite of small proportion within the GDP structure, will be increased due to planned launch of new investment projects (1.4 percentage points).

33. Ensuring of sustainable economic growth requires significant amount of private investment, which inflow was substantially decreased last time (in 2009-2010, rate of private investment inflow was negative - in average $-8 \%$ ). Considering this fact, the Government intends to put efforts on restoration of investment attractiveness of the country, in particular: (i) further deregulation of the economy; (ii) exclusion of non-grounded interventions of the state bodies in activity of the business entities; (iii) elimination of administrative barriers and restrictions for business development; (iv) introduction of effective instrument of the public regulation; (v) ensuring of predictability of the legislation.

34. Solution of these objectives will allow achieving an average annual growth of the gross investment by $12.5 \%$, and their average weight will be increased to $33.2 \%$ to GDP in 2014 . It is supposed that growth will be guaranteed mainly by private investment, which proportion will be increased from $21.9 \%$ in 2011 to $28.8 \%$ to GDP in 2014. Leading growth of private investment will be determined by flow of investment in the big mid-term and long-term national projects.

35 . In 2012-2014, share of private consumption will be decreased from $83.5 \%$ to GDP in 2011 to $82.4 \%$ in 2014 since investment costs will dominate compare to consumption costs in order to maintain the economic growth. However, rate of real growth of private consumption will be retained at level of $5.6 \%$ in annual average. Private consumption costs will be complemented by forecasted growth of monetary income of the population due to creation of new jobs and increase of average wages.

36. Forecasted reduction of the public consumption (from $17.8 \%$ in 2011 to $16.4 \%$ to GDP in 2014) will be a result of decreasing of expenses for operation of the governance institutions.

37. Growth of private consumption will stimulate leading growth of the import (by $4.7 \%$ in average per annum) compare to the export (by $3.7 \%$ in average per annum), and it will be one of reasons of worsening of indicator of the pure export (from -29\% to GDP in 2011 to $-32 \%$ to GDP in 2014). At the same time, growth of the import will be determined not only by the import of consumer goods, but also by increasing of the import of investment goods (in average by $1.3 \%$ annually).

38. Restrained rate of growth of the export will be determined by fact that stimulating effect of investment inflow in the country's economy due to startup of the big national projects and growth of the export capacity are expected mainly beyond the forecasted period. 


\subsection{Fiscal Policy}

\subsubsection{Tax Policy}

39. Since January 1, 2009, a new version of the Tax Code of the Kyrgyz Republic (hereinafter "Tax Code") has been in effect - the unified codification document covering all types of taxes and tax operations. Achievement of the new version of the Code is reduction of rates of basic taxes, reduction of total number of taxes and revenues from 16 to 8 , elimination of the cascade non-market taxes, liberalization of tax administration in relation to good-will tax payer, and introduction of partnership mechanisms.

40. The liberal tax regime for the entrepreneurs and investors established by the new version of the Tax Code is very important for their attraction in legal field of activity, increasing of production volume, and correspondingly, it stimulates growth of tax revenues in the county's budget, what has happened already in 2009.

41. In 2010, in spite of the political events and decline in the economy, tax collections were increased by $9.1 \%$ (3.3 billion soms), and in 2011 , the budget revenues were increased through taxes by $34.7 \%$ (13.6 billion soms).

42. Achieved results allowed to increase indicator of proportion of tax revenues to GDP up to $19.4 \%$, however, this figure is still low. Growth of tax revenues is hampered because of existence of some problems in the tax system (i) uneven tax burden; (ii) big number of privileges and tax exemptions; (iii) insufficient use of modern technologies under implementation of tax and customs administration; (iv) corruption.

43. Tax policy of the state in the nearest future will be conducted under conditions of the budget deficit. Therefore, the Government has crucial task to establish efficient and stable tax system ensuring the budget sustainability in mid-term and long-term period.

44. To evening up the tax burden and ensuring completeness of tax collections the following measures will be undertaken: (i) drafts of the regulatory-legal acts aimed towards simplification of the tax and customs administration will be elaborated; (ii) list of activities carried out on the basis of a voluntary patent will be shortened, including by gradually increasing the patent cost, and reducing the types of the patents; (iii) amendments will be made in the Tax Code of the Kyrgyz Republic regarding step by step decrease of sale tax rates up to complete annulment of this tax for deliveries imposed by VAT during 2013-2016. For purposes of reimbursing budget losses, the sales tax rate will be raised for the communications sector as it is one of the economy's most highly profitable industries, and a windfall profits tax on gold mining enterprises will also be introduced.

45. Optimization of the existing system of tax preferences is another area of the policy aimed towards increasing of income capacity of the tax system including non provision of new inefficient and unjustified benefits and elimination of existing possibilities to avoid taxation.

46. In order to modernize the tax and customs service it is envisaged to: (i) introduce the automated informational system of the customs service including a system of electronic submission of the customs declarations and making easy information exchange between the participants of the foreign-economic activity (FEA) and the customs service; (ii) introduce the automated informational system of the tax service for submission of the tax reporting in electronic format, application of the modern technologies in the tax administration in order to simplify procedure of execution of the tax liabilities by the tax payers.

47. To enhance trust of the public to the tax and customs service and decrease level of corruption it is planned to: (i) set up the centers of processing of the tax declarations; (ii) equip the customs check-points with video-camera systems; (iii) introduce the programs preventing corruption in the tax and customs institutions; (iv) introduce systematic survey regarding level of corruption in the tax and customs institutions among the tax payers and objects of the foreign-economic activity.

48. Stability and consistency of decisions made earlier in tax policy area, particularly, not increasing and gradually decreasing the tax burden shall be a stimulus to economic activation. 
49. The tax administration needs further improvement; the program on administration improvement will target on optimization of interaction of the tax service and the economic entities. Improvement of the tax reporting system in order to reduce big number of reports and streamlining periods of their submission, and introduction of the automated system of tax control based on risk criteria will increase effectiveness of the tax administration and significantly save time and resources spent on tax procedures by the business entities.

\subsubsection{Public finance management and budgetary policy}

50. Political events took place in the country affected on the budget of 2010 what was determined by substantial growth of additional expenditures of the budget, mainly used for restoration and rehabilitation activities after the April and June events in the south of the country and social benefits to the affected people. Nevertheless, as a result of constructive cooperation of the Government with the donor community on budget support issues, a deficit of the state budget was in amount of $4.9 \%$ to GDP in 2010 . It was lower by $0.7 \%$ than it was expected.

51. In 2011, expenditures of the budget were significantly increased due to rising of wages to the workers of social sphere and the law-enforcement bodies, restoration of the south region of the country and increasing of financing for the development projects. The Government elaborated a number of measures to attract additional sources of the budget revenues in order to reduce a budget deficit. Along with growth of tax revenues it gave a positive result to retain growth of the budget deficit. Under initially planned deficit indicator as $7.5 \%$ to GDP in 2011 , actually, this indicator was at 5\% level.

52. Substantial budget deficit dictates a need of its optimization through improvement of traditional mechanisms as well as a search of alternative sources of income. .

53. In general, the county's budget continues to be socially oriented. Growth of socially vulnerable group of the population and poverty growth in 2010 affected an increase of social expenditure of the budget in 2011 up to $43 \%-45 \%$ of total expenses of the republican budget.

54. The principal goal of government spending policy in the coming three years will consist in complete and timely financing of all of the state's social guarantees and the creation of favorable conditions for economic growth in the interests of the poor strata of the population.

55. The Government recognizes importance of beginning of the budget consolidation. The consolidation strategy includes measures on increasing of the revenues and retaining growth of expenditures.

56. Increasing of budget revenues in the mid-term prospective will be ensures through: (i) improvement of the customs administration through transition of major part of the imported goods from a system of the customs clearance based of weight to the price-based system; (ii) annulment of some preference on VAT; (iii) revision of the excise policy; (iv) reform on non-tax payments aimed towards optimization of the public payment services and efficient management of the state property and natural resources.

57. The Government has following challenges to overcome the budget deficit and optimize expenditures: (i) improvement of the budget planning; (ii) enhancing of control of effectiveness of the public expenditures; (iii) improvement of the budget legislation.

58. Key priority is reforming of the public finance management system, increasing of the budget discipline and transparency of budget funds spending.

59. Measures of reforming of the public finance management include: (i) design of an assessment system of economic effectiveness of budget resources spending; (ii) step by step transition to the program-based budgeting; (iii) comprehensive training of the staff of the pilot ministries how to conduct sector-based analysis and develop the program-based budget; (iv) modernization of the Treasury including centralization of the public finance management through connection of the Treasury to a package clearing system and transition to the Unified Treasury Account; (v) 
introduction of electronic trades for public procurements; (vi) setting up the unified centralized public finance management system for capital construction (UKS).

60. It is planned to revise and update "The Mid-Term Action Plan on Reforming of the Public Finance Management System in the Kyrgyz Republic for 2009-2013" based on achieved results, assessment of further prospective with mainstreaming of reliable monitoring and evaluation system of reform implementation.

61. Reforming process is focusing to achieve three broad outcomes: (i) reliable budget providing predicted resources; (ii) improving of supervision/control to establish a reporting system of the management staff; (iii) improving of link between priorities of the policy and annual and mid-term planning.

62. In light of recent transformations, it is necessary to design a unified conceptual document, which regulates basics of the public finance management. In this relation, work will be conducted to elaborate the Budget Code of the Kyrgyz Republic aimed to ensure organization of efficient and transparent system of the public finance management, develop appropriate legal norms for budgeting, which meet the national interests and introduce the world-wide best regulations of the budget system.

63. In order to improve the inter-budgetary relations, transition to two-level budget will be held. Within a system of inter-budgetary relations, notion "local budgets" will anticipate the budgets of local communities of the village, town and city, formation, approval and execution of which will be performed by the municipalities. Norms of deductions from the state taxes (income tax, patentbased tax) will be revised. Local self-governance bodies can influence on the budget through creation of new jobs and providing conditions for small business development. It will allow enhancing the local budgets at own expenses, increasing interest of the local municipalities in growing of the income capacity and improving effectiveness of expenditures. Implementation of the reform of financial decentralization supposed formation and execution of the local budgets directly by the local self-governance bodies.

64. To stimulate growth of economic capacity of the local communities, increasing of role and responsibility of the local self-governance bodies for efficient local budget management within inter-budgetary relation, the work will be continued in following areas: (i) improving of the legal acts regulating a system of inter-budgetary relations, (ii) improving system of inter-budgetary transfers considering the mid-term planning of the local budgets.

65. Ensuring transparency of the public finance, cooperation with a number of non-governmental organizations on budget transparency issues and access of the citizens to budget information - all these activities will be continued. Special attention will be paid to drafting of the annual civic budget.

66. Planned reforms in the public finance management and budget consolidation including measures on revenues increasing and retaining of expenditure growth in mid-term prospective will strive to bring the budget deficit to $2.6 \%$ to GDP in 2014. Besides, it is expected that current expenses will be covered only by current revenues in the mid-term prospective.

\subsection{State debt administration strategy}

67. The Kyrgyz Republic still depends on the state borrowing and it is sensitive to risk related to the state debt. Along with progress in the state debt area achieved in 2002-2006, crisis in the world economy in 2008-2009, and events in the country in 2010 led to active accumulation of the state debt. Increasing of amount of the state debt is determined by attraction of big loans from the Russian Federation and China for development of the energy sector and transport infrastructure, and devaluation of the Kyrgyz som. In 2011, the state debt was increased by 0.7 billion USD and became $47.7 \%$ to GDP (2.8 billion USD) regarding 2008 .

68. In order to ensure sustainability of the state debt and achieving its effective administration the Mid-term Strategy on state debt administration for 2012-2014 has been approved. Goal of this 
strategy is to form an optimal structure of the state debt in mid-term prospective. The strategy presumes an orientation towards preferential financing in mid-term prospective in terms of the state debt under simultaneous accumulation of internal component of public borrowings in order to develop the public security market as a complementary source of financing of the Government's needs.

69. To improve the public finance management system, form the optimal structure of the state debt and ensure stability of the debt the Government's policy will focus on following: (i) timely provision of the debt service; (ii) attraction of foreign loans and grants in line with priorities of the state; (iii) guarantee compliance of minimum preferences (grant-element) for all new foreign borrowings at 35 percent level; (iv) undertake measures to reduce level of the state debt through negotiation holding with the countries-creditors in bilateral format on provision of debt restructuring, implementation of swap-transactions (debt for assets, development and so on), and its forgiveness or transformation into grant; (v) accumulation of proportion of the domestic component of the state debt through development of the public security market.

\subsection{Country's asset management}

70. A passive policy of the public asset management was held till 2010. Enhancing of control on financial-economic activity of the companies allowed increasing of revenues by dividends within the state share holding in 2011 up to 2.9 billion som (more than $4 \%$ of total revenues of the republican budget). In 2011, a practice was introduced when the public enterprises transferred not less than half of earned a net profit to the republican budget. Actions of the Government in 20102011 regarding privatization of the state property were purposed to increase transparency and accountability of whole process to the Jogorku Kenesh of the Kyrgyz Republic and civil society. After the April 2010 events a vicious practice of the auction and tender holding without fixing of the price was eliminated. Structural composition of the commissions on privatization has been revised. The members of the parliament, representatives of the law-enforcement and supervisory bodies, non-governmental and non-commercial organizations joined the commission. In order to restore the property interest of the republic, 47 objects have being illegally privatized in the past were nationalized. At present, more than 90 percent of the public objects are transformed into the private property.

71. Strategic enterprises, which privatization was conducted in line with concepts and programs approved by the Jogorku Kenesh of the Kyrgyz Republic are at disposal of the state. Today, problems of the public property management are the following: (i) low-effectiveness of right of the shareholder possessed by the state; (ii) ineffective management of the state enterprises what is one of reasons of deterioration of financial status of majority of the companies with state shareholding; (iii) unbalanced structure of the state property.

72. In order to improve quality of the state property management which will allow creating of conditions for growth of the earning yield, some intervention will take place in order to introduce new principles of asset management of the country. On legislation base, criteria and requirements will be identified for selection of: (i) companies for trust managing; (ii) top-managers, consulting and auditing companies; (iii) personnel of the authorized state institution on public asset management.

73. Considering practice and international experience on privatization issues, the state property use and management, the legislation base will be improved, and sources of financing to develop the state property management system will be defined on legal base. Priorities will be revised, which have been set in policy area of the state asset management. Principle of the public-private partnership will be developed further.

74. Full-scale inventory of all state assets is planned to develop and introduce the register of the state property. Classification of the state assets will be designed. System of management tools will be elaborated for each type of property depending on purpose of use of this type of the state asset. 
Three groups will be distinguished by purposes of use of the state property: (i) assets directly used by the state (the buildings of the public administration, infrastructure facilities and so on) - in order to improve efficiency of their use and costs reduction; (ii) assets of social profile (public housing, municipal assets) - to reduce subsidies; (iii) residue assets used to get revenues (various investment property), - to maximize profit.

75. The Government will introduce the effective strategy on the state property management based on centralization of the asset management and dividend sharing functions.

76. Today, the economy of Kyrgyzstan urgently needs new stimulus of economic development, and existing assets are not mobilized to address this problem. One of the most optimal options to address this problem is involvement of a part of the state holding of stock of the gold mining company "Centera Gold Inc." The Kyrgyz Republic owns 33\% of stock of "Centera Gold Inc"; which current market cost is about 1.6 billion USD. These assets must be used to get a maximum profit. The Government plans to sell part of the shares in order to get funds and invest them in the priority national projects by creating a State Development Bank.

\subsection{Financial sector:}

\subsubsection{Banking and non-banking sector}

77. Development of the banking system of the Kyrgyz Republic during 2008-2010 was accompanied by influence of the external and internal factors. So, in 2010, the financial intermediation indicator decreased. Based on the 2011 results, the financial intermediation indicator was 24.4 percent.

78. Volume of deposit base of the commercial banks decreased in 2010 and began to grow in 2011, and increased by 12.9 percent.

79. Cost of credit resources is quite high at present; the interest rate was reduced slightly.

80. High cost of the loans and super short period of borrowing are typical for the non-banking financial-credit institutions sector.

81. In spite of growth of the credit portfolio of the commercial banks in 2011 compare to 2010 (by $18.3 \%$ ), problems of development of the banking sector are associated with the continuing judicial proceedings in problem banks, as well as the lack of a resolution on issues relating to nationalized facilities that are collateral for bank credits and deposits. There are no sufficient financial resources to extend volume of the floating assets in a system of the credit unions and micro-financial organizations. Problems of poor management and activity organization in the nonbanking financial-credit institutions and high interest rates are not solved yet.

82. To address above-mentioned problems, the policy in this sector will focus on following areas: (i) enhancing of sustainability of the banking and non-banking system in order to extend accessibility of financial services, (ii) transparence of the management system and bank regulation, (iii) attraction of the big foreign banks; (iv) accessibility of financial services through introduction of new various financial instruments meeting needs of the customers; (v) fulfilling obligations under the framework of the Memorandum on Economic Financial Policy for 2012-2014 on the question of the open joint-stock company "Zalkar Bank" and preparation of the Banking Code of the Kyrgyz Republic; (vi) development of the strategy on selling of the JSC "RSC Bank".

83. Measures on implementation of the policy on enhancing of sustainability of the financial system will be undertaken in terms of design and adoption of new legal mechanisms of the competition and prevention of actions restricting freedom of commercial activity in the banking sphere, introduction of new risk assessment system.

84. As to the non-banking sector, amendments will be made in the Law of the Kyrgyz Republic "On micro-financial organizations" aimed to extend list of transactions and services of the microfinancial organizations. 
85. To enhance transparency of the bank management and regulation system, following interventions will be implemented: (i) strengthen responsibility of the shareholders and management bodies of the bank for public disclosure of information on activity of the commercial bank including data on its financial status, structure of the owners and management; (ii) introduce a mechanism of involvement in the deposit protection system for the banks, which was established through restructuring in accordance with the Law of the Kyrgyz Republic "On conservation, liquidation and bankruptcy of the banks".

86. Accessibility of financial services will be ensures through: (i) fulfillment of Islamic banking principles and introduction of instruments of Islamic financing; (ii) adoption of the risk assessment system under introduction of new banking products including those based on innovation technologies; (iii) design of mechanisms integrating system of inter-banking clearing with trading systems on the financial markets; (iv) introduction of infrastructure on receiving payments from the population.

87. In addition, an action plan will be implemented for the transfer (sale) of the limited liability company "Financial Company for the Support and Development of Credit Unions" to credit unions.

\subsubsection{Stock/security and insurance market}

88. During three years, capital of the insurance companies was increased by $18.7 \%$, aggregate assets of insurance companies increased by $21.9 \%$, liabilities (including insurance funds) increased by $2.2 \%$, the volume of insurance premiums increased by $48.3 \%$, and insurance payouts by $14.5 \%$.

89. Approval of the new Law of the Kyrgyz Republic "On security markets" in 2009 became an important event for the stock market. Documents regulating issue of the securities based on Islamic financing principles were approved in order to extend number of instruments of the stock market.

90. Possibilities of the corporative bonds and public securities market are used insufficiently; level of corporative management in the joint-stock companies is immature. Reliable instruments of long-term insurance reserve floatation.

91. Capacity building of the stock, insurance markets and non-state pension funds is a priority in solution of existing problems. It is planned: (i) improvement of the legislation base to introduce new financial instruments on the market of corporative securities and introduce new mandatory types of insurance (insurance of transport, housing, notary public, auditors); (ii) making amendments in the Law of the Kyrgyz Republic "On Non-Governmental Pension Funds in the Kyrgyz Republic" anticipating activity of the non-governmental pension funds as a participant on mandatory saving pension insurance.

92. Following measures will be undertaken to enlarge the infrastructure and improve informational support of the market: (i) the state and municipal securities will be issued and placed through the stock exchange to address issues on financing of the budget deficit, national and local investment projects; (ii) trading of the state securities will be transferred to trading platform of the licensed organizers of the security trade; (iii) regulatory-legal acts stimulating establishing the guarantee funds and actuary institution will be adopted; (iv) regulatory-legal acts on development of the state re-insurance company will be drafted. This company could cover high risk; (v) regulations on increasing of minimum size of the equity capital of the insurance companies were adopted; (vi) amendments were made in the regulatory-legal acts of the country for unification of the legislation of the EurAsEC and CIS states-members on the security market. 


\subsection{Economic priorities:}

\subsubsection{Energy}

93. During several years, energy of the Kyrgyz Republic is facing numerous problems. Level of commercial and technical loss is unacceptably high. Last years, the Government undertook a number of effective measures what allowed reducing of loss, but positive changes are very slow. Shortage of good quality independent analysis of generation and distribution of electric power, losses, tariffs, consumption structure, and energy supply for big consumers is a problem. Also, independent analysis of the corporative management is required.

94. Financial situation of the energy enterprises is unfavorable. High and not always justified costs of the enterprises are the main reason. Fixed socially oriented tariffs reducing economically required revenue level are also important.

95. Generation of the electric and heating energy depends on cost of imported hydrocarbons, prices on which are formed by the market. Under domestic fixed prices on electric and heating energy it creates financial gap requiring regular budget subsidies. Fixed price structure for primary fuel and energy resources encourages the population to use electric power for heating purposes as the most affordable among available resources (coal and gas).

96. Functional depreciation/obsolescence reached a huge size under which high risk occurs for sustainable functioning of the sector. Number of accidents and failures in operation of energy equipment is supernormal, especially, during peak seasonal overloads.

97. Quality of corporative management at the energy enterprises is still poor. System of selection and motivations providing the companies with high professional and responsible managers is not established.

98. Problem of sustainable electric power supply in winter in the Northern parts of the country when peak seasonal overloads take place is not solved. Also, sustainable power supply in the northern oblasts is problematic. Last years, this problem became crucial since some countries have intention to quit from the Unified Energy System of the Central Asian countries (CA UES). Lack of the domestic high voltage power transmission line connecting the South and the North make problem very topical.

99. Power generation is not strongly diversified. To large extent, it depends on hydropower; own fuel and energy resources and non-traditional renewable sources of energy are used improperly.

100. Kyrgyzstan has a huge export hydropower potential of the country, which can be a source of profit generation. In the nearest future, export of the power can be increased up to 3 billion kilowatt/hour; however this potential remains substantially unrealized.

101. Measures on improvement of the state regulation of the energy enterprises undertaken after 2010 helped to enhance responsibility of the companies and transparency of their activity to certain degree. However, corruption factors exist - required level of energy flow control and relevant payments is not achieved yet. Activity of the Department on regulation of fuel and energy complex (the Regulator) highly depends on non-economic factors.

102. Policy of the Government will focus on three main pillars: (i) improvement of the state regulation of the energy sector; (ii) improvement of management at the energy enterprises, enhancing transparency of their activity; (iii) growth of volume of the production and export of electric energy, strengthening of sustainability of power supply, effective implementation of the current projects and programs.

103. A number of measures will be undertaken to improve the state regulation of the energy sector. It is necessary to design and adopt appropriate legal basis and procedures for their implementation.

104. Decreasing of dependence of the regulator on the sector-based interests will favor clear division of functions of the policy elaboration, regulation, accountability, tariff setting and relations between the objects of the energy sector. Implementation of the regulator's functions will rely on updated methodology of net production cost and tariffs calculation in the energy sector. 
105. During 2012-2013, an independent clearing center will be formed for the energy enterprises. It will account mutual power flow and payments. It will improve transparency of the wholesale transactions and ensure reliability of the estimates.

106. An alternative of transfer of the state's share holding to the specialized management companies will be one of measures improving management of the energy companies. Also, legal basis and procedures will be drafted, which regulate transfer of the sectoral enterprises and branches of the state enterprise "Kyrgyzzhylcommunsoyuz" to the local self-governance bodies.

107. Ensuring of security of the energy activity requires mandatory licensing, availability of preand post-license commitments of the objects of energy activity and their execution.

108. Legislative norms will be adopted to improve financial discipline, decreasing of accounts receivable of the power consumers. These norms allow applying more strict measures in relation to the defaulters including power cutoff. Prepayment counters/meters will be used widely.

109. Formation of the mid-term tariff policy for electric and heating power will be an important component increasing sustainability of operation of the energy enterprises. In future, tariffs will be balanced with allowance for all social development factors, including access to these services for the poor, goals ensuring financial sustainability of the energy enterprises, stimulation of growth of the real sector of economy and energy saving policy. Tariffs on the fuel and energy resources (electric power, gas and coal) will be more oriented towards optimization of consumption structure.

110. Reforms in the tariff policy will be possible only after improvement of schemes of social protection of the domestic consumers. Targeting program of social protection will be developed for this purpose - it will build upon requirements of the current legislation with regard to monetization of privileges on power supply. At the same time, financing of expenditures for social welfare in the energy sector will be envisaged in the republican budget.

111. Development of energy efficiency policy remains a priority. Measures will be strived towards design and improvement of the regulations and mandatory requirement on energy-saving for different sectors of economy and non-production sphere. Also, programs of material incentives for energy efficiency will be elaborated. Strong attention will be paid to public awareness rising.

112. Broaden cooperation in the water management, fuel and energy sectors in the Central Asian region. Efforts will be put to ensure and maintain sustainable work of the United Energy System of Central Asia (OES TsA). Package of measures was developed aimed to improve quality of services for the OES TsA on regulation of capacity and efficient water reserve management in the Toktogul water reservoir. The Kyrgyz Republic will continue to play active role in creation of the Central Asian South regional electric power market (CASAREM) through preparation and implementation of the CASA-1000 project.

113. Development of the small and medium energy will be encouraged through approval of the legislative measures aimed towards increasing of economic attractiveness of the small hydropower development, use of non-traditional renewable sources of energy, and development of the coal industry. Mechanism of tariff compensation under power generation through the mini-hydropower stations and use of renewable sources of energy (hereinafter - VIE) will be one of the instruments. Program on VIE use will be drafted; the pilot project on power generation from alternative sources of energy, particularly, production of ethanol fuel and biogas, will be implemented. Construction of the Kara-Keche heating plant will ensure diversification of power generation and enhancing of sustainability of power supply in the north of Kyrgyzstan.

114. Interventions supported by the regulatory-legal acts will be carried out in order to improve management at the energy enterprises, transparency of their activity.

115. Selection and incentives formation system will be updated and improved to attract high professional and responsible managers to manage and run the companies. High level appointments in the energy companies (the governing boards and executive director) will be conducted through implementation of maximum transparent procedures of the open completion selection. Requirements on improving quality of the staff of the energy companies will be incorporated in the operational agreements. 
116. Conclusion of the management contracts between the governing boards and the executive director from one side and the Government of the Kyrgyz Republic from other side, stipulating possibility of incentive depending on results of work will be introduced in practice.

117. Annual audit of operation of the energy companies conducted by the independent auditors according to international standards regarding publication of the audit report and recommendations, and regular provision of information will contribute in enhancing of transparency and accountability.

118. Crucial factor of transparency is development of the state interactive web-pages of the Regulator and companies, which contain information on key decisions of the government institutions on the fuel and energy complex and main results of economic and management activity of the energy enterprises (development strategies, balance sheets, procurement plans, tenders and their results, key decisions of the management staff, key decisions of staffing).

119. Besides, maximum transparency of the energy sector export-oriented operation including physical and financial division of accounting of electric power generated by the energy companies for the domestic market and export will be ensured. Within activity of the Public Supervisory Council for the Transparency Initiative of the Fuels and Energy Complex of the Kyrgyz Republic (IPTEK), procedure of interaction of the energy enterprises with the civil society, consumers will be improved substantially.

120. Technical assistance in design and introduction of the first line of automated informational and measuring system of commercial accounting of electric power (AIMSCAE) will facilitate enhancing of accounting reliability of generated and distributed power.

121. Increased volume of generated and exported electric power, growth of energy supply sustainability, efficient implementation of the current projects and programs will be succeeded through design and implementation of the big national projects planned for mid- and long-term prospective: (i) commissioning of the second starting complex of the Kambarata HPP-2; (ii) completion of design of the feasibility study for construction of the Kambarata HPP-1; (iii) construction of the Verhne(Upstream)-Naryn cascade HPP (4 HPPs); (iv) realization of the construction project for the substation Datka of 500 kilovolt and Power Transmission Line (PTL) 220 and 110 kilovolt in the south; (v) and beginning of construction of PTL 500 kilovolt DatkaKemin substation kW "Kemin"; (vi) construction of high voltage line $500 \mathrm{~kW}$ "Kemin-Almaty"; (vii) ongoing works within the project of $500 \mathrm{~kW}$ "Datka-Khudjent" ("CASA-1000" project); (viii) search of investment to construct the heating power plant with capacity of 600 (1200) megawatt on the coal deposit Kara-Keche; (ix) reconstruction of the Bishkek Heating Plant-1, upgrading its capacity up to 400 megawatt; (ix) reconstruction of the backbone heating networks in the cities of Bishkek and Osh.

\subsubsection{Mining}

122. Last years, certain measures have being undertaken to improve situation in the mining sector. Kyrgyzstan joined initiative on transparency in mining industry (IPDO). The draft law was prepared to attract the local communities and local authorities in the deposit mining. This draft law anticipates deductions in amount of $2 \%$ of earnings without indirect taxes gained in the local budgets for development and maintenance of the local infrastructure.

123. At the same time, some problems are unsolved regarding imperfectness of the legislation, unregulated relations with regard to property right and land use, complex and non-transparent tender procedures and passive introduction of the IPDO.

124. It will create conditions for implementation of various corruption schemes in decisionmaking process what will bring to the protracted trials and complaints of the local communities in future. Existing problems impede the investment flow both for industrial operation of the proven deposits and prospecting ones. 
125. The government recognizes a need in crucial reform of the public administration in the subsoil use area.

Working group on reforming of subsoil use sphere was set up. This task force designed the draft laws stipulating transition to economic regulation methods, creation of favorable environment to do business and ensuring transparency of procedures for tenders and decision-making. These draft laws will be presented at the public hearings. Following draft laws will be considered at the first stage: (i) "On Subsoil"; (ii) "On making amendments and additions in the Tax Code of the Kyrgyz Republic"; (iii) "On making amendments and additions in the Land Code of the Kyrgyz Republic"; (iv) "On making amendments and additions in the Law of the Kyrgyz Republic "On Non-Tax Payments".

Following draft laws will be considered at the second stage: (i) "On concessions"; (ii) "On mining concession"; (iii) "On agreement on production sharing in the utilization of mineral resources".

126. Approval of these draft laws will allow creating stable and transparent conditions for business, introducing the tender and action-based licensing method, transition to "one stop shop" principle.

127. It is supposed to create incentives to irritate interest of the local communities in the deposit mining through infrastructure development, new jobs, training of the youth and support of social initiatives.

128. Program of tripartite interaction of the state with the subsoil users and local community will be designed to regulate relations with the local population, consider interests of all stakeholders and introduce mechanisms of compromise achieving.

129. Work will be continued for further development and introduction of the initiative on transparency in mining industry (IPDO). Big mining companies will bring their financial statements in line with requirements of these international principles.

130. It is planned to attract private investment to launch four national projects on operation of the following gold mining deposits: Ishtamberdy, Bozymchak, Jeruy, Taldybulak levoberezhny, which will provide about 5 billion som of tax earnings, create 3100 jobs in coming three years.

131. Negotiations will be held with the potential investors to prospect and develop new gas and oil deposits.

132. Broad access to geological information will facilitate database development based on digitalized archival data.

\subsubsection{Agricultural sector and processing of the agricultural products}

133. The level of poverty in rural raions is especially high, and the Government believes that creating the conditions for rapid production growth in the agricultural sector could yield very good results from the standpoint of raising employment and reducing poverty in rural raions.

134. However, by this time problems have accumulated in the agriculture, which impede development. Kyrgyzstan does not have sufficient level of self-reliance by main types of food products. Degradation of the agricultural land is increased including arable land and pastures. Water resources are not used efficiently, water losses are very excessive.

135. The state poorly supports the seed-farming and cattle-breeding activities, phytosanitary and veterinary, land reclamation and other services required for agricultural production. Crop rotation is disturbed; structure of crop planting, level of agriculture should be improved. All these factors put obstacles for productivity growth of the crop sector and livestock-breeding.

136. Access of the rural producers to financial resources is problematic in spite of support from the state. Problem of collateral provision of the loans limits access to banking crediting. Currently, land plots can't be used as the collateral since the land market is not formed in Kyrgyzstan.

137. Portion of the small commodity production is large in the agriculture. Small size of land plots of the farmers is a serious constraint for wide use of the agricultural machinery. 
138. The farmers experience big problems in selling their goods. One of the reasons is a shortage of forecasted information about market of agricultural goods to identify structure of crops.

139. Volumes of processing of the agricultural goods are grown very slowly. Discrepancy between level of certification of the domestic agricultural goods and processing and needs of the sector has negative impact on food export.

140. Cooperation among the farmers, development of agro-industrial clusters, and interaction of the agriculture with the processing industry must be supported. Potential actors of the cooperative relations are not satisfied with legal conditions and economic conditions of the cooperation.

141. Agricultural policy will focus on solution of following key objectives: (i) growth of production volume and quality of agricultural products; (ii) increasing of yield of the crop production and livestock-breeding; (iii) extension of irrigation systems, water use optimization; (iv) development of the land market; (v) cooperative development; (vi) increasing access of the rural producers to financial resources, crediting and leasing development.

142. The Government will provide support in increasing of access to financial, material-technical resources, extension of the markets in order to ensure growth of production volume. The state will continue provision of privileges under access to financial resources, fuel and lubricants. The Government will develop a mechanism how to use the public request/order on processed goods and it will facilitate development of the processing enterprises based on principles of the public-private partnership with further delivery of the state's part to the private sector. The Government will provide marketing assistance to promote agricultural and processed goods on the foreign markets. Modern system of the good certification will be developed. Promotion of production of the environment friendly goods using organic technology for the export will be important area. Kyrgyzstan will join organization of agricultural production based on principles of "green economy".

143. Mechanism of monitoring of the wholesale and retail markets for agricultural goods and mechanism of price stabilization with a help of the public procurements and commodity interventions will be developed to reduce risk of speculation of the agricultural goods. The Government will prepare annual forecast of demand and supply in the agricultural sector and provide support for functioning of the informational resource.

144. Capacity building of the seeding and breeding farms, improvement of accounting of the pedigree cattle and support of agro-technology development will favor increasing of the yield of the crop production and livestock-breeding and improving of plant and cattle protection. The Center on organization and coordination of selection-breeding operations and artificial insemination of the livestock will be established. Support in establishing of the functioning market of seeds, pedigree cattle and materials will provided. The fund supporting renewal of the seeding and breeding materials of the specialized farms and compensation mechanism for the rural producers will be formed. Part of costs of the farmers would be compensated if they purchase high yield seeding and breeding materials.

145. Development of the irrigation systems and water use optimization will be implemented in two directions: (i) increase efficiency of water sharing between different levels of water management; (ii) increase capacity of the irrigation system, reduction of water loss, capacity building of the water management entities and water user associations. Also, measures will be undertaken to improve soil fertility, and requirements to reduce land degradation will be formulated. Incentives on rational water and land resources use will be designed.

146. Measures on land market development will focus on improvement of the legal provisions for the land market functioning and creation of required market infrastructure. Land transactions will be held only through competitive bidding under the state and public control.

147. Cooperative development will be supported through improvement of the legislation in terms of protection of the property and interests of the potential players of cooperative relations. Procedures of the first-priority support of the rural cooperatives, export-oriented clusters ensuring growth of production volume and creating new jobs will be designed. The public contracting/request will be one of the tools. 
148. The Government will continue policy of extension of the credit-financial institutions financing the agriculture in order to increase access of the rural producers to financial resources and crediting and leasing development. Access to credit funds will be ensured through both direct financial support of the state and creation of conditions to reduce interest rates of the credit institutions. Leasing company for agricultural machinery will be formed. The Government will establish a fund supporting the crediting and leasing activity for the processing enterprises.

149. The Government will continue cooperation with the World Bank (WB), Asian Development Bank (ADB), Islamic Development Bank (IDB), International Financial Corporation (IFS), European Bank for Reconstruction and Development (EBRD), Representative Office of the European Union in the Kyrgyz Republic, Swiss Bureau for Cooperation (SECO), United States Agency on International Development (USAID), UN Development Program (UNDP) and others. The process of integrating and establishing direct contacts between the agricultural economic entities of the CIS, EurAsEC, SOC countries will be stimulated through harmonization of the regulatory-legal acts and agreements signed within these agencies.

150. Mid- and long-term investment component includes: (i) networking of the agricultural cooperatives; (ii) establishing of seven-nine seeding farms; (iii) establishing of seven-nine pedigree livestock farms; (iv) development of the crediting system; (v) affordable agricultural machinery (establishing of the leasing company on agricultural machinery); (vi) development of new irrigated land in the Suzak rayon of the Jalalabad oblast and the Uzgen rayon of the Osh oblast from Yassy river system; (vii) development of new irrigated land in the Kara-Suu rayon of the Osh oblast from Kurshab river; (viii) construction of aqueduct in Maksat village of the Leylek rayon of the Batken oblast with water supply to the Arkin massive; (ix) Development of land of the Burgandin massive of the Kadamzhai rayon of the Batken oblast; (x) construction of the Ak-Terek canal of the Aksysk rayon of the Jalalabad oblast; (xi) construction of the Karimberdy canal in the village "Yntymak" of the Nookat rayon of the Osh oblast.

\subsubsection{Processing industry}

151. Measures of the state regulation significantly influence on development of the processing industry creating favorable conditions for business and investment attraction. There are following measures: elimination of the road tax and deductions in the emergency fund, reduction of VAT from $20 \%$ to $12 \%$. To stimulate replenishment of the key assets, the enterprises are exempted from VAT on imported technological equipment included in their foundation capital. Mechanisms of accelerated depreciation are introduced. Processers of agricultural products are exempted from VAT and tax on revenues for three year period.

152. However, introduction of tax on sale in amount of $2,5 \%$ for the industrial enterprises including the exported goods has negative impact.

153. At the same time, problems exist in the processing industry, and specific measures are required to address them. There is a strong dependence on import of the raw material and material resources. Shortage of the qualified specialists is observed. Shortage of floating assets and limited access to commercial loans because of high interest rates impede replenishment of the key assets and new technology use. It leads to uncompetitiveness of numerous domestic goods by cost and quality.

154. Draft concept of industry development of the Kyrgyz Republic for 2012-2015 was developed to form a comprehensive approach to address existing problems. This draft concept contains general vision and main areas of the industry development; problems typical for majority of industrial sectors and possible ways of their solution are presented also. Strategies of individual sectors will be elaborated based on this document.

155. Following key strategic areas of the industrial policy are defined in the Concept of industry development of the Kyrgyz Republic for 2012-2015: (i) export orientation; (ii) import substitution/ protection of the local producers;(iii) increasing of goods competitiveness; (iv) stimulation of 
deeper processing of the raw material resources in order to form high added value; (v) improvement of investment climate and attraction of investment in processing industry; (vi) development of investment technologies and scientific developments; (vii) training of all level personnel for the industry.

156. The Government also intends to continue implementation of the Strategy on Textile and Garment Industry Development for 2011-2013 including measures on enlargement of the existing and operation of new sowing facilities, promotion of garment goods on the international markets, enabling conditions to increase export and development of the vertical-integrated chain in the textile sector.

157. Exemption on shipments by leasing transactions from VAT and tax on sale will facilitate process of replenishment of the key assets.

158. It is planned to develop the export-industrial areas to attract the investors, new technologies to produce modern types of goods.

159. Changes to trading conditions related to introduced norms and requirements of the Customs Union will be taken in account under conclusion of the international treaties on standardizing in order to apply the technical regulation of the Customs Union's states on the territory of Kyrgyzstan. Testing laboratories need modernization.

\subsubsection{Construction}

160. Permitting procedures were simplified, terms and quantity of required documents was reduced in order to provide favorable conditions for construction industry development. At the same time, current status of the construction industry does not allow providing of the population with demanded housing in the country.

161. Problems in the sector are also linked with insufficient availability of the town planning documentation for the dwellings (master-plans, projects of detailed planning, etc.), lack of clear procedures on provision of land plots for new construction and lack of modern requirements on seismic safety applied to construction of the buildings and facilities.

162. The Government considers the construction of affordable housing for the staff of the budgetary institutions as one of its priority objectives. The Program "Affordable Housing" was adopted, which stipulates the following: (i) launching of the mortgage mechanism for the population with repayment period of 10-20 years; (ii) privileged crediting for the population to buy housing; (iii) identify areas for construction taking into account seismicity and communication and engineering networks; (iv) construction of apartment blocks for the personnel of the budgetary institutions.

163. Action Plan was prepared to ensure full coverage of the settlements in development of the master plans for 2012-2014. Town planning documentation and compliance with requirements of seismic safety are important.

164. To improve the decision-making system under allocation of the land plots for construction purposes, following is necessary: (i) to make amendments in the regulatory-legal documentation regarding allocation of the land plots; mandatory compliance with the seismic safety (the Land Code of the Kyrgyz Republic, the Law of the Kyrgyz Republic On Town Planning and Architecture, and other regulations); (ii) database on land plots for construction in the dwellings of the Kyrgyz Republic was developed; (iii) action plan on inventory and step by step reconstruction of engineering infrastructure of the dwellings was approved.

\subsubsection{Tourism}

165. Tourism is considered as one of key economic priorities of the country. However, proportion of the tourism within GDP is still low. Development of tourism is hampered by poor quality of the 
services, underdeveloped infrastructure, complex visa procedures and low level of awareness among the foreign investors and tourists. Urgent problem is a guarantee security of the foreign tourists.

166. Establishing of the special ex-territorial area in the Issyk-Kul oblast with preferential taxation will attract the tourists. In this area, the cultural-entertainment facilities, recreationrehabilitation complexes, hotel and restaurant business will be located. It is expected that such area will be a popular place for the foreigners with middle and high income to visit. Required regulatorylegal documents will be drafted and approved. It is important to attract the investors for construction.

167. Continuation of reconstruction of the automobile road "Bishkek - Torugart" will allow creating conditions to travel to the Issyk-Kul Lake, which will be in compliance with the international standards.

168. The Government continues to advertise tourism capacity of Kyrgyzstan abroad. The Embassies of the Kyrgyz Republic will be involved in these advertising activities. The website "Kyrgyzstan is the country of tourism" was designed and launched. Foreign mass media will also used.

169. It is planned to abolish visas for the tourists from the countries with income per capita not less than 7000 USD.

170. Institute of "the free tourism areas" based on tourism clusters will be formed to develop tourism in all regions. New version of the Law of the Kyrgyz Republic "On Tourism" will be drafted.

171. Conservation of the cultural-historical objects on the Great Silk Road will also contribute in attractiveness of Kyrgyzstan and the region in general for the tourists.

172. Development of required infrastructure is connected with implementation of the projects such as "Rehabilitation of the drinking water supply system of Karakol city" (grant of the Swiss Government), "Sustainable Development of the Issyk-Kul" (ADB's loans and grants), "Improvement of water supply system of Bishkek city", "Improvement of water supply system of Osh city and Jalalabad city" (grants of the Swiss Government, EBRD's loans), etc.

173. Brand "Kyrgyzstan is a country of celestial mountains" will be actively promoted to increase attractiveness of tourism sector. The law-enforcement bodies and representatives of the local selfgovernance will be involved to ensure security of the tourists.

\subsubsection{Foreign and domestic trade}

174. Accession of Kyrgyzstan to the Customs Union (CU) will have a substantial influence on development of the foreign trade in mid-term prospective. It is expected that is will improve trading relations with the CU's countries, but problems can occur in trade with the countries, which are not members of the Customs Union.

175. Retaining of level of supply and price of import of the oil products, metal, timber from the countries-members of the Customs Union and access to the CU's countries markets, improvement of employment conditions for the migrants are the most obvious advantages for the Kyrgyz economy. Increasing of the inflow of direct foreign investment can be expected due to lower cost of labor in Kyrgyzstan.

176. If Kyrgyzstan will increase the foreign tariff in accordance with the CU's regulations, it will lead to re-export decreasing (mainly, the Chinese goods), and provide space for claims from the countries-members of the WTO, which interests will be also infringed.

177. Concluded agreements and requirements on technical regulation, sanitary, veterinary and phytosanitary measures in the Customs Union made difficult access of the agricultural goods from Kyrgyzstan to the markets of the countries-members of the Customs Union.

178. At present, god quality laboratory base is absent in Kyrgyzstan. It is demanded to get conformance evaluation meeting the world standards and requirements if the Customs Union. 
179. Procedures on processing of the export-import documentation are still complex and nontransparent.

180. To create enabling conditions during transition period of accession of Kyrgyzstan to the Customs Union, negotiating positions on involvement in the agreements of the Customs Union and the Unified Economic Space will be elaborated and consulted; the international agreements on technical regulation and standardizing were signed in order to apply the European directives and regulations of the Customs Union and other partners in Kyrgyzstan. Also, conditions of compensation provision to the countries-members of WTO will be discussed, for whom the trading regime will be less favorable rather status quo. Agreements on recognition of results of conformance evaluation of the national and baseline standards of Kyrgyzstan will be concluded with main trading and economic partners. Also, the national legislation will be harmonized with the Custom Union's agreements. Studies on consequences of accession of Kyrgyzstan to the Customs Union will be conducted since an impact of the Customs Union on economy of Kyrgyzstan is expected as multiple-valued in short- and mid-term period.

181. Re-orientation towards export production of the enterprises dealt with re-export in the past will be carried out to maintain transit capacity of the country and the objects such as "Dordoi" and "Kara-Suu" as logistics centers.

182. Work will be continued to startup a "one stop shop" system under issuance of permitting documents for the export and import.

183. Domestic trade development: Total volume of the domestic trade turnover was increased by $6,7 \%$ in 2011 versus reduction by $4,9 \%$ in 2010 . Growing of the trade indicates restoration of purchase requirement after negative consequences of the international financial crisis and June 2010 events.

Trend of increasing of the big network enterprises formed in last years has a positive impact on quality of offered services, but at the same time it leads to monopolization of the retail trade, narrowing interests of the suppliers and impediment of production development, "washing-out" of the small business from retail trade area. It contradicts the policy of the small business support and development, requires active interfering of the state in order to achieve balance of various trade forms. High level of the non-observed economy (over 60\%) is maintained in the domestic trade. New version of the Law of the Kyrgyz Republic "On domestic trade" will be drafted and amendments will be made in existing Code of Trade of the Kyrgyz Republic to formulate a solid state policy aimed to regulate mutual relations between the entities and suppliers. New methodology of turnover accounting will be developed and introduced - it will help to elaborate measures on reduction of scope of non-observed economy in the domestic trade.

\subsubsection{Road-transport complex}

184. Road network ensures up to $95 \%$ of all domestic passenger and cargo automobile transportation. International transport corridors are main priority in development of the road network. To develop transit capacity, the road rehabilitation is made in the republic: "OshSarytash-Irkeshtam», «Sarytash-Karamyk», «Osh-Batken-Isfana», «Bishkek-Naryn-Torugart», «Taraz-Talas-Suusamyr»... Special attention is paid to provision of transport independence of the country through construction of the bypass roads to avoid transit through the neighboring states.

185. Today, deterioration of the domestic road network is a serious barrier for economy development. Rural citizens have difficult access to big domestic markets because of poor condition of the roads. Lack of the shortest transport ways to the world markets makes difficult development of the foreign economic links; increases transport costs of the exporters. The Kyrgyz railway does not meet needs of the regional links. There is an urgent need to replace the air-navigation equipment because of expiration of its service time and non-compliance with modern technical requirements.

186. The road-transport complex will be developed by following strategic directions: 1) ensure access to the regional markets of goods and services and development of transit capacity; 2) ensure access to the local markets of goods, works and services. 
187. To ensure access to the regional markets of goods and services, development of the transit capacity and transport independence, implementation of the following projects is envisaged:

(i) Rehabilitation of the international transport corridors of the south direction supposes construction of the auto road «Osh - Sarytash - Irkeshtam». The road is continuation of the auto road Bishkek - Osh and it provides an exit to the Chinese border from the south and further to the South-East Asia. This project is implemented under support of the Asian Development Bank, the Islamic Development Bank and China.

(ii) Rehabilitation of the international transport corridors of eastern direction (auto road Bishkek - Naryn - Torugart) provides exit to China's borders from north. Besides, this road includes a section of the auto road "Bishkek - Issyk-Kul", which will play important role for the tourism development. This project is implemented under support of China, ADB and the Arabic Coordination Group.

(iii) Rehabilitation of the international transport corridors of western direction allows transport independence in south of the country. The auto road "Osh - Batken - Isfana" is only and main transport line connecting the Batken oblast with other oblasts and capital of the Kyrgyz Republic. The European Union, the World Bank and EBRD support this project.

(iv) Rehabilitation of the international transport corridors of north direction (auto road "Taraz Talas - Suusamyr") ensures transport communication for the Talas oblast with other regions of our republic through the road on territory of Kyrgyzstan. This project is implemented under support of the Islamic Development Bank.

(v) Implementation of the project "Rehabilitation of the auto road "Issyk-Kul Circle/Ring" will favor development of whole infrastructure of the Issyk-Kul oblast; improve access of the population to the Issyk-Kul lake from other regions; create conditions to attract the foreign tourists.

188. To ensure access to the local markets of goods, works and services, the Program "Bus communication in each dwelling" anticipating a complex of measures covering the dwellings in rural area will be implemented. Domestic roads will be repaired in order to bring them to minimum working standards, and operation of the State Transport Inspection will be enhanced.

189. Under the Law of the Kyrgyz Republic "On Public-Private Partnership in the Kyrgyz Republic", adopted on February 22, 2012, this mechanism will be broadly introduced in the infrastructure projects. Therefore, based on the public-private partnership, the Government intends to launch two projects on construction of two highways: (i) Kara-Balta - Kemin and (ii) Alma-Ata - Kemin - Cholpon-Ata.

190. The US Government declared its willingness to allocate grant in amount of 30,0 million USD to the Kyrgyz Republic for modernization of the air-navigation equipment. Investment for modernization of the airports "Osh" and "Issyk-Kul" will be attracted.

191. It is planned to attract the investors to start design of the feasibility study on construction of the railway "China - Kyrgyzstan - Uzbekistan" and "Balykchi - Kochkor - Kara-Keche - Arpa".

\subsubsection{Communication and Information}

192. One of the key areas of the National Strategy "ICT for development of the Kyrgyz Republic" is integration into world-wide information network through construction of the modern network of data delivery, which will be a basis for transit capacity building of the Kyrgyz Republic. Work is actively underway on projects to build a fiber-optical communication line (VOLS) in the Kyrgyz Republic in the directions of Tajikistan, Uzbekistan, and China. In particular, construction of the VOLS will continue along the Balykchi-Karakol, Osh-Irkeshtam, and Osh-Uzgen-JalalabatTashkumyr lines.

193. The Law of the Kyrgyz Republic "On high technology park in the Kyrgyz Republic" was approved to attract investment and modern technologies in design of the software demanded on the international markets. 
194. Nevertheless, the sector faces with plenty of problems, in particular: (i) uneven development of the telecommunication infrastructure of the regions and big cities of the republic; (ii) poor condition of telecommunication in rural area (TV and radio broadcasting is absent in 142 settlements; and telecommunication - in 126 settlements); (iii) existing communication network in the rural and remote areas has high production cost and its is unprofitable - it is subsided through revenue re-distribution; (iv) status of TV and radio broadcasting in the rural area does not meet requirements today; (v) equipment of the microwave-link stations is outdated; quality of transmission is unsatisfied; (vi) low level of automation of the postal communication services and poor ICT equipping.

195. Terrestrial digital television and radio broadcasting is being introduced in the Kyrgyz Republic. Plans call for digital coverage of 90 percent of the population of the Kyrgyz Republic by the end of 2014. Work is underway to replace outmoded equipment and build new antenna towers and automatic digital television translators.

196. An "Electronic Government" system is planned for introduction in the Kyrgyz Republic: (i) the introduction of a multiservice information and communications system and an electronic document management system for use in bodies of state; (ii) implementation of the "Internet in Every Aiyl Okmotu" program; (iii) creation of Public Access Centers (TsOD) based on the GP [State Enterprise] "Kyrgyz Pochtasy".

197. It is planned to extend the postal and financial services to modernize and develop network of the communication units of the State Enterprise "Kyrgyz Pochtasy". Also, it is planned to install modern technologies in the communication units of the State Enterprise "Kyrgyz Pochtasy" and establish the "Bank Post Office".

\subsubsection{Foreign Economic Policy}

198. Protection of the national interests, development of the friendly and mutually beneficial relations with the neighboring countries, leading world nations and active participation in the integration processes are main priorities of the foreign policy of the Kyrgyz Republic. This Program stipulates following things to broadening of cooperation and active promotion of interests of Kyrgyzstan within integration associations and bilateral cooperation:

(i) Cooperation is within the regional associations. Cooperation will be continued within multilateral organizations and unifications (CIS, EurAsEC, Customs Union, SOC, ODKB, etc.). Participation in these organizations will provide Kyrgyzstan with a possibility to get positive effects from numerous vital regional projects in the transport, energy, banking and other spheres. Implemented and planned big regional economic projects will create conditions for Kyrgyzstan to ensure internal political stability and prospective for economic growth.

(ii) Cooperation with the countries-donors and international financial institutions is a basis for financial support of the infrastructure projects and implementation of the structural reforms in the Kyrgyz Republic. Existing problems of insufficient coordination of the foreign financial assistance require formulation and realization of the unified policy on foreign aid management. Therefore, the Government intends to develop and introduce a system of the foreign aid coordination... The Government will create a unified database on the foreign aid projects and ensure their efficient implementation.

(iii) Increasing role of the inter-governmental trading-economic commissions. Proposals on capacity building of the Secretariat of the inter-governmental commissions will be formulated, and mechanisms of monitoring and evaluation of their effectiveness will be developed. 


\section{Governance}

\subsection{Public Service Reform}

199. Low awareness of the society on results of activity of the state institutions, excessive influence and interfering of the state authorities in business environment, existing contradictions in the legislation base, lack of transparent and efficient mechanism of state asset management are serious barriers in the state development.

200. Reforming of the executive power structure is purposed to develop rational model of the governance system under conditions of rigid budget restrictions, and elimination of unnecessary public services, functions and responsibilities.

201. It is necessary to build a compact mobile system of the executive power aimed towards outcome guaranteeing efficient state's asset management and based on principles of openness and constructive dialogue with the society. The Government intends to: (i) distinguish and optimize functions of the state bodies to prevent overlapping and duplication; (ii) cut the staff of the public institutions; (iii) optimize sphere of the public services and carry out transition to electronic format of their provision («Electronic Government»); (iv) reduce quantity of the vehicles on service of the state bodies; (v) conduct a gap analysis of replacement of some jobs by new technologies (process automation) and approaches in the governance area with gradual decrease of number of the public servants; (vi) introduce the resource agreements to increase effectiveness and professionalism in the governance system.

202. Mechanisms of compulsory involvement of the representatives of the civil society and public Advisory Councils (ONS) in elaboration of the strategic documents and regulatory-legal acts, expertise of the state decisions and monitoring and evaluation will be incorporated in the regulations of the government institutions. It will allow enhancing of transparency and effectiveness of solutions approved by the Government.

203. Timely, necessary and reliable information on decision-making will be provided regularly to the public and society.

204. Special attention will be paid to status and quality of existing institutional websites, integration of feedback mechanism to keep contacts with the public, discussion of problematic issues, and regular update of the news block.

205. Mechanisms reducing influence of the official on business will be elaborated including strict control of his/her performance.

206. Maximum reduction of need of the citizen to apply to the official for any permit. Some public services, functions and institutions will be eliminated.

207. Corruption reduction will be a result of these measures, incentives to develop business, reduce burden on the budget and increase effectiveness of the governance.

\subsubsection{Assessment of effectiveness of the government institutions activity}

208. The Government will design and apply the balances system of indicators and assessment criteria to assess effectiveness of performance of the governmental instoitutions. System of indicators will be designed and fulfilled to assess final result of performance of each governmental institution and its staff oriented towards: (i) creation of conditions to compare assessments; (ii) assessment of results, and not process; (iii) use of results of assessment as a basis to adjust actions of the executive bodies; (iv) involvement of the civil society in evaluation process; (v) use of independent international rating surveys, etc. 


\subsubsection{Reform of working conditions of the public servants}

209. Competence, professionalism and creativity of the public servants are key assessment criteria of conducted reforms. Today, existing competition system does not allow capacity building of the public servants and reduces motivation of the public servants towards career promotion. It is supposed to organize transition from model of total competition for all public administration positions to the career-based system in order to address this problem. The competition will be mandatory only at "the entry point" of the system for the young specialists. Further promotion of the specialist will be fulfilled based on personal characteristics and abilities of this individual considering quality of his/her work.

210. Lack of system of the targeted and standard training, re-training and upgrading qualification of the public servants determines their low level of competence.

211. Within intended reforms, the Government plans to: (i) draft new version of the Labor Code of the Kyrgyz Republic and the Law of the Kyrgyz Republic "On Public Service"; (ii) carry out transition from the model of total competition selection at all public administration positions to the system of career promotion; (iii) adopt the regulations and norms anticipating advantageous recruiting, growth and promotion at the public and municipal service for the individuals speaking fluently the Kyrgyz, Russian and English (command level); (iv) design and introduce a payment system by results of performance appraisal of the public servants; (v) design and approve the legal norms on application of complementary techniques to examine professional and personal characteristics of the public servants including psychometric testing and polygraph-testing; (vi) introduce the regulations stipulating strict responsibility of the public servants for violation of the legitimacy and ethics of the public service behavior; (vii) conduct transition to unified system of the public contracting for training, retraining and improving qualification for the public service through the Management Academy under the President of the Kyrgyz Republic; (viii) make amendments and additions in the Law of the Kyrgyz Republic "On Public Service" regarding restriction of appointments of the advisers and assistants on the public administration positions without the competition selection.

\subsection{Administrative and territorial reform}

For purposes of creating an effective system of national and municipal management, focused on strengthening the potential of the regions and enhancing the welfare of the country's population, a balanced system for the administrative and territorial division of the Kyrgyz Republic will be developed.

At the initial stage, a Concept of Administrative and Territorial Reform in the Kyrgyz Republic has been approved by a governmental decision.

In future, administrative and territorial reform will be directed at: (i) eliminating redundancy in the structure of national and municipal management, increasing their efficiency, and reducing budget expenditures; (ii) harmonizing the legal regulatory base in the area of municipal management; (iii) enhancing the regions' potential by strengthening their financial autonomy; (iv) creating an accessible and effective system for providing national and municipal services; (v) creating conditions for the people's kurultai to function effectively.

\subsection{Combating corruption}

212. Corruption in the Kyrgyz Republic is a serious threat to the national security of the country. According to data of the international assessments, the Index of Corruption Perception, 
Transparency International, the Kyrgyz Republic was on $164^{\text {th }}$ place of 178 countries in the world in 2010 and $166^{\text {th }}$ place in 2011 (among 180 countries, and it is in a group of the countries with high corruption level.

213. Therefore, the Government combats against corruption within the governance reform. Mechanism reducing influence of the official on business will be designed including strict control on his/her activity. Maximum reduction of need of the citizen to apply to the official for any permit. Some public services, functions and institutions will be eliminated.

214. The President established the Anti-Corruption Service under the State Committee of National Security of the country to address these challenges. This Service is responsible for informationalanalytical and awareness work, detection and preclusion of the corruption schemes, facts of bribery and extortion from side of the judges, prosecutors, police and military at all levels.

215. Public support is one of key elements of fight against corruption. Therefore, the civil society will be involved through increased number of events. The Government will provide comprehensive support in development of the public control system.

216. The Government will initiate and introduce strict laws and radical measures of punishment for corruption and malpractice, and actual mechanisms guaranteeing an unavoidability of punishment for criminal offences will be proposed.

217. Up to date, the declaration campaign was limited by collection of the public servants' declarations. The Government intends to initiate mechanisms of checks and verification of the public servants' declarations and approve measures of liability for provision of false information.

218. Anti-corruption website of the Government will be updated, and system of electronic accounting of submitted applications and feedback on application consideration will be improved.

219. Unified body will be set up to carry out public procurements with public disclosure of terms and conditions and decisions made. Due to transition to the unified electronic system of public procurements, existing units on public procurements in some governmental institutions will be eliminated with retaining or delegation of functions to one employee (certified procurement specialist).

Policy measures to fight against corruption, which have being used in the world practice and closely interlinked, will be conducted in following areas: (i) attraction of the civil sector institutions to fight against corruption through established committees of the civic control; (ii) development of the system of legal education of the public and rising awareness on corruption risk in any sphere; (iii) improve and develop legal basis for anti-corruption interventions; (iv) eradication of corruption causing factors impeding favorable conditions for investment attraction; (v) improve the accounting system of state property and assess its effectiveness; (vi) introduce form and methods ensuring effectiveness of anti-corruption actions in the state administration and local self-governance bodies; (vii) apply restriction, banning and duties specified in the legislation of the Kyrgyz Republic in order to prevent corruption among the persons taking the public positions; (viii) examine status of corruption and effective measures undertaken for its prevention, detection and eradication including roots and causes creating and provoking the corruption; (ix) improve the low-enforcement practice of the law-enforcement bodies and trials on corruption cases; (x) improve investigation techniques of corruption offences and their application in the law-enforcement activity; (xi) improve the forms of anti-corruption expertise of the regulatory-legal acts and their drafts; (xii) ensure clear regulation of cash collection in all public institutions; (xiii) extend participation of the Kyrgyz Republic in the international and regional anti-corruption programs including broadening of cooperation with the OECD network combating against corruption; (xiv) ensure regular experience sharing with the foreign anti-corruption structures.

\subsection{Reform of legislation}

220. For optimization of drafting legislation and harmonization of the current legislation with the basic ideas and principles, enshrined in the new Constitution of the Kyrgyz Republic, the 
Government has plan to: (i) develop draft regulations, aimed at elimination of conflicts and gaps in legislation; (ii) develop mechanisms for coordination of activities of government agencies, involved in the legislation drafting process, in the issues of planning and forecast in development of legislation; (iii) to legislate the end to the adoption of regulations, implementation of which is not provided with adequate financial resources; (iv) develop a draft regulation, aimed at regulation of activities of physical and juridical persons, which will be carrying out specialized types of examinations of draft regulations.

221. For improving quality of implementation of international obligations in the area of human rights protection it is envisaged to: (i) carry out a functional analysis of the executive authorities, the competencies of which include ensuring human rights; (ii) approve a single coordinating governmental agency and determine a uniform policy in the sphere of drawing up of national reports on human rights.

\section{Improvement of development environment}

\subsection{State regulatory policy}

222. At this time the private sector, including small and medium-sized business, is making a substantial contribution to the country's economic development. The foundation for effective business development is the implemented by the state policy for support and development of entrepreneurship, aimed at creating an effectively functioning economic system capable of selfdevelopment.

223. The principal source of employment in Kyrgyzstan today is entrepreneurship, the accelerated development of which can be accomplished with relatively small levels of investment while making a significant positive impact toward solving the problem of reducing poverty in the country.

224. Core reforms in the sphere of entrepreneurship were carried out through the efforts of the Government and the business community in the country. Significant legal and regulatory framework, enshrining in law the rights and obligations of the government and business to the citizens of the country, is available. Business platforms for dialogue of the state and business, for adoption of proposals and decisions on development and business support have been established. Currently a big number of various business associations and communities are functioning. Cardinal reforms took place at the end of 2011, when the reform was carried out in the public administration system, which allowed to significantly reduce the state apparatus in the Government of the Kyrgyz Republic, reconsider the need for operation of individual departments/agencies, eliminate duplicate functions between government agencies and others. One of the most important steps in the field of inspections of businesses became the establishment of two new inspection bodies: (i) the State Inspectorate for Food and Phytosanitary Security under the Government of the Kyrgyz Republic and (ii) the State Inspectorate for Technical and Environmental Safety under the Government of the Kyrgyz Republic.

225. The current legislation system continues to be a problem. Its execution in the administrative sphere has a number of drawbacks, which include a significant amount of overlapping, contradictory regulations, availability of juridical conflicts, inconsistency of the newly adopted regulations to the laws, regulating relations in the sphere of entrepreneurship or distortions of their norms.

226. Adopted laws, regulating business operations have not been analyzed in terms of their regulatory impact. Cases of adopting drat laws while bypassing business, without public hearings, regulatory impact analysis and other examinations required by law are not infrequent.

227. Until now, there are many barriers to business entities that restrict their entry to domestic and foreign markets, as well as create problems for the business (unclear and vague licensing procedures). There is still no clear statutory requirements of the state to doing business, on ensuring safety of life and health of citizens, the environment (pre-licensing and post-licensing requirements, 
technical regulations). At present there are over 500 types of licenses and permits, which in the opinion of the business community should be reduced.

228. The current system of governmental regulation in the control and supervision sphere is ineffective, costly, and often duplicative, for the most part of formal nature, creating at the same time significant corruption risks. The on-going inspections do not provide for the necessary level of protection and safety in general for consumers, who use results of business activities. Monitoring in the field of inspection demonstrates that at present regulatory bodies inspect all business entities, which in turn requires significant human and financial resources to conduct such total inspections. In order to optimize the existing system of inspection, in February 2012 a Resolution of the Government on the approval of criteria for the ranking businesses by the level of risk of their businesses, allowing businesses, allowing to breakdown business entities into three risk categories: high, medium and low. The introduced risk criteria will allow the state regulatory authorities to effectively use available financial and human resources, thus significantly reduce the number of inspections.

229. In order to solve the above mentioned problems the Government policy will be focused on two main areas: (i) development of stable legislation, meeting the requirements of the economy and taking into account the view of the business community; (ii) reduction of government interference in business activities regulation, violating the balance of interests between government and business.

230. To create stable legislation that meets the requirements of the economy and takes into account views of business community, conditions for annulment or prevention of adoption of regulations that violate the requirements of the legislation in the field of entrepreneurship will be established through: (i) reform of the system for assessment of regulatory impact on managerial decisions; (ii) development of recommendations for elimination of unreasonable and not market-oriented regulations through regular meetings with business community, with public oversight councils and other public organizations;

231. Measures will be taken to reduce the level of governmental intervention in regulation of entrepreneurial activities will be passed in the form of regulatory and procedural regulations. Reform of state regulation and licensing and permitting and control-and-supervisory spheres will be continued through: (i) reduction in the number of operating licenses and permits; (ii) the development and adoption of the new Law of KR "On licensing and permitting system of the Kyrgyz Republic" in accordance with the concept of deregulation of the economy; (iii) reduction of excessive control-and-supervisory functions; (iv) introduction of a new system of risk assessment criteria by regulatory agencies; (v) introduction of specialized checklists by each state regulatory authority; (vi) creation of an updated mechanism for inspections based on risk criteria system .

\section{Social development and poverty reduction strategy}

\subsection{Poverty incidence}

232. One of the main tasks of the Government is to reduce poverty in the country. To date, $33.7 \%$ of the population lives below the poverty line. In addition, a poverty depth indicator ${ }^{2}$ increased from $5.1 \%$ in 2009 to $7.5 \%$ in 2010 .

233. Moreover, there is a large gap between the level of poverty in urban $(23.6 \%)$ and rural $(39.5 \%)$ areas. Poverty in rural areas is much higher than in urban areas. Over 1 million 846.2 thousand people lived below poverty line in 2010, thereof $74.4 \%$ were residents of rural settlements.

234. Poverty level in urban settlements increased by 1.7 percentage points, while in rural area - by 2.4 percentage points.

\footnotetext{
${ }^{2}$ The level of consumption by the poorest strata of population in percent from the consumption level corresponding to poverty line for the country.
} 


\begin{tabular}{|c|c|c|c|c|c|c|}
\hline \multicolumn{7}{|c|}{ Table 1: Poverty level of urban and rural populations, in \% } \\
\hline Year & \multicolumn{2}{|c|}{ Total } & \multicolumn{2}{c|}{ Urban population } & \multicolumn{2}{c|}{ Rural population } \\
\hline & Poor & very poor & poor & very poor & poor & very poor \\
\hline 2006 & 39,9 & 9,1 & 26,7 & 5,5 & 47,7 & 11,3 \\
\hline 2007 & 35,0 & 6,6 & 23,2 & 3,2 & 41,7 & 8,5 \\
\hline 2008 & 31,7 & 6,1 & 22,6 & 3,2 & 36,8 & 7,7 \\
\hline 2009 & 31,7 & 3,1 & 21,9 & 2,7 & 37,1 & 3,3 \\
\hline 2010 & 33,7 & 5,3 & 23,6 & 4,2 & 39,5 & 6,0 \\
\hline
\end{tabular}

235. The table demonstrates that the overall poverty rate declined from $39.9 \%$ in 2006 to $31.7 \%$ in 2008 , but in 2010 this figure had risen to $33.7 \%$. Especially sharply poverty increased in rural areas, and reached almost $40 \%$, while extreme poverty doubled and amounted to $6.6 \%$.

236. Unequal income distribution is also confirmed by the Gini coefficient.

\begin{tabular}{|l|r|r|r|r|r|}
\hline \multicolumn{5}{|c|}{ Table 2: Gini coefficient (by incomes) } \\
\hline Year & 2006 & 2007 & 2008 & 2009 & 2010 \\
\hline Gini coefficient (by incomes) & 0.446 & 0.422 & 0.363 & 0.371 & 0.371 \\
\hline
\end{tabular}

237. The unevenness of incomes distribution reduced (from 0.446 in 2006 to 0.363 in 2008), but later this coefficient increased to 0.371 in 2010.

238. High child poverty is of a particular concern. According to data of the National Statistical Committee of the Kyrgyz Republic, of the total number of children aged 0-17 years old 40.9\% lived in poverty, of which $6.5 \%$ were in the category of extremely poor. Child poverty in rural areas was $46.3 \%$, which is 16.3 percentage points higher than in urban areas.

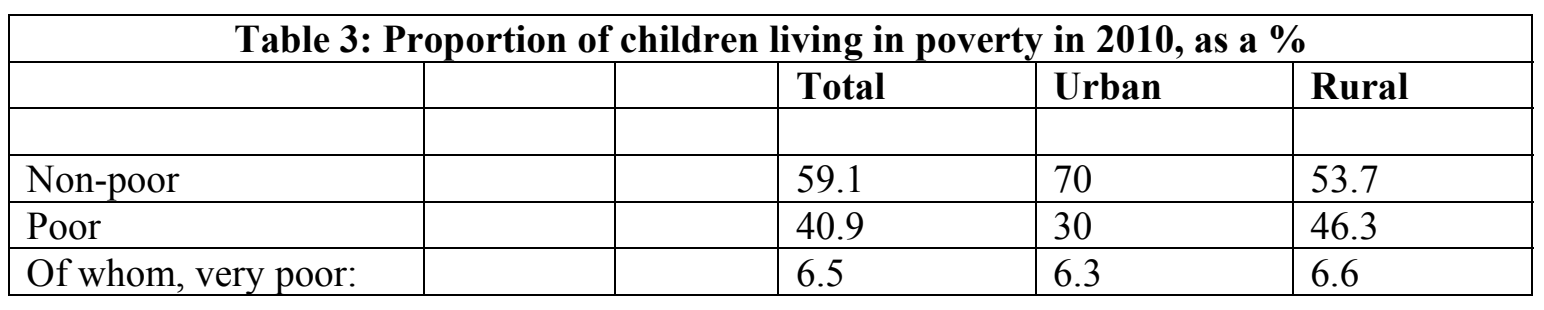

239. The level of access to utilities differs greatly between urban and rural areas. Poor households and households in rural areas own less comfortable housing, because infrastructure in rural areas is underdeveloped. Electricity is the only kind of amenities, covering the entire country. $33.5 \%$ of urban households and only $1.3 \%$ of rural households are equipped/connected to the centralized heating system. This indicates an exclusively urban nature of the service associated with the provision of centralized heating to the population. $20.9 \%$ of households has access to the gas pipeline network. Insufficient coverage with gas pipeline network through the country denies access to almost all the rural population to piped gas supply.

\begin{tabular}{|l|r|r|r|r|}
\hline \multicolumn{7}{|l|}{ Table 4. Access to utilities by poverty level in 2010, in \% } \\
\hline & Running water & $\begin{array}{r}\text { Gas through } \\
\text { piping network }\end{array}$ & Central heating & Telephone \\
\hline Total & 25.7 & 20.9 & 13.0 & 33.1 \\
\hline including: & & & & 39.2 \\
\hline non-poor & 34.5 & 24.9 & 17.6 & 3.9 \\
\hline \multicolumn{2}{|r|r|r|}{ Poor } & 8.8 & 13.0 & 3.0 \\
\hline
\end{tabular}




\begin{tabular}{|c|r|r|r|r|}
\hline of whom, very poor: & 8.0 & 9.6 & 2.8 & 23.5 \\
\hline Urban settlements & 52.4 & 46.0 & 33.5 & 58.0 \\
\hline Rural area & 9.9 & 6.7 & 1,3 & 19.0 \\
\hline
\end{tabular}

240. Every third dwelling is connected to a telephone communication line. The level of public telephones availability in urban areas is almost three times higher than in rural areas. At the same time, coverage of the Kyrgyz Republic with availability cellular communications today has reached a level exceeding $90 \%$.

\begin{tabular}{|c|r|r|r|r|}
\hline \multicolumn{5}{|c|}{ Table 5: Sources of water supply, depending on } \\
place of residence and poverty level (in percentages)
\end{tabular}

241. Figures for 2010 show that the rural area is also well behind on indicators of access to potable water and poverty level is correlated with access to potable/drinking water.

242. Women play an active role in the socio-economic life of the country and constitute $41.3 \%$ of the total employed population. The proportion of women among the employed population is highest in the services sector, and especially in such types of activities as health and social services $(80.3 \%)$, education $(76.6 \%)$, hotels and restaurants $(71.0 \%)$, community, social and personal services (56.6\%). Quite significant is women's employment in manufacturing (46.4\%); the proportion of women has reached to $87.4 \%$. in the sub-sector of textile and clothing industry. However, women hold lower-paid positions than men, and their wages comprise $63.9 \%$ of men's wages. Taking this into account, as well as a high proportion of women engaged in household labor, the risk of falling into the category of the poor is higher for women than for men.

243. According to NSC estimates for 2010, the average life expectancy in the Kyrgyz Republic is 69 years old, but the birth rate and death rate dropped to 6.6 per thousand persons. Population grows in 2010 was $1,1 \%$.

244. Taking into account that the problem of poverty requires a comprehensive approach, the Government intends to ensure fair public access to sources of economic growth and to manage economic growth in the interests of the poor. The reforms underway in the system of government administration, including the fight against corruption, will promote transparent management in the process of forming revenues from economic activities and the effective use thereof in the interests of the poor population.

245. Therefore this Program is aimed at implementing objectives tied to the creation of conditions in which the private sector will be able to develop, prosper, and provide the jobs necessary to raise incomes and reduce poverty. Along with this, the state will concentrate its efforts on social development, applying more productive and effective approaches to social protection policy and to genuine care for the people in society who are in need of basic necessities.

246. the Government intends to carry out reforms in the spheres of social protection, health, social security, education, labor market and gender politics. In particular, the Government intends to increase the effectiveness of social protection of socially vulnerable segments of the population 
through the provision of timely and good quality social services. The concept paper on social protection is the Strategy for development of social protection of the Kyrgyz Republic for 20122014, approved by the Government of the Kyrgyz Republic. In the next three years, the main object for the protection of the state will be children who are in difficult situations, people with special needs (LOVZ), senior citizens and persons in the risk group (homeless persons).

\subsection{Social protection}

247. The Government attaches great importance to providing good quality services on social protection to the population and, in spite of the economic and political upheavals of 2009 and 2010, the Government succeeded in fulfilling all the obligations of social guarantees in full.

248. The main problem that hinder promotion o effective public policies for social protection of population and poverty reduction are: (i) lack of the system of standards for the provision of social services to families and children in difficult situations; (ii) lack of real instruments to make social protection system more targeted ( iii) inefficient distribution of resources to provide services to children in institutions/orphanages, which leads to the necessity of de-institutionalize institutions like orphanages; (iv) low level of coverage of persons with special needs (LOVZ) with social protection measures, as well as the lack of a developed system for integration of persons with disabilities (LOVZ) in public life ; (v) lagging behind of sizes of pensions and social allowances from the minimum subsistence level; (vi) lack of prophylaxis (prevention) and social rehabilitation of homeless.

249. In order to improve quality of social protection the Government intends to implement a number of measures, including development of minimum social standards and methods of calculating the cost of social services.

250. To reform the system of targeted services the Government intends to develop and introduce a system of social work at the local level, based on the needs of families in difficult situations.

251. Work on development and implementation of various forms of enrollment of children in difficult situations (in day care centers, foster homes, adaptation and rehabilitation centers, etc.) will be continued. Thus, by 2014 it is planned to establish one rehabilitation center for street children in each region (oblast) (total 9).

252. For improvement of quality of social services for persons with special needs (LOVZ) the Government will introduce new forms and methods of stationary social institutions, as well as a new system of definitions of disability while at the same time improving access to information and educational programs.

253. Also day care centers for senior citizens will be established based on the needs of older citizens in the cities of Bishkek and Osh. It is planned to develop and introduce new forms and methods of operation in stationary governmental social institutions for elderly citizens.

254. The Government will conduct a phased increase in the size of government allowances and by 2014 their level will reach $100 \%$ of basic part of pension.

255. The main objective of the Government for providing social protection to populations at risk will be creation of local social infrastructure available for the prevention and rehabilitation of homeless (a network of social services and the Institute of Social Work).

\subsection{Pension reform}

256. The system of compulsory pension social insurance is one of important components in the prevention of poverty and reduction of poverty of people who lost income due to old age, loss of ability to work or loss of breadwinner survivor benefits. For the first time on the basis of increase of pensions in October 2011 the average pension size became close to the subsistence level (99\%). 
257. The budget of the Social Fund is formed due to insurance premiums and revenues from the national budget. The size of pensions depends on the size of insurance premiums made. Phased until 2014) financing of basic part of pension is made from the funds of he republican budget, as well as of additional accrual to pensions, pensions of military personnel, compensational payments for electricity. During recent nine years the budget of the Social Fund was I surplus. Mandatory savings element was introduced in 2010.

258. Despite the progress achieved, there are several unresolved issues: (i) $70 \%$ of pensioners receive pensions below the subsistence level; (ii) The current pension formula requires revision in order to strengthen the insurance principle of a pension; (iii) the actuarial imbalance of revenue sources and long-term pension liabilities system in the long term; (iv) the ratio of working population and those actually paying people to retirees is reduced each year (1:1.4); (v) the problem of low coverage of migrants with social security.

259. Given these problems, the Government will focus its efforts on the following objectives: (i) ensuring financial sustainability of the pension system; (ii) increase of pensions based on governmental social insurance; (iii) improving the savings component of the Kyrgyz Republic.

260. The main policy measures which are planned to improve the financial sustainability of the pension system will be: (i) broaden the base of insurance payments; (ii) improve assets management; (iii) liquidation of the Fund for recovery of workers; (iv) revision of the tariff rate payments for peasant farmers and individual entrepreneurs (IE) working in the bazaars; (v) involvement of local governments and administrations of markets to collection of insurance contributions; (vi) involving labor migrants in a system of governmental social insurance.

261. To maintain the effectiveness of the pension system it is planned as follows : (i) an annual increase of pensions to the level not lower than the inflation rate; (ii) setting norms and standards for overcoming poverty among the pensioners through carrying out policy of assigning the basic pension for the disabled and pensioners due to loss of bread winner, regardless of the number of years worked; (iii) review and development of an adequate pension formula; (iv) reduction of privileges when calculating pensions; (v) improving the indexing mechanism for pension deposits in personal accounts of citizens to protect them from inflation.

\subsection{Development of the system of education}

262. The education system in recent years carried out comprehensive reforms affecting all its levels, as well as the most important aspects of development: financing, management and monitoring system necessary for decision-making and change of the content of education.

263. Priority attention to the school level of education was due to the responsibility of the State (Article 45 of the Constitution of the Kyrgyz Republic), and the need to halt the growth of poverty, since the provision of access to good quality education can improve the capabilities of each graduate in the labor market.

264. The reforms in the sector of preschool education aimed at improvement of psychological and pedagogical preparedness of children to school and success in further education, as well as all levels of professional education should lead to the creation of continuity, flexible and open resultsoriented system of education.

265. The main strategic goal of education reform in the medium term will be the formation of the basic framework for good quality results oriented education.

266. To achieve this goal the policy measures of the Government will focus on the following areas: (i) improvement of education system management; (ii) improvement of the efficiency of funding; (iii) changes in educational content and optimization of training of teachers.

267. Within the framework of improving educational system management (i), the Government is planning to develop regulations, aimed raising quality of the system for decision making system and strategic planning in the sector of education on the basis of monitoring and evaluation of results for all levels of education. 
268. In order to increase the effectiveness of preschool education management the following will be developed: (i) regulations to the Law "On Pre-School Education" and the standard of "Early childhood education and child care" will be reviewed to improve the social competence of children; (ii) particular attention will be paid at the pre-school education as preparing and continuity in education of preschool and school children; (iii) to ensure affordability of preschool education, including for children from poor families a mechanism of public-private partnership in early childhood education and establishment of alternative pre-school organizations will be launched.

269. At the level of school education a phased reduction of the school education workload from 1200 hours to the average international level will be carried out. Also, a system of sub-regulatory documents is being developed- a new type of standards (curricula). In the 2009 Framework national standard (curriculum) of general school education was adopted, based on it currently subject curricula are being developed for the 5-9 and 10-11 classes, but in the long term - school curricula that will lead to greater autonomy in the choice of school development priorities.

270. Within the framework of initial vocational education it is planned: (i) to create qualifications framework for selected areas of training (Qualifications System/Framework), which provides for recognition of education documents by employers of both Kyrgyzstan, CIS and other courtiers abroad; (ii) reducing the time for education at the expense of development of a wide range of short courses to meet the needs of the population and the demands of employers. Availability of a variety of courses will allow to get education hat is in demand for children from poor families, as well as provide a quick re-training of adults who do not have work/employment. On average in secondary vocational education in 2010 a new generation of standards will be developed and introduced. In higher vocational education in connection with the transition to a two-tier system of education (bachelor's and master's) the following will be carried out: (i) internal and external quality control mechanisms, which should ensure the recognition of diplomas of higher education institutions of the Kyrgyz Republic abroad will be strengthened; (ii) system of upgrading qualifications will be development for employees of higher education institutions, including the development of mechanisms to attract employers into the process.

271. For effective use of skills of the system for upgrading qualifications a voucher mechanism will be introduced for its provision. This step will lead to an increase in the number of providers offering services for training, diversity of programs offered, and, as a result, ensuring the quality of education of students.

272. For improving efficiency of funding (ii) the Government intends to use the following mechanisms in 2012-2014: (i) transition to a funding model based for the sector of education based on the sector-wide approach (SWAP); (ii) transition to per capita funding at the level of school education; (iii) transition of part of higher educational institutions to self-financing.

273. Transition to sector-wide approach starting from 2013 will allow consolidating donor funds and direct them into the education system directly through the budget that will eliminate duplication in the direction of funds and will allow using external assistance to solve major problems of the education system, in the first place, of school and basic vocational education.

274. Strengthening responsibility to the recipients of educational services requires the transfer of comprehensive education institutions on the principles of financial and administrative autonomy. Prior to 2015 all public educational institutions will be transferred to per capita funding.

275. At the level of primary vocational training optimization of the number of educational institutions will take place and of the budget for training of skilled workers demanded by the labor market. This process will also lead to increased targeting of social assistance to children from poor families.

276. Since 2012 a system for rating and accreditation of higher education will be introduced. Profiling and transfer of a part of higher educational institutions to principles of self-financing will start, which will allow to focus training of students on a grant basis in the national higher educational institutions and universities, that are prepared to fulfill the state order.

277. For the formation of a new content of education (curriculum) (iii) the Government will be develop or update standards at all levels, from preschool to higher education. The standards of a 
new generation will provide for the transition to learning based on competencies that form the result-oriented educational system.

278. The Standard "Early childhood education and care after children" puts greater emphasis on social and emotional development of children, formation of a system of values that provide for socialization of a child.

279. Further introduction of a new type of standards (curriculums) in school education will increase students' motivation to study and achieve better quality education through a balanced curriculum.

280. For improving social and communicative competences of students particular attention will be focused on the study of the Kyrgyz (the State), Russian (the official) and the English languages.

281. An important element of post-conflict resolution in schools will become introduction of multilingual and multicultural education aimed at increasing the level of tolerance, mutual understanding, and civil accord.

282. To ensure good quality results-oriented education, new methods of diagnosing and monitoring the results of the educational process at the level of student, class and school will be introduced.

283. For provision of school with teachers who have high level of knowledge on the subject, whom possess modern technology of teaching and a high level of motivation to work in educational institutions, new standards on pedagogical specialties will be introduces in 2012 on the bachelor's level and updating of curriculums for upgrading teachers' skills will take place.

\subsection{Health system development}

284. As a result of the carried out reforms in the public health sector, a system of compulsory health insurance and family medicine institution were introduced, public health organization were restructured, new principles of the budget formation mechanism were introduced. Progress was accomplished in access to public health services.

285. The events of April-June 2010 were a big challenge for the public health system. The crisis did not have a significant impact on the public health in the affected areas and public health organizations were able to cope with the influx of patients during the conflict. However, the crisis clearly demonstrated the weakness and limitations of the public health system, deterioration of the infrastructure and lack of appropriate equipment and supplies.

286. Despite the achievements, there is a number of unresolved problems: (i) the financial gap in implementation of the program of state guarantees (PSG) to provide citizens with medical and sanitary assistance due to an increase of the population entitled to benefits who received access to public health services within the PSG; (ii) decrease of availability of medication for socially vulnerable categories of the population; (iii) insufficient progress in accomplishment of MDG 4 and MDG 5 MDG 6; (iv) insufficient level of material and technical equipping of public health organizations, the number of ambulance vehicles is at the level of $60 \%$ of the required number; (v) shortage and uneven distribution of human resources, decline in the quality of personnel training; (vi) insufficient development of public health services; (vii) inadequate legislation for introduction of public-private partnership mechanisms in the public health sector.

287. Based on these problems, the main directions of the public health system development policy will be as follows: (i) development of a sustainable financing system aimed at increasing the financial protection of the population and poverty reduction; (ii) increasing the availability for people of the preferential provision of medicines within PSG and the Supplementary program of compulsory health insurance; provision of medicines for insured citizens on an outpatient basis (SP $\mathrm{CHI}$ ); (iii) improving the quality of health care with a public health focus on accomplishment of MDGs; (iv) preservation and optimization of the existing system of health care delivery; (v) improving the availability of medical personnel and improving the quality of medical education; 
(vi) strengthening the role of public health; (vii) development of market mechanisms in the public health system.

288. Policies for development of a sustainable system of financing include: (i) establishment of a system of a basic state medical care insurance; (ii) gradual transition of public health organizations that provide specialized medical care (TB, mental health, oncology, hematology) into the Single Payer system; (iii) revision of the list privileged categories of citizens in obtaining medical services; (iv) amend the Regulations on the procedure for making, keeping and use of co-payments in public health organizations which implement PSG; (v) improving public awareness of rights when receiving health care, preventive and pharmaceutical services within the PSG .

289. To increase access of the population to preferential provision of medicines it is planned to: (i) revise of the standard of per capita out the CHI to determine the amount of funding allocated for implementation of the SP CHI; (ii) conduct a periodic review of the basic prices to compensate for preferential provision of medicines within the PSG and SP CHI, (iii) increase public awareness of the population about preferential SP CHI programs.

290. To improve the quality of health care with the public health sector focus on accomplishment of MDGs the following measures were initiated: (i) development and introduction of standards of medical services based on evidence-based medicine in practical public health; (ii) implementation of programs to improve the nutritional status of women and children; (iii) full coverage of TB patients with DOTS Plus program, including the penitentiary system institutions; (iv) undertaking preventive measures, training of medical professionals, provision to high-risk groups of rapid tests, antiretroviral drugs; (v) further expansion of harm reduction programs among drug users.

291. In order to improve material and technical base of public health organizations construction work at the National Center for Maternal and Child Welfare will be carried out, as well as major repairs of the main building. Renovation of the Osh Interregional joint hospital and Jalal-Abad oblast joint hospital will be completed. In addition, A FMC will be built in Osh. Equipment and ambulance vehicles will also be procured.

292. The Government considers resolution of the personnel issue and improvement of the quality of medical education as one of the main policy priorities. For this a number of measures are planned: (i) introduce the State Educational Standard (GOST) for the profession "General medicine" and training programs with a focus on training of general practitioners (family doctors) in all the higher medical educational institutions and revision of state standards for other professions, (ii) revise the regulations governing the "Doctor's deposit" program; (iii) develop a concept paper for development of postgraduate medical and pharmaceutical education; (iv) provide a procedure for mandatory state distribution of specialists who received education funded from the state budget, and responsibility for the abandonment of the mandatory two years of internship.

293. To strengthen the role of public health the following steps are stipulated: (i) to develop new ways of working with people in the framework of "Community Action for Health" and expand the activities of village health committees on topical issues of safety and health; (ii) revise the legislative basis to ensure the effective operation of the service; (iii) carry out structural reforms in public health sector to transfer control and supervisory functions to the newly created State Inspectorate on sanitary, veterinary and phytosanitary safety; (iv) equip and accredit core laboratories.

290. For development of market mechanisms in the public health system mechanisms for publicprivate partnership will be developed and introduced and also transfer of some public health organizations to self-financing will be carried out.

\subsection{Labor market and Employment}

295. The quantitative capacity of the human resources of Kyrgyzstan is estimated as rather high. Over the past years in the labor market the situation is described as the excess of demand over supply, which leads to dynamic growth in unemployment. 
296. The number of unemployed recently is replenished not only by the citizens, released from the production sites due to reduction and elimination of commercial enterprises, but also in connection with the ongoing reform of public administration.

297. On January 1, 2012 for the entire country the supply of labor exceeded the demand in more than 32 times, in some regions this figure is ten times higher. The public sector hardly creates jobs, the real capacity for job creation only the private sector has. The level of overall unemployment rate, calculated according to ILO methodology, for the period 2009-2011 increased from $8.4 \%$ to $8.6 \%$.

298. Number who applied to public employment services hovers around 160 - 170 thousand people. At the beginning of 2012 in the city and district employment offices there were registered about 95 thousand seekers for jobs citizens in the country, including 61,000 who have the official status of unemployed.

299. Underdeveloped labor market information infrastructure, limited opportunities for professional development, training and retraining of personnel create certain obstacles in the labor market to achieve a balance between the labor supply and demand.

300. The role of the government will be to provide the appropriate environment in which the private sector performance will develop and improve, as well as measures of social protection of officially registered unemployed.

301. Policy measures to promote employment will be targeted at: (i) determination of the supply and demand in the labor market (through research); (ii) improvement of the training and retraining of the unemployed; (iii) development of micro-credit system of the unemployed; (iv) development of the labor market information infrastructure and helping unemployed people to find work; (v) expansion of social projects for temporary employment; (vi) undertake active measures to create new jobs, including in rural areas; (vii) increasing the proportion of women in the workforce through the employment of women; (viii) development of social partnership in the issues of employment, including development of a new Labor Code of the Kyrgyz Republic.

\subsection{Culture and religious aspects}

\subsubsection{Culture}

302. The Government recognizes the input of culture in social development. In 2009, a new Law of the Kyrgyz Republic "On culture" and the National Program "Development of culture and art in the Kyrgyz Republic until 2010" a number of initiatives for development of this area of public life were undertaken.

303. However, there is a number of unresolved problems caused by low material support and regulatory framework.

304. Moreover, in violation of the Law of the Kyrgyz Republic "On the use and protection of historical and cultural heritage" there is changing of the condition of monuments, indiscriminate use, which leads to their deterioration and loss of valuable skills and integrity of both individual monuments and historic environment. Often, local executive authorities give permission to build monuments in protected zones without taking into account of the issues of their preservation. This problem is compounded by high level of rural poverty, which seeks to obtain short-term gains from the misuse of cultural monuments.

305. The disparity in services between rural and urban areas is of a particular concern, which is aggravated by the lack of personnel training / retraining.

306. Realizing the importance of preserving cultural heritage, the first step in this direction will be to develop and introduce the single national electronic database on cultural values.

307. In addition, the Government will introduce the project practices for the preservation of historical and cultural heritage, which will improve the material and technical condition of the monuments of culture. Also, for the promotion of cultural heritage it is proposed to develop a 
consolidated national calendar of cultural and recreational activities of local and national significance, along with a program to attract tourists to the cultural - recreational activities.

308. In order to develop culture in the countryside, mechanisms to encourage tours and theatrical and entertainment events will be introduced.

309. The government also plans to work to improve the personnel training system, including the formation of an order for a grant study taking into account the needs of the country in cultural specialists, as well as mechanisms for targeted training / retraining of specialists in foreign educational institutions.

\subsubsection{Religion}

310. The Kyrgyz Republic is a multi-confessional country where the population holds more than 30 directions and trends. The law "On Freedom of Beliefs and Religious Organizations in the Kyrgyz Republic" the government protects the freedom of worship of all confessions In recent years, there active work was carried out to preserve religious harmony and tolerance within the frameworks of a series of roundtables, workshops, training sessions, with the participation of government agencies, NGOs and donor organizations in resolving problems and disputes arising in the area of religion.

311. To increase the capacity of law enforcement bodies to combat religious extremism and radicalism, in 2011 in all regions of the country training sessions were conducted for police inspectors.

312. But despite the efforts of the Government, the threat of religious extremism and terrorism, is relevant today both domestically and in the region. High level of poverty and unemployment among young people in rural areas leads to an increase in supporters of extremism and terrorism. To date, the exact number of sects and religious trends is difficult to determine because of their clandestine activities.

313. The number of people, who received a religious education, is growing every year, but the state does not have information about their number and quality of their education.

314. Fragmentation and lack of dialogue between different confessions and communities represents a threat of radicalization of religious trends. The events of June 2010 revealed a lot of problems, including the ones of a religious nature that must be addressed with the participation of all stakeholders.

315. Also the active process of politicization of some religious organizations also is a matter of concern, because it can lead to a conflict in the society.

316. To prevent the threat of religious extremism, the Government will continue working with the law enforcement bodies and local authorities as well as religious organizations. There will also be developed a mechanism to record the people receiving religious education abroad and in the country.

317. In order to create a common platform an Interfaith Council - an advisory body on matters of religion will be created. The Council is assumed to contribute to reducing the radicalization and politicization of religious organizations.

\subsection{Development of physical culture and sports}

318. Physical education and sport in the country actively develops in the recent years. Successful performance of athletes of Kyrgyzstan on the world sporting arena is an undeniable proof of development in this area, winning of medals at world championships and international tournaments. Successful performance of athletes of Kyrgyzstan in the international arena attracts young people to physical culture and sports. Annually the Government conducts national contests among rural youth, school sports day, Universiade, championships, and championships. 
319. However, in this area there is very poor infrastructure and sports equipment. Since 1992 no funded from the state budget sports facility was built in the country. Sports halls are in less than a half of secondary schools and their equipment was not updated during 15-20 years, provision of public sports facilities ranges from $16 \%$ to $1 \%$.

320. There was deterioration in the health of different population groups, including children and adolescents: $20 \%$ of preschool children and about $80 \%$ of school leavers have various deficiencies in their health status. Mass Physical Culture and Sports reaches only 6-7\%, which is below the threshold level of safety of the gene pool (15\%). And there is also high level of poverty in rural areas, which is a major obstacle for the promotion of sports in the regions.

321. In the medium term perspective the activity of the Government will be targeted at (i) development of sports infrastructure; (ii) an increase in the number of coaching and teaching staff.

322. To optimize the logistical support of the infrastructure an inventory of sports facilities of the network of children's sports schools will be conducted and appropriate changes to the Law of the KR "On the Republican Budget of the Kyrgyz Republic" will be made.

323. In order to improve the quality and number of the personnel in the area of physical culture and sports, a transfer to the Bologna system of specialists' training at the Kyrgyz state academy of Physical Culture and Sport and conducting of short courses "High school coaches" is planned.

\subsection{Gender equality achieving policy}

324. The Kyrgyz Republic signed and ratified a number of basic documents of the United Nations to achieve gender equality. By joining the international initiatives, Kyrgyzstan intends to promote policies of gender equality in the country.

325. For an effective promotion of gender policy the regulatory framework was established: (I) the Law of the Kyrgyz Republic "On state guarantees of equal rights and equal opportunities for men and women" and (ii) the Law of the Kyrgyz Republic "On social and legal protection from domestic violence" were adopted. Introduction of special measures into the Elections Code of the Kyrgyz Republic and other laws ensured women representation in the Parliament, Government, judiciary.

326. The role of the Government in the area of gender equality will be to conduct legal and institutional changes designed to eliminate gender discrimination.

327. Therefore, gender equality policy will be focused on promoting gender initiatives through institutional enhancement as well as funding gender policy measures and integrating gender equality policy in national, sector, and regional strategic documents. The key initiatives for the promotion of gender policy in the medium term will include: (i) improvement of national legislation in the area of gender policy, bringing it into line with the international legal standards, taking of legal, organizational and administrative measures aimed at improving the status of women, protection of their rights and interests, promotion of equality between men and women; (ii) creation of institutional mechanisms for implementation of the gender policy; (iii) development and implementation of state programs aimed at achieving gender equality; (iv) education and promotion of a gender equality culture.

328. Key policy measures to achieve gender equality will be: (i) amend the Law of the Kyrgyz Republic "On Social and Legal Protection from Domestic Violence"; (ii) compile a National Report on implementation of the Convention on the Elimination of all Forms of Discrimination against Women (CEDAW); (iii) elaborate more refined mechanisms for the conduct of mandatory expert studies for gender issues of all draft legal regulatory acts and development programs; (iv) elaborate and approve a National Strategy for Gender Development to 2020, for the successful implementation of which a National Action Plan to Achieve Gender Equality for 20122014 will be developed and approved during the initial stage; (vi) develop and approve a National Action Plan to Fulfill UN Security Council Resolutions 1325 (2000) and 1820 (2008) on ensuring the participation of women at all levels in making decisions on issues of preventing, managing, and 
resolving conflicts. These plans are an indivisible part of the current Program for the Development of the Kyrgyz Republic (2012-2014).

\section{Security}

\subsection{Internal and external security}

\subsubsection{Establishing the rule of law and ensuring security of the citizens}

329. Political events in the country in 2010 clearly revealed the accumulated problems in the area of internal security. As a result of errors and miscounts in the organizational and management, and especially personnel work, law enforcement agencies were weakened, lost confidence of the population and could not fully properly perform their functions. At the same time, the inherent law enforcement bodies' functions, such as: (i) fight against organized crime; (ii) ensuring public safety; (iii) preventive measures and informing political leaders about the negative processes and contradictions, including the sphere of interethnic conflicts, retreated into the background.

330. There were revealed the facts of illegal possession of firearms, rampant of crime and uniting it with the authorities. Seizure of property without court decisions, raider takeovers of ownership became the norm. Unfair decisions of law enforcement agencies increasingly reduced the level of confidence of the business. Kyrgyzstan was not included in the rating of the International Index of Property Rights - 2011.

331. Based on the tragic experience of the events of April and June 2010, the target activity in law enforcement and public safety will be retention of the unity of Kyrgyzstan, taking of effective measures to combat manifestations of nationalist and regionalist nature, countering drug trafficking, organized crime and extremist infiltration, formation of an atmosphere of safety.

332. A crucial step in establishing law and order and ensure public safety will be a reform of the law enforcement sector to subject their activities to the interests of protection of rights of ordinary citizens, eradication of corruption, relationships with the crime, application of tortures and violence, human rights violations. The government already took effective measures to decriminalize society and economy, including the establishment of the Main Directorate for Combating Organized Crime. The most influential members of organized criminal groups are in prison or hiding outside the country.

333. Reforming the system of law enforcement bodies is planned for the following areas: (i) procedural stipulation of the special status of investigators; (ii) revival of the institute of inquiry officers; (iii) legislative stipulation of the status of the prosecutor office of the Kyrgyz Republic as an oversight body only to civil, administrative and criminal cases (excluding the function general supervision); (iv) reforming of the General Directorate of the Road Safety under the Ministry of Interior (GAI); (v) establishment of a special technical unit under the Ministry of Interior with application of the latest technology; (vi) redistribution of powers between the central bodies and local governments in the area of law enforcement and public safety, etc.

334. In order to improve the effectiveness of law enforcement bodies to ensure public order and crime prevention with participation of the civil society the following measures will be undertaken: (i) development and introduction of mechanisms to encourage and inspire civil society representatives for providing assistance to law enforcement bodies; (ii) revival of voluntary people's guards (DND); (iii) development and introduction of mechanisms to protect witnesses; (iv) increase in the activity of the Public preventive center (PPC) in the regions; (v) expansion of measures for redemption and confiscation of weapons from the population.

335. In order to record unlawful acts and accidents in the cities and towns the "Safe City" project with CCTV installation will be implemented.

336. In order to reduce functional duplication and budget cuts, optimization and delimitation of functions between the law enforcement bodies of the Kyrgyz Republic in the area of investigation 
of economic and official crimes will be carried out, with concentration of economic crime investigation functions in one body.

\subsubsection{External security}

337. The Kyrgyz Republic will continue to strengthen its own armed forces and will cooperate in the military area with international partners, guided by its national interests.

338. The Government will actively participate in preparation of the single concept of strengthening the defense capacity and national security, initiated by the supreme commander of the Kyrgyz Republic.

339. The Reform of the State Committee of the National Security of the Kyrgyz Republic (SCNS) will be accelerated based on a clear delineation of functions among the law enforcement agencies. The work of intelligence agencies will be completely redirected to prevent and eliminate external threats and the fight against terrorism.

340. Through structural reforms in the State Service for Drug Control under the Government of the Republic the "Batken pass" will be strengthened.

341. The undertaken reforms in the area of military units and formations assume: (i) granting the status of an independent agency of the Border Service of the SCNS of the Kyrgyz Republic; (ii) establishment of "Mountain Riflemen" subdivision due to structural changes within the Ministry of Defense of the Kyrgyz Republic.

342. To improve the quality of the educational standards of personnel training, gradual replacement of morally and technically outdated military equipment and weapons, as well as improvement of material and technical equipment the following measures are suggested: (i) preparation of specialists for aviation, anti-aircraft missiles, radar, radio and technical large units and formations of the Armed Forces of SWO of the Kyrgyz Republic; (ii) installation of digital automatic telephone exchanges and VPN communication channels in the troop command and control.

\subsection{Reform of the judiciary and guaranteeing of property rights}

343. Without a reform of the judicial system the desired effect of the undertaken reforms in all spheres of life of the state and the society cannot be accomplished.

344. The main problem with the judicial system functioning is the lack of adequate transparency and accountability to the public about the results of its work. The judicial system lost confidence of the Kyrgyz society as an independent institution for protection of human rights and freedoms.

345. Government-initiated measures designed to eradicate criminals do not bring proper results, as in the judicial system there is both incompetence and corruption of a certain part of the judiciary.

346. Therefore, the issue of judicial system reforming today is timely and urgent. The reform of the judicial system will be aimed at achieving the following results: (i) improvement the transparency of the procedures and criteria for selection of judges; (ii) improvement the efficiency and quality of consideration of cases with the placement of judicial decisions on departmental websites; (iii) improving execution of judgments; ( iv) development of self-government of judges through the Congress of Judges and establishment of an independent Judicial Council and other bodies of judicial self-government; (v) minimization of terms of imprisonment for minor offenses.

347. As a part of the ongoing reform of the judicial system the foundation for transparency and openness in consideration property rights' violations cases will be established. The government here recommends the following specific measures: (i) a moratorium on the arbitrary deprivation of private property via nationalization until the review of nationalization procedures and stipulation of the procedures in the laws in accordance with the Constitution and international law norms; (ii) establishment of a closed list of grounds for granting the right to make seizures of private property by the state (requisition, compulsory acquisition in the public interest, temporary removal, etc.), 
including adoption of special laws providing for fair mechanisms for impoundment and full compensation of the market value of property.

\subsection{Ensuring environmental safety}

348. The high altitude characteristic of the overwhelming majority of the country (96\%) predetermines high vulnerability of ecosystems to natural and anthropogenic influences. In this regard, ensuring environmental sustainability in the unity with the socio-economic and institutional aspects creates a framework for sustainable development of the country and achieving the millennium development goals (TsRT).

349. New challenges related to climate change and process of degradation in natural resources are having a detrimental effect on citizens' quality of life and demanding that timely steps be taken. The second report of the Kyrgyz Republic on the TsRT notes that climate change will also lead to an increase in extreme weather phenomena, the destruction of ecosystems, threats to human health, loss of biodiversity, and degradation of land resources. Issues of food and energy security, which directly affect the level of poverty in the country, could become especially urgent.

350. The environmental sector of Kyrgyzstan is under the influence of long-and short-term economic difficulties of the country, which restrict the financial resources. Lack of funding is not only due to the limited state budget, but also because of poor promotion of initiatives for conservation and sustainable use of natural resources in relation to economic development and poverty level in particular in the regions.

351. The Kyrgyz Republic is a party to 13 international environmental treaties and conventions, fulfillment of obligations under, which contributes to environmental sustainability and allows to attract external funding for stabilization and prevention of degradation processes of natural resources, enhance the capacity of the country's livelihood as a basis for poverty reduction and socio-economic development.

352. Kyrgyzstan has significant foreign debt. Therefore, promotion of the activities aimed at its exchange for the national environmental protection and sustainable development projects are of particular relevance, requiring constant and purposeful joint activities of government agencies.

353. The recommendations of the Second Report of the Kyrgyz Republic on the MDGs (2010) specified the need to improve legislation in the area of environmental management and environmental protection, including environmental regulatory regimes of environmental management, regulatory functions for the possession, use and disposal of natural resources and harmonization with international agreements to which Kyrgyzstan is a party.

354. Progressive urbanization of territories is accompanied by a decrease of access to good quality drinking water and adequate sanitation, a significant increase in air pollution emissions from stationary sources and motor vehicles, the problem of accumulation of solid waste. No sound management of chemicals is one of the causes of pollution of the environment, especially in places of burial of obsolete pesticides. In this direction development of a comprehensive program for the proper management of chemicals, using a multisectoral approach is planned.

355. In the Kyrgyz Republic the loss of biodiversity is observed. The status of an endemic ichthyofauna of the Issyk-Kul is of a particular concern. Due to the lack of sufficient funding, biodiversity conservation is carried out only in the protected areas and there is a need to expand their territory, capacity building, conservation of biodiversity in productive landscapes, as well as to develop a strategy for biodiversity conservation.

356. To solve these problems, the Government intends to promote such initiatives as: (i) reform of state environmental policy and legislation, (ii) development of national policies on climate change, (iii) development of international cooperation to address the national environmental problems; (iv) improvement of the effectiveness of measures aimed at biodiversity conservation and sustainable use of natural resources. 
357. As part of the reform of the state environmental policy, legislative separation of permits policy and control system will be made for development and revision of the national environmental strategic documents. To demonstrate the contribution of the environment into the economic development, reducing poverty and achieving the MDGs the UNDP / UNEP "Poverty and the Environment" initiative will be implemented.

358. National policy and a package of measures for adaptation, climate change mitigation will be developed, including promotion of low-carbon development, principles of "green" economy and improving the energy efficiency of buildings.

359. In the framework of international cooperation to address national environmental problems a number of projects aimed at fulfillment of the obligations under the global environmental conventions and agreements will be implemented.

360. Considerable attention will be paid to improving the investment climate for addressing national environmental problems via improving the transparency of engagement of financial resources of the GEF and other donors to promote the "Exchange of external debt for sustainable development" country mechanism, coordination of measures to ensure radiation safety within the IAEA framework 3, through the development of a national report on the Status of the Environment based on international indicators of the UNECE 4.

361. As part of measures to enhance biodiversity conservation and sustainable use of natural resources capacity-building activities of the network of protected areas and restoration of forest ecosystems will be carried out. Forest management of the single forest and protected areas' fund and an inventory of hunting grounds will be initiated, as well as planting of forest species plantations on the territory of the State Forest Fund and out of these lands.

362. One of the priorities will be development of inter-agency and inter-sectoral collaboration through: (i) undertaking of measures contained in the "Package of measures for environmental safety of the KR until 2015"; (ii) development of a framework for the implementation of the Strategic Environmental Assessment; (iii) improvement the awareness and involvement of the civil society in development and implementation of environmental policies and legal acts.

\subsection{Ensuring comprehensive safety of the population and the territory from natural disasters and catastrophes}

363. Natural disasters, technological accidents each year represent more and more threat for our country. Earthquakes, landslides, mudflows and floods, avalanches, glacial mountain lakes and groundwater flooding present the greatest threat to human life, life support facilities, settlements.

364. In Kyrgyzstan, there are at least 14,000 hazardous sites, areas and zones of sources of natural disasters and emergencies. Analysis of the disasters that occurred in the country in recent years, confirms the trend of annual growth. Therefore, there is a need for greater state influence on risk management, when the issue of protection of the population in emergency situations shall be a priority and most important task of the state and government at all levels. At all levels of the authorities and administration activities shall be explicitly carried out to increase efficiency, strengthen the level of training, the capacity and means of the civil protection authorities.

365. Further improvement and development of the single network of Crisis Management Centers plays an important role in the timely operational decisions and actions for prevention and elimination of emergencies. Conducting of an effective monitoring and forecasting is of paramount importance in prevention of natural and man-made situations. The annual amount of allocated budget funds is mainly used for emergency response. To improve the provided to hydrometeorological services, public authorities, industries and people forecasting of dangerous natural processes and phenomena it is necessary to arrange for the reconstruction and technical upgrading

\footnotetext{
${ }^{3}$ IAEA - International Atomic Energy Agency

${ }^{4}$ UNECE - UN European Economic Commission
} 
of hydro-meteorological monitoring network. Formation of an effective monitoring and forecasting in conjunction with the availability of information management system in emergency and crisis situations will allow starting preventive activity, and in the long term to reduce the cost of disaster management and decrease human casualties.

366. The existence in the country of 37 dumps and 35 tailings, which accumulated as a result of many years work of uranium mines and processing plants, are of a particular concern. In the tailings and rock dumps about 250 million cubic meters of toxic and radioactive mining waste is buried.

367. Under the state budget deficit area development of international cooperation in the area of emergency prevention and response is an important direction.

368. Given these problems, the Government intends to create an advanced state system of Civil Protection of the Kyrgyz Republic. Addressing of this task involves: (i) development of a strategic legal and regulatory framework for civil protection; (ii) improved monitoring and forecasting of natural disasters and catastrophes; (iii) timely preventive, protective measures and (iv) international cooperation in the area of prevention and emergency response.

369. As part of the strategic development of the regulatory framework in the area of civil protection a set of documents for the establishment of the National Platform, including by-laws will be developed.

370. To increase the effectiveness of monitoring and forecasting of natural disasters and catastrophes there will be: (i) launched four Crisis Management Centers (CMC) in Chui, Osh regions and Osh, Bishkek; (ii) set up 9 centers of the state comprehensive system of informing and alerting the population; (iii) launched the single state duty and dispatch service in Bishkek, Osh, in 7 regional and 56 district centers.

371. To ensure timely taking of preventive and protective measures remediation and rehabilitation activities in the tailings and containing radioactive and toxic wastes rock dumps will be carried out. Protective nature capital construction rescue and restoration work will be carried out with good quality. Training of government bodies and civil protection forces, public awareness and dissemination of knowledge in the area of civil protection will be carried out.

372. Within the framework of international cooperation in the area of emergency prevention and response efforts will be undertaken to attract and implement international projects in the area of prevention and liquidation of natural and manmade emergency situations.

\section{Regional development}

373. The need for reform of public administration and local governments in the regions is due to the existing economic and social problems of the regions, which major causes include poor quality programming of development at all levels of administration, lack of internal and external economic integration and socio-oriented local budgets and inefficient fiscal system formed on the distribution principle.

374. Local development programs are based primarily only on budgetary resources, partnership resources of local communities, private businesses and nonprofit organizations are not involved into their development and implementation, there is no logical connection between a development program at the local level and the budget as a tool for its implementation.

375. As a consequence of an inefficient financial and economic policy, the traditional division of regions by economic and social development is preserved: (i) developed: the city of Bishkek, IssykKul and Chui regions; (ii) medium: Jalal-Abad, Osh regions. (Iii) poor: Batken, Talas, Naryn and Osh.

376. Generation of more than half of the country's GDP is formed by the city of Bishkek, Issyk-Kul and Chui regions. The smallest contribution to the GDP accounts for the Batken region (3.21\%), the Talas region (3.53\%) and Naryn region (3.52\%).

377. Significant regional differences in poverty levels are preserved. There were identified four regions where the poverty level in 2010 exceeded 40\%: Naryn region - 53.5\%, Jalal-Abad region- 
44.7\%, Talas region $-42.3 \%$ and Osh region $-41.9 \%$. In other regions the indicator was less than $40 \%$. In almost all regions the poverty level in rural areas is higher than in urban areas.

378. The average ratio of an average monthly salary to the subsistence level has reached the highest value in Bishkek (2.36), and the Issyk-Kul region - (2.03). The smallest value of this indicator for the period of 2008 to 2010 and was for the Osh region (0.99), i.e. the average monthly salary in the region as an average was below the subsistence level for the period 2008-2010.

379. The existing difference between the major macroeconomic indicators of regional development leads to the migration of working-age population from the regions lagging behind to the more successful ones. The main factor, affecting the internal mobility of the population, is the existence of disparities in the economic development of the regions, in the ratio of supply and demand for labor and, accordingly, the regional differentiation of incomes.

380. In the Jalal-Abad, Issyk-Kul and Naryn regions the need for labor is 5-10 times lower than in Bishkek and Chui regions. Nowadays, Bishkek and Chui region became the zones of the biggest influx of migrants from the regions of the country. The main suppliers of internal migrants in Bishkek are Batken - 25.7\%, Naryn region - 19.1\%, Osh and Jalal-Abad regions - 15.6\% and $15.0 \%$, respectively.

381. However, the external dynamics of the population outflow remains. The main outflow of the population falls on the Chui region and the city of Bishkek. This is because both Bishkek and Chui region are "transit areas". Osh region in comparison with other regions is leading in "supply" of migrants in the Russian Federation: $36.9 \%$ of the total outflow of the population from Kyrgyzstan to Russia and $72.8 \%$ in an outflow from the region.

382. The consequence of the population loss for the regions is the shortage of qualified labor force and reduction the attractiveness of the region for residence, which is a bad "signal" that requires an immediate response at all levels of administration.

383. To solve the above problems the Government's efforts will be targeted at creating conditions for qualitative changes in economy and social development of the regions through the administrative-territorial reform, reform of public administration and local government. Assisting in the decentralization of state administration, local communities are to be given even greater powers, thus more fully mobilizing the populace in the process of combating poverty.

384. By 2014 the Kyrgyz Republic shall become a country in which the conditions for moderate but stable growth rates of the regional economy and improving living standards of the population in the regions will be created. Conditions will be created for: (i) reduction of the uneven economic development of the regions; (ii) capacity growth of local economies and their investment attractiveness; (iii) reduction of the population outflow from rural areas and (iv) formation of public-private partnership and development infrastructure at the local and regional levels.

385. For a comprehensive development of the regions a new concept for regional development will be developed.

386. Regional Development involves formation of a new economic matrix of Kyrgyzstan, consisting of economic districts. As part of this process it is scheduled to reach the following objectives: (i) ensure the maximum utilization of the production potential of the regions; (ii) develop national and local development programs and strategies, taking into account the comprehensive planning to support the "growth points", the need for infrastructure development in the region and interregional economic integration; ( iii) involve the key representatives of local communities, private businesses and nonprofit organizations to develop and implement regional development programs; (iv) develop a system of public-private partnership of local authorities and business; (v) develop local budgets with program budgeting, on the basis of regional socioeconomic programs; (vi) improve the system of formation of budgetary subsidies; (vii) direct the investment of local budgets and local private capital in infrastructure restoration and creation; (viii) strengthen the capacity of public authorities in the regions and local governments to develop strategies, investment initiatives and projects; (ix) improve the quality of administration of regional and local authorities; $(\mathrm{x})$ develop a national partnership program for coordination of international 
and national non-governmental organizations in the regions aimed at achieving the effect of joint efforts of the authorities, programs and projects of the civil society and donor organizations.

387. Development of local government. To create a sustainable system of local government the following measures are involved: (i) inventory of normative legal acts to confirm the compliance with the Constitution and the Law of the KR "On local government"; (ii) develop draft laws on amendments to sectoral laws on the procedure for delegation of powers to the state to local governments; (iii) develop legal acts on the administrative and civil responsibility of officials for the quality of municipal services; (iv) amend the normative and legal acts in the area of intergovernmental relations, aimed at strengthening of local capacity; (v) amend the Law "On the non-tax payments" with regard to the issue of local taxes; (vi) develop standards and regulations for municipal services delivered to the population; (vii) develop and run a system for monitoring and evaluating the quality of services (administrative, social, infrastructural, information, etc.) ; (viii) strengthen the material and financial base of local governments; (ix) develop mechanisms to attract private business and public sector to the delivery of municipal services; (x) create a multi-purpose centers in the regions to deliver services to the public; (xi) develop a system of training and retraining of municipal employees; (xii) create public supervisory councils at the local government.

\section{Expected Results}

388. As a result of the Program implementation, following main results will be achieved: (i) acceleration of the GDP growth from $5,7 \%$ in 2011 to $7,5 \%$ in average a year; (ii) poverty alleviation in the country from $33,7 \%$ in 2010 to $28 \%$ in 2014 ; (iii) reduction of the budget deficit from 5\% of GDP in 2011 to $2.6 \%$ of GDP in 2014; (iv) it is forecasted that inflation rate will not exceed 10\% in 2012-2014; (v) due to the big national projects, the foreign investments will be attracted; (vi) decreased interference of the state in business regulation, brining to minimum inspections and checks, improvement of interaction between the business and power; (vii) partnership and participation of the civil sector in the most important political decision-making on the country development issues.

\section{Conclusion}

389. Close and coherent work of the President of the Kyrgyz Republic, the Government and the Jogorku Kenesh of the Kyrgyz Republic under constructive interaction with the civil sector is required to fulfill this Program. Sustainability of the country development will depend on their coherent work.

390. It is obvious that the Program implementation is impossible without trust of the people to the power and support of the plans of the Government by the society. World practice shows that progress in the prosperous countries was achieved due to availability of the strong political will and maximum trust of the people to the power.

391. The Government is fully responsible for implementation of the Program. Previous authorities of Kyrgyzstan did not present the country development documents for approval by the Parliament and they approved them through their decrees. First time, the country development program is submitted for consideration to the Jogorku Kenesh of the Kyrgyz Republic. Legislative support of the proposed reforms is provided by the Jogorku Kenesh of the Kyrgyz Republic, and in case of endorsement, the distinguished MPs would be their co-authors.

392. Role of the non-governmental organizations (NGOs) was substantially increased in the public life of Kyrgyzstan. Input of the civil society is great in terms of change of the power, adoption of new Constitution and transition to the parliamentary form of ruling. Extension of forms of 
interaction of the power with the civil society is supported to enhance democratic processes, and first steps are taken towards actual participation of the civil society in strategic decision-making. The civil society will be engaged actively in process of discussion and monitoring of this program implementation.

Implementation process. The Program will be implemented through design and fulfillment of annual plans together with package of national projects using the budget and off-budget sources of financing.

393. Solutions of the Program adjustment will be made based on monitoring data and evaluation of results of realization of the annual plans of three year Program.

394. Management process of the Program fulfillment stipulates: (i) systematic analysis and assessment of implementation of the annual plans to make political decisions regarding progress achieved in the Program implementation; (ii) justification of required costs to implement the projects and sector based programs; (iii) identify potential sources of financing, stimulation of investment projects; (iv) create conditions required to fulfill the sector programs and projects; (v) create required regulatory-management environment for successful realization of the Program; (vi) launch a monitoring and evaluation system, identify some deviations from declared goals and objectives, analysis of causes and adjustment if necessary.

395. Coherent actions of all stakeholders in realization of the annual plans of the Program will be ensured under general coordination of the Prime-Minister of the Kyrgyz Republic.

396. Main challenges of the executive bodies will be: (i) mobilization of required budgetary funds; (ii) coordination of attraction of borrowings; (iii) synergy of the central, sectoral and regional authorities; (iv) provision of institutional conditions for the private sector and civil society to participate in realization of the Program; (v) coordination of implementation of the sectoral programs and projects within this Program.

Monitoring and evaluation. Regular monitoring and evaluation of implementation of the sectoral programs and projects of the Program will be an efficient instrument to track progress in its realization, which will help to: (i) make preventive decisions through proposal of correction in a process and (ii) assess their impact $\mathrm{n}$ general country development.

397. Annual plan on the Program implementation with its system of indicators will be an essential component of monitoring and evaluation of progress in development of the economic and social priorities outlined for 2012-2014 within this Program. Indicators of monitoring and evaluation of the annual action plans will have both quantitative and qualitative characteristics.

398. Set of indicators of monitoring and evaluation will allow tracking and measuring of: (i) interim results of progress of the Program considering invested resources; (ii) final results through indicators of fulfillment of outlined goals and objectives; (iii) national indicators reflecting dynamics of development of the Kyrgyz Republic at macroeconomic level including MDGs.

399. Based on monitoring data, effectiveness of the program implementation will be evaluated regularly. During this evaluation, achieved progress will be thoroughly studied, and "weakness" and shortcomings in fulfillment of activities and projects of the program will be identified. Based on received results, political decisions will be made regarding selection of alternative options on further steps in implementation of three year Program, resource re-distribution and their optimal use, proving coordination of efforts with the donor community, better satisfaction of expectation of the society. 


\section{Attachments:}

1. Macroeconomic indicators.

2. Budget of the Medium-term Development Program of the Kyrgyz Republic for 2012-2014, including national projects.

2.1. National projects budget. 
Attachment 1

Macroeconomic indicators

\begin{tabular}{|c|c|c|c|c|c|c|c|c|c|c|}
\hline \multirow{2}{*}{ Indicators } & 2005 & 2006 & 2007 & 2008 & 2009 & 2010 & 2011 & 2012 & 2013 & 2014 \\
\hline & actual & actual & actual & actual & actual & actual & preliminary & projected & projected & projected \\
\hline \multicolumn{11}{|c|}{ GDP } \\
\hline $\begin{array}{l}\begin{array}{l}\text { Nominal GDP } \\
\text { (billion soms) }\end{array} \\
\end{array}$ & 100,9 & 113,8 & 141,9 & 188 & 201,2 & 220,4 & 273,1 & 319,2 & 365,4 & 425,0 \\
\hline $\begin{array}{l}\text { Nominal GDP } \\
\text { (million US dollars) }\end{array}$ & 2460,8 & 2849,6 & 3827,6 & 5061,4 & 5573,6 & 4778,2 & 5943,8 & 6792,3 & 7775,4 & 9041,9 \\
\hline $\begin{array}{l}\text { Real GDP growth rate } \\
(\%)\end{array}$ & 99,8 & 103,1 & 108,5 & 108,4 & 102,9 & 99,5 & 105,7 & 107,5 & 107,6 & 107,4 \\
\hline $\begin{array}{l}\text { GDP per capita (US } \\
\text { dollars) }\end{array}$ & 478,4 & 548,9 & 731,2 & 959,4 & 1148,4 & 922,6 & 1130,7 & 1296,1 & 1449,0 & 1666,7 \\
\hline \multicolumn{11}{|c|}{ Prices, wages and incomes of population } \\
\hline GDP deflator & 107,1 & 109,4 & 114,9 & 122,2 & 104,0 & 110,0 & 117,3 & 108,8 & 106,4 & 108,3 \\
\hline $\begin{array}{l}\text { CPI (in \% to December of } \\
\text { previous year) }\end{array}$ & 104,9 & 105,1 & 120,1 & 120 & 99,7 & 119,2 & 105,7 & 109 & 108,9 & 108,2 \\
\hline $\mathrm{CPI}$ (in \% to previous year) & 104,3 & 105,6 & 110,2 & 124,5 & 106,8 & 108 & 116,6 & 106,3 & 108,3 & 108,8 \\
\hline $\begin{array}{l}\text { Exchange rate (som/US } \\
\text { dollars) }\end{array}$ & 41 & 40,2 & 37,3 & 36,6 & 42,9 & 45,96 & 46,14 & 46,5 & 47 & 47 \\
\hline $\begin{array}{l}\text { Monthly average pension } \\
\text { (soms) }\end{array}$ & 775 & 906 & 1114 & 1435 & 1664,8 & 2886 & 3760,0 & 4172 & 4589 & 5551 \\
\hline $\begin{array}{l}\text { Nominal average monthly } \\
\text { wage (soms) }\end{array}$ & 2613 & 3270 & 3970 & 5378 & 6401 & 7189 & 9352,0 & 11316,5 & 13034,5 & 14991,3 \\
\hline $\begin{array}{l}\text { Subsistence minimum (SM) } \\
\text { of working-age population } \\
\text { in a month (soms) }\end{array}$ & 2127,8 & 2619,7 & 3082,8 & 3930,9 & 3624,9 & 3905,4 & 4920,7 & 5230,7 & 5664,9 & 6163,4 \\
\hline $\begin{array}{l}\text { Average wage/SM of } \\
\text { working-age population (\%) }\end{array}$ & 122,8 & 124,8 & 128,8 & 136,8 & 170 & 184,1 & 190,1 & 216,3 & 230,1 & 243,2 \\
\hline \multicolumn{11}{|c|}{ National accounts (in \% of GDP) } \\
\hline GDP at market prices & 100 & 100 & 100 & 100 & 100 & 100 & 100 & 100 & 100 & 100 \\
\hline Consumption & 102 & 113,1 & 104,6 & 110,1 & 96,7 & 102,7 & 101,3 & 100,5 & 100,1 & 98,8 \\
\hline Private & 84,5 & 95,1 & 87,5 & 92,5 & 78,3 & 84,6 & 83,5 & 83,3 & 83,3 & 82,4 \\
\hline Government & 17,5 & 18 & 17,1 & 17,5 & 18,4 & 18,1 & 17,8 & 17,2 & 16,7 & 16,4 \\
\hline Gross capital formation & 16,4 & 24,2 & 26,6 & 28,9 & 27,3 & 27,4 & 27,7 & 30,0 & 31,8 & 33,2 \\
\hline Government investment & 4,2 & 3,9 & 4,4 & 3 & 4,3 & 4,4 & 105,8 & 5,1 & 4,3 & 4,4 \\
\hline Private investment & 12,2 & 20,3 & 22,2 & 25,9 & 23 & 23,0 & 21,9 & 24,9 & 27,5 & 28,8 \\
\hline Export (goods and services) & 38,3 & 41,7 & 52,9 & 53,5 & 54,7 & 51,6 & 53,7 & 53,7 & 52,3 & 50,4 \\
\hline $\begin{array}{l}\text { Import (goods and services) } \\
(-)\end{array}$ & $-56,8$ & -79 & $-84,1$ & $-92,6$ & $-78,7$ & 81,7 & 82,7 & 84,1 & 84,2 & 82,4 \\
\hline $\begin{array}{l}\text { Net export of goods and } \\
\text { services }\end{array}$ & $-18,5$ & $-37,3$ & $-31,2$ & $-39,1$ & -24 & $-30,1$ & $-29,0$ & $-30,5$ & $-31,9$ & $-32,0$ \\
\hline \multicolumn{11}{|c|}{ Government budget (in \% of GDP) } \\
\hline $\begin{array}{l}\text { Total government budget } \\
\text { resources }\end{array}$ & 26,8 & 28,4 & 30,0 & 29,2 & 39,7 & 34,8 & 36,8 & 36,7 & 33,6 & 31,2 \\
\hline Total revenues & 20,8 & 22,6 & 26,1 & 25,3 & 27,5 & 26,0 & 28,3 & 28,3 & 26,5 & 25,8 \\
\hline Of which tax revenues & 16,3 & 17,6 & 18,7 & 19,1 & 17,9 & 17,9 & 19,4 & 20,6 & 20,9 & 21,4 \\
\hline Total expenditures & 23,2 & 25,6 & 27,6 & 25,2 & 28,9 & 30,9 & 33,3 & 33,4 & 30,1 & 28,4 \\
\hline Of which PIP (external) & 3,2 & 3,3 & 2,6 & 1,8 & 2,8 & 3,8 & 4,7 & 5,7 & 4.0 & 1,7 \\
\hline Interest payments & 0,8 & 0,8 & 0,6 & 0,7 & 0,8 & 0,8 & 1,0 & 1,0 & 0,9 & 0,7 \\
\hline Deficit (including PIP) & $-2,4$ & $-3,0$ & $-1,5$ & 0,2 & $-1,4$ & 4,9 & 5,0 & 5,1 & 3,6 & 2,6 \\
\hline
\end{tabular}




\begin{tabular}{|c|c|c|c|c|c|c|c|c|c|c|}
\hline \multicolumn{11}{|c|}{ Money and credit } \\
\hline $\begin{array}{l}\text { Rates of growth of M2X (at } \\
\text { end period) }\end{array}$ & 9,9 & 51,6 & 33,3 & 12,6 & 17,9 & 21,1 & 14,9 & 16,2 & 19,7 & 20,5 \\
\hline $\begin{array}{l}\text { Velocity of M2X } \\
\text { circulation }\end{array}$ & 4,8 & 4,5 & 4 & 4,1 & 4,3 & 3,7 & 3,8 & 3,6 & 3,5 & 3,5 \\
\hline $\begin{array}{l}\text { Reserves in months of } \\
\text { imports }\end{array}$ & 3,2 & 3 & 3 & 4 & 4,9 & 4,2 & 4,1 & 3,9 & 3,8 & 3,8 \\
\hline \multicolumn{11}{|c|}{ External sector } \\
\hline $\begin{array}{l}\text { Current account } \\
\text { (in millions of US dollars) }^{2}\end{array}$ & $-37,4$ & $-263,1$ & $-225,9$ & $-705,4$ & $-104,6$ & $-385,1$ & -453 & -464 & -380 & -364 \\
\hline $\begin{array}{l}\text { Current account } \\
\text { (in } \% \text { of GDP) }\end{array}$ & $-1,5$ & $-9,2$ & $-5,9$ & $-13,9$ & $-1,9$ & $-8,1$ & $-7,6$ & $-6,8$ & $-4,9$ & $-4,0$ \\
\hline $\begin{array}{l}\text { Export of goods and } \\
\text { services (in millions of US } \\
\text { dollars) }\end{array}$ & 946,2 & 1284,7 & 2022,6 & 2770,5 & 2553,6 & 2471,8 & 3152 & 3645 & 4070 & 4559 \\
\hline $\begin{array}{l}\text { Rates of growth of exports } \\
\text { of goods and services, } \%\end{array}$ & 135,8 & 135,8 & 157,4 & 137 & 92,2 & 88.3 & 111,2 & 103,9 & 104,3 & 104,0 \\
\hline $\begin{array}{l}\text { Import of goods and } \\
\text { services (in millions of US } \\
\text { dollars) }\end{array}$ & 1395,8 & $\stackrel{-}{2252,1}$ & $-3218,1$ & $-4746,4$ & $-3682,5$ & $-3905,1$ & -4857 & -5713 & -6548 & -7453 \\
\hline $\begin{array}{l}\text { Rates of growth of imports } \\
\text { of goods and services, } \%\end{array}$ & 161,3 & 161,3 & 142,9 & 147,5 & 77,6 & 93,1 & 107,2 & 104,8 & 104,2 & 105,1 \\
\hline \multicolumn{11}{|c|}{ Debt and debt servicing } \\
\hline $\begin{array}{l}\text { Gov. external debt (in \% of } \\
\text { GDP) }\end{array}$ & 77,6 & 66,3 & 52,0 & 45,3 & 55,6 & 55,9 & 47,7 & $\leq 40,0$ & $\leq 40,0$ & $\leq 40,0$ \\
\hline $\begin{array}{l}\text { Servicing of gov. external } \\
\text { debt /budget revenues(in } \\
\%)^{1 / 3}\end{array}$ & 26,4 & 10,4 & 6,8 & 6,1 & 6,8 & 7,6 & 7,3 & $\leq 30,0$ & $\leq 30,0$ & $\leq 30,0$ \\
\hline $\begin{array}{l}\text { Servicing of gov. external } \\
\text { debt /exports (goods and } \\
\text { services) (in \%) } \text { ) }^{1 / 3}\end{array}$ & 19 & 5,3 & 3,2 & 2,8 & 3,4 & 3,2 & 3,4 & $\leq 20,0$ & $\leq 20,0$ & $\leq 20,0$ \\
\hline \multicolumn{11}{|c|}{ Social indicators } \\
\hline Poverty level, \% & 43,1 & 39,9 & 35,0 & 31,7 & 31,7 & 33,7 & 31,6 & 30,1 & 29,1 & 28,0 \\
\hline $\begin{array}{l}\text { Resident population (year- } \\
\text { end, million persons) }\end{array}$ & 5,189 & 5,247 & 5,289 & 5,348 & 5,418 & 5,489 & 5,552 & 5,66 & 5,749 & 5,846 \\
\hline $\begin{array}{l}\text { Level of total } \\
\text { unemployment (in \% of } \\
\text { economically active } \\
\text { population) }\end{array}$ & 8,1 & 8,3 & 8,2 & 8,2 & 8,4 & 8,6 & 8,8 & 8,3 & 8,1 & 7,9 \\
\hline $\begin{array}{l}\text { Life expectancy at birth, } \\
\text { years (both sexes) }\end{array}$ & 67,9 & 67,7 & 67,9 & 68,4 & 69,1 & 69,1 & 69,2 & 69,4 & 69,7 & 70,1 \\
\hline Men & 64,2 & 63,5 & 63,7 & 64,5 & 65,2 & 65,5 & 65,6 & 65,9 & 66,2 & 66,5 \\
\hline Women & 71,9 & 72,1 & 72,3 & 72,6 & 73,2 & 72,8 & 72,9 & 73 & 73,2 & 73,6 \\
\hline
\end{tabular}




\begin{tabular}{|c|c|c|c|c|c|c|c|c|}
\hline \multirow[b]{4}{*}{ № } & \multicolumn{7}{|c|}{ Budget of the Kyrgyz Republic National Development Program (2012-2014) } & \multirow[b]{4}{*}{ Financing gap } \\
\hline & & & & & & I & & \\
\hline & \multirow[b]{2}{*}{ Sector } & \multicolumn{3}{|c|}{ Required } & \multicolumn{3}{|c|}{ Available } & \\
\hline & & $\begin{array}{c}\text { Internal } \\
\text { sources } \\
\text { thou. soms }\end{array}$ & $\begin{array}{c}\text { External } \\
\text { sources } \\
\text { thou. soms }\end{array}$ & Total & $\begin{array}{c}\text { Internal } \\
\text { sources } \\
\text { thou. soms }\end{array}$ & $\begin{array}{c}\text { External } \\
\text { sources thou. } \\
\text { soms }\end{array}$ & Total & \\
\hline V. & State regulatory policy & & & & & & & \\
\hline & Macroeconomic policy & 877,100 & 91,500 & 968,600 & 248,964 & 91,500 & 340,464 & $-628,137$ \\
\hline & 2012 & 300,100 & 44,500 & 344,600 & & 44,500 & 44,500 & 300,100 \\
\hline & 2013 & 285,100 & 23,500 & 308,600 & & 23,500 & 23,500 & 285,100 \\
\hline 5.2 . & 2014 & 291,900 & 23,500 & 315,400 & & 23,500 & 23,500 & 291,900 \\
\hline & Government debt management strategy & 7,255 & 0 & 7,255 & 7,255 & 0 & 7,255 & 0 \\
\hline & 2012 & 924 & 0 & 924 & 924 & 0 & 924 & 0 \\
\hline & 2013 & 924 & 0 & 924 & 924 & 0 & 924 & 0 \\
\hline 5.3 . & 2014 & 924 & 0 & 924 & 924 & 0 & 924 & 0 \\
\hline & Business environment and investment climate & 9,288 & 5,364 & 14,652 & 7,132 & 0 & 7,132 & $-7,520$ \\
\hline & 2012 & 6,444 & 4,056 & 10,500 & & 0 & 0 & 10,500 \\
\hline & 2013 & 1,692 & 744 & 2,436 & & 0 & 0 & 2,436 \\
\hline 5.4. & 2014 & 1,152 & 564 & 1,716 & & 0 & 0 & 1,716 \\
\hline & Financial sector development & $35,152,649$ & 169,567 & $35,322,216$ & $35,145,614$ & 145,440 & $35,291,054$ & $-31,162$ \\
\hline & 2012 & $11,717,552$ & 67,028 & $11,784,580$ & & 53,440 & 53,440 & $11,731,140$ \\
\hline & 2013 & $11,717,720$ & 61,864 & $11,779,584$ & & 52,000 & 52,000 & $11,727,584$ \\
\hline 5.5 . & 2014 & $11,717,377$ & 40,675 & $11,758,052$ & & 40,000 & 40,000 & $11,718,052$ \\
\hline & Tax policy & $4,890,028$ & 194,148 & $5,084,176$ & $4,890,028$ & 190,666 & $5,080,694$ & $-3,482$ \\
\hline & 2012 & 10,732 & 64,716 & 75,448 & & 63,555 & 63,555 & 11,893 \\
\hline & 2013 & 10,732 & 64,716 & 75,448 & & 63,555 & 63,555 & 11,893 \\
\hline 5.6. & 2014 & 10,732 & 64,716 & 75,448 & & 63,555 & 63,555 & 11,893 \\
\hline & Policy of achieving gender equality & 10,179 & 42,305 & 52,484 & 10,179 & 0 & 10,179 & $-42,305$ \\
\hline & 2012 & 3,393 & 14,102 & 17,495 & & 0 & 0 & 17,495 \\
\hline & 2013 & 3,393 & 14,102 & 17,495 & & 0 & 0 & 17,495 \\
\hline 5.7 & 2014 & 3,393 & 14,102 & 17,495 & & 0 & 0 & 17,495 \\
\hline VI. & Directions and priorities of development & & & & & & & \\
\hline 6.1 . & Security: & & & & & & & \\
\hline & Public order and security & $22,943,876$ & 748,027 & $23,691,903$ & $22,943,876$ & 0 & $22,943,876$ & $-748,027$ \\
\hline & 2012 & 175 & 332,288 & 332,463 & & 0 & 0 & 332,463 \\
\hline & 2013 & 160 & 207,919 & 208,079 & & 0 & 0 & 208,079 \\
\hline 6.1.1. & 2014 & 160 & 207,819 & 207,979 & & 0 & 0 & 207,979 \\
\hline & Defense complex & $10,032,425$ & 777,600 & $10,810,025$ & $10,032,425$ & 777,600 & $10,810,025$ & $\mathbf{0}$ \\
\hline & 2012 & 1,281 & 7,200 & 8,481 & 0 & 7,200 & 7,200 & 1,281 \\
\hline & 2013 & 280 & 675,000 & 675,280 & 0 & 675,000 & 675,000 & 280 \\
\hline 6.1.2. & 2014 & 3,450 & 95,400 & 98,850 & 0 & 95,400 & & 98,850 \\
\hline 6.2 . & Public administration: & & & & & & & \\
\hline & Reform of public adminis tration & 56,224 & 49,205 & 105,429 & 56,224 & 0 & 56,224 & $-49,205$ \\
\hline & 2012 & 26,886 & 34,391 & 61,276 & & 0 & 26,886 & 34,391 \\
\hline & 2013 & 27,603 & 14,814 & 42,417 & & 0 & 27,603 & 14,814 \\
\hline 6.2.1. & 2014 & 1,735 & 0 & 1,735 & & 0 & 1,735 & 0 \\
\hline & Development of local self-government & $32,300,000$ & 0 & $32,300,000$ & $32,300,000$ & 0 & $32,300,000$ & 0 \\
\hline & 2012 & $6,545,000$ & 0 & $6,545,000$ & & 0 & $6,545,000$ & 0 \\
\hline & 2013 & $5,621,000$ & 0 & $5,621,000$ & & 0 & $5,621,000$ & 0 \\
\hline 6.2.2. & 2014 & $4,389,000$ & 0 & $4,389,000$ & & 0 & $4,389,000$ & 0 \\
\hline & Law and legislation & $6,921,967$ & $1,713,600$ & $8,635,567$ & $6,921,967$ & 0 & $6,921,967$ & $-1,713,600$ \\
\hline & 2012 & $3,251,079$ & $1,713,600$ & $4,964,679$ & & 0 & $3,251,079$ & $1,713,600$ \\
\hline & 2013 & $2,304,068$ & 0 & $2,304,068$ & & 0 & $2,304,068$ & 0 \\
\hline 6.2.3. & 2014 & $1,366,820$ & 0 & $1,366,820$ & & 0 & $1,366,820$ & 0 \\
\hline 6.3 . & Economic priorities: & & & & & & & \\
\hline & Energy & $10,269,787$ & $45,949,128$ & $56,218,915$ & $10,269,787$ & $45,949,128$ & $56,218,915$ & $\mathbf{0}$ \\
\hline & 2012 & $2,490,680$ & $11,468,376$ & $13,959,056$ & & $11,468,376$ & $13,959,056$ & 0 \\
\hline & 2013 & $2,280,340$ & 667,320 & $2,947,660$ & & 667,320 & $2,947,660$ & 0 \\
\hline 6.3.1. & 2014 & $2,118,673$ & $33,813,432$ & $35,932,105$ & & $33,813,432$ & $35,932,105$ & 0 \\
\hline & Mining & 555,885 & 0 & 555,885 & 520,196 & 0 & 520,196 & $-35,689$ \\
\hline & 2012 & 182,951 & 0 & 182,951 & & 0 & 42,243 & 140,709 \\
\hline & 2013 & 173,842 & 0 & 173,842 & & 0 & 42,976 & 130,866 \\
\hline 6.3.2. & 2014 & 199,092 & 0 & 199,092 & & 0 & 44,428 & 154,664 \\
\hline & Development of agriculture and manufacturing & $10,154,788$ & 274,857 & $10,429,645$ & $4,698,720$ & 274,857 & $4,973,577$ & $-5,456,068$ \\
\hline & 2012 & $3,470,178$ & 196,225 & $3,666,403$ & & 196,225 & $3,666,403$ & 0 \\
\hline & 2013 & $3,331,882$ & 78,632 & $3,410,514$ & & 78,632 & $3,410,514$ & 0 \\
\hline 6.3.3. & 2014 & $3,352,728$ & 0 & $3,352,728$ & & 0 & $3,352,728$ & 0 \\
\hline & Manufacturing & 7,251 & 57,600 & 64,851 & 7,898 & 0 & 7,898 & $-56,953$ \\
\hline & 2012 & 3,285 & 0 & 3,285 & & 0 & 1,785 & 1,500 \\
\hline & 2013 & 3,966 & 0 & 3,966 & & 0 & 966 & 3,000 \\
\hline 6.3.4. & 2014 & 0 & 57,600 & 57,600 & 0 & 0 & 0 & 57,600 \\
\hline & Construction & 254,729 & 0 & 254,729 & 254,729 & 0 & 254,729 & 0 \\
\hline & 2012 & 95,143 & 0 & 95,143 & 0 & 0 & 0 & 95,143 \\
\hline & 2013 & 84,264 & 0 & 84,264 & 0 & 0 & 0 & 84,264 \\
\hline 6.3.5. & 2014 & 75,322 & 0 & 75,322 & 0 & 0 & 0 & 75,322 \\
\hline & Development of tourism & $24,521,160$ & 1,880 & $24,523,040$ & 458,074 & 1,880 & 459,954 & $-24,063,086$ \\
\hline & 2012 & \begin{tabular}{|l|l|}
$8,174,735$ \\
\end{tabular} & 560 & $8,175,295$ & & 560 & 103,746 & $8,071,549$ \\
\hline & 2013 & $8,165,220$ & 620 & $8,165,840$ & & 620 & 94,291 & $8,071,549$ \\
\hline 6.3.6. & 2014 & $8,181,205$ & 700 & $8,181,905$ & & 700 & 110,356 & $8,071,549$ \\
\hline
\end{tabular}




\begin{tabular}{|c|c|c|c|c|c|c|c|c|}
\hline 6.3.7. & Development of trade: & & & & & & & \\
\hline \multirow[b]{4}{*}{ 6.3.7.1. } & Foreign & 142,265 & 78,144 & 220,408 & 142,265 & 71,808 & 214,073 & $-6,336$ \\
\hline & 2012 & 27,015 & 29,469 & 56,484 & & 26,472 & $\begin{array}{l}53,487 \\
\end{array}$ & 2,997 \\
\hline & 2013 & 1,839 & 26,198 & 28,037 & & 24,528 & 26,367 & 1,670 \\
\hline & 2014 & 553 & 22,478 & 23,031 & & 20,808 & 21,361 & 1,670 \\
\hline \multirow[b]{4}{*}{ 6.3.7.2. } & Domestic & 71,132 & 0 & 71,132 & 71,132 & 0 & 71,132 & $\mathbf{0}$ \\
\hline & 2012 & 125 & 0 & 125 & & 0 & 125 & 0 \\
\hline & 2013 & 174 & 0 & 174 & & 0 & 174 & 0 \\
\hline & 2014 & 960 & 0 & 960 & & 0 & 960 & 0 \\
\hline \multirow[b]{4}{*}{ 6.3.8. } & Trans port infrastructure & $10,848,120$ & $21,903,543$ & $32,751,662$ & $21,574,314$ & $10,979,841$ & $32,554,155$ & $-197,507$ \\
\hline & 2012 & $3,047,249$ & $9,693,705$ & $12,740,954$ & & $5,797,605$ & $7,493,508$ & $5,247,446$ \\
\hline & 2013 & $4,009,295$ & $7,229,481$ & $11,238,776$ & & $3,480,181$ & $5,121,211$ & $6,117,565$ \\
\hline & 2014 & $3,791,576$ & $4,980,356$ & $8,771,932$ & & $1,702,054$ & $3,303,955$ & $5,467,977$ \\
\hline \multirow[b]{4}{*}{ 6.3.9. } & Communications and IT & 909,363 & $2,366,850$ & $3,276,213$ & 464,425 & 0 & 464,425 & $-2,811,787$ \\
\hline & 2012 & 261,452 & 788,617 & $1,031,497$ & & 0 & 154,513 & 876,984 \\
\hline & 2013 & 370,178 & 788,617 & $1,158,795$ & & 0 & 303,511 & 855,284 \\
\hline & 2014 & 277,732 & 789,616 & $1,067,348$ & & 0 & 211,066 & 856,282 \\
\hline \multirow[b]{4}{*}{ 6.3.10. } & Housing and utility services & $2,368,484$ & $2,205,168$ & $4,573,652$ & $2,368,484$ & $2,205,168$ & $4,573,652$ & $\mathbf{0}$ \\
\hline & 2012 & 249,548 & $1,488,427$ & $1,737,975$ & & $1,488,427$ & $1,737,975$ & 0 \\
\hline & 2013 & 94,957 & 716,741 & 811,697 & & 716,741 & 811,697 & 0 \\
\hline & 2014 & 0 & 0 & 0 & & 0 & 0 & 0 \\
\hline \multirow[b]{4}{*}{ 6.3.11. } & Development of innovation technologies & 619,990 & 9,673 & 629,663 & 619,990 & 0 & 619,990 & $-9,673$ \\
\hline & 2012 & 741 & 4,644 & 5,385 & & 0 & 741 & 4,644 \\
\hline & 2013 & 109 & 2,515 & 2,623 & & 0 & 109 & 2,515 \\
\hline & 2014 & 109 & 2,515 & 2,623 & & 0 & 109 & 2,515 \\
\hline \multirow[b]{4}{*}{ 6.3.12. } & Foreign economic policy/relations & 74,227 & 0 & 74,227 & 35,566 & 0 & 35,566 & $-38,661$ \\
\hline & 2012 & 23,322 & 0 & 23,322 & & 0 & 13,413 & 9,909 \\
\hline & 2013 & 24,840 & 0 & 24,840 & & 0 & 14,470 & 10,370 \\
\hline & 2014 & 26,065 & 0 & 26,065 & & 0 & 15,246 & 10,818 \\
\hline 6.4 . & Social development: & & & & & & & \\
\hline \multirow[b]{4}{*}{ 6.4.1. } & Education & $49,592,600$ & 485,209 & $50,077,809$ & $22,344,494$ & 410,303 & $22,754,797$ & $-27,323,012$ \\
\hline & 2012 & $15,079,391$ & 138,322 & $15,217,713$ & & 120,166 & $14,967,900$ & 249,812 \\
\hline & 2013 & $16,532,879$ & 196,716 & $16,729,595$ & & 164,453 & $16,402,950$ & 326,645 \\
\hline & 2014 & $17,980,330$ & 150,171 & $18,130,501$ & & 125,684 & $17,598,644$ & 531,857 \\
\hline \multirow[b]{4}{*}{6.4 .2} & Health care & $31,193,838$ & 398,095 & $31,591,933$ & $31,193,838$ & 165,775 & $31,359,613$ & $-232,320$ \\
\hline & 2012 & $6,633,125$ & 398,095 & $7,031,220$ & & 165,775 & 165,775 & $6,865,445$ \\
\hline & 2013 & $6,962,632$ & 0 & $6,962,632$ & & 0 & 0 & $6,962,632$ \\
\hline & 2014 & $7,186,747$ & 0 & $7,186,747$ & & 0 & 0 & $7,186,747$ \\
\hline & Social protection system & $14,026,540$ & 0 & $14,026,540$ & $13,495,384$ & 36,000 & $13,531,384$ & $-495,156$ \\
\hline & 2012 & $3,860,930$ & 0 & $3,860,930$ & & 12,000 & $3,784,830$ & 76,100 \\
\hline & 2013 & $4,632,650$ & 0 & $4,632,650$ & & 12,000 & $4,534,650$ & 98,000 \\
\hline 6.4.3. & 2014 & $5,532,960$ & 0 & $5,532,960$ & & 12,000 & $5,423,960$ & 109,000 \\
\hline & Social insurance system & $108,299,955$ & 0 & $108,299,955$ & $108,299,955$ & 0 & $108,299,955$ & $\mathbf{0}$ \\
\hline & 2012 & $28,440,183$ & 0 & $28,440,183$ & & 0 & $28,440,183$ & 0 \\
\hline & 2013 & $33,019,079$ & 0 & $33,019,079$ & & 0 & $33,019,079$ & 0 \\
\hline 6.4.4. & 2014 & $38,547,474$ & 0 & $38,547,474$ & & 0 & $38,547,474$ & 0 \\
\hline & Labor market and employment & $4,486,946$ & 670,696 & $5,157,642$ & $3,650,330$ & 174,786 & $3,825,116$ & $-1,332,527$ \\
\hline & 2012 & $1,421,382$ & 233,794 & $1,655,176$ & & 80,262 & $1,371,341$ & 290,935 \\
\hline & 2013 & $1,501,441$ & 215,551 & $1,716,992$ & & 47,262 & $1,407,792$ & 309,200 \\
\hline 6.4.5. & 2014 & $1,545,673$ & 221,351 & $1,767,024$ & & 47,262 & $1,444,784$ & 327,690 \\
\hline & Culture and religion & $5,036,139$ & 8,790 & $5,044,929$ & $5,036,139$ & 2,695 & $5,038,834$ & $-6,095$ \\
\hline & 2012 & $1,683,790$ & 2,780 & $1,686,570$ & & 965 & 28,777 & $1,657,793$ \\
\hline & 2013 & $1,579,134$ & 3,780 & $1,582,914$ & & 965 & 28,887 & $1,554,027$ \\
\hline 6.4.6. & 2014 & $1,577,778$ & 2,230 & $1,580,008$ & & 765 & 28,501 & $1,551,507$ \\
\hline & Development of physical culture and sport & 823,260 & 226,800 & $1,050,060$ & 482,160 & 0 & 482,160 & $-567,900$ \\
\hline & 2012 & 274,420 & 75,600 & 350,020 & & 0 & 160,720 & 189,300 \\
\hline & 2013 & 274,420 & 75,600 & 350,020 & & 0 & 160,720 & 189,300 \\
\hline 6.4.7. & 2014 & 274,420 & 75,600 & 350,020 & & 0 & 160,720 & 189,300 \\
\hline 6.5 . & Environmental protection: & & & & & & & \\
\hline & Environmental safety & $1,332,313$ & 494,995 & $1,827,308$ & $1,332,313$ & 194,755 & $1,527,068$ & $-300,240$ \\
\hline & 2012 & 223,398 & 186,053 & 409,451 & & 109,253 & 332,651 & 76,800 \\
\hline & 2013 & 225,181 & 170,088 & 395,269 & & 67,848 & 293,029 & 102,240 \\
\hline 6.5.1. & 2014 & 227,555 & 138,854 & 366,409 & & 17,654 & 245,209 & 121,200 \\
\hline & \begin{tabular}{|c}
$\begin{array}{c}\text { Safety measures for protecting the population from natural } \\
\text { disasters and catastrophes }\end{array}$ \\
\end{tabular} & $4,197,989$ & 802,138 & $5,000,126$ & $4,197,989$ & 408,938 & $4,606,926$ & $-393,200$ \\
\hline & 2012 & 685,359 & 258,712 & 944,071 & & 119,270 & 650,078 & 293,993 \\
\hline & 2013 & 728,507 & 268,977 & 997,484 & & 142,173 & 680,273 & 317,211 \\
\hline 6.5.2. & 2014 & 851,170 & 274,448 & $1,125,619$ & & 147,494 & 743,096 & 382,522 \\
\hline & & & Required & & & Available & & \\
\hline & & \begin{tabular}{|c|c}
$\begin{array}{c}\text { Internal } \\
\text { sources thou. } \\
\text { soms }\end{array}$ \\
\end{tabular} & $\begin{array}{c}\begin{array}{c}\text { External } \\
\text { sources } \\
\text { thou. soms }\end{array} \\
\end{array}$ & Total & $\begin{array}{c}\text { Internal } \\
\text { sources } \\
\text { thou. soms } \\
\end{array}$ & $\begin{array}{c}\text { External } \\
\text { sources thou. } \\
\text { soms }\end{array}$ & Total & Financing gap \\
\hline & Total: (thou. soms) & $392,987,751$ & $79,724,881$ & $472,712,632$ & $344,081,847$ & $62,081,139$ & $406,162,987$ & $-66,549,646$ \\
\hline & Total: ( thou. dollars) & $8,187,245$ & $1,660,935$ & $9,848,180$ & $7,168,372$ & $1,293,357$ & $8,461,729$ & $-1,386,451$ \\
\hline
\end{tabular}




\begin{tabular}{|c|c|c|c|c|c|c|c|c|}
\hline 6.3.7. & Development of trade: & \multirow[b]{2}{*}{142,265} & \multirow[b]{2}{*}{78,144} & \multirow[b]{2}{*}{220,408} & \multirow[b]{2}{*}{142,265} & \multirow[b]{2}{*}{71,808} & \multicolumn{2}{|c|}{ Attachment 2 (continued) } \\
\hline \multirow[b]{4}{*}{ 6.3.7.1. } & Foreign & & & & & & 214,073 & $-6,336$ \\
\hline & 2012 & 27,015 & 29,469 & 56,484 & & 26,472 & 53,487 & $\begin{array}{l}-0,900 \\
2,997 \\
\end{array}$ \\
\hline & 2013 & 1,839 & 26,198 & 28,037 & & 24,528 & 26,367 & 1,670 \\
\hline & 2014 & 553 & 22,478 & 23,031 & & 20,808 & 21,361 & 1,670 \\
\hline & Domestic & 71,132 & 0 & 71,132 & 71,132 & 0 & 71,132 & $\mathbf{0}$ \\
\hline & 2012 & 125 & 0 & 125 & & 0 & 125 & 0 \\
\hline & 2013 & 174 & 0 & 174 & & 0 & 174 & 0 \\
\hline 6.3.7.2. & 2014 & 960 & 0 & 960 & & 0 & 960 & 0 \\
\hline & Trans port infrastructure & $10,848,120$ & $21,903,543$ & $32,751,662$ & $21,574,314$ & $10,979,841$ & $32,554,155$ & $\begin{array}{l}-197,507 \\
\end{array}$ \\
\hline & 2012 & $3,047,249$ & $9,693,705$ & $12,740,954$ & & $5,797,605$ & $7,493,508$ & $5,247,446$ \\
\hline & 2013 & $4,009,295$ & $7,229,481$ & $11,238,776$ & & $3,480,181$ & $5,121,211$ & $6,117,565$ \\
\hline 6.3.8. & 2014 & $3,791,576$ & $4,980,356$ & $8,771,932$ & & $1,702,054$ & $3,303,955$ & $5,467,977$ \\
\hline & Communications and IT & 909,363 & $2,366,850$ & $3,276,213$ & 464,425 & 0 & 464,425 & $-2,811,787$ \\
\hline & 2012 & 261,452 & 788,617 & $1,031,497$ & & 0 & 154,513 & 876,984 \\
\hline & 2013 & 370,178 & 788,617 & $1,158,795$ & & 0 & 303,511 & 855,284 \\
\hline 6.3.9. & 2014 & 277,732 & 789,616 & $1,067,348$ & & 0 & 211,066 & 856,282 \\
\hline & Housing and utility services & $2,368,484$ & $2,205,168$ & $4,573,652$ & $2,368,484$ & $2,205,168$ & $4,573,652$ & $\mathbf{0}$ \\
\hline & 2012 & 249,548 & $1,488,427$ & $1,737,975$ & & $1,488,427$ & $1,737,975$ & 0 \\
\hline & 2013 & 94,957 & 716,741 & 811,697 & & 716,741 & 811,697 & 0 \\
\hline 6.3.10. & 2014 & 0 & 0 & 0 & & 0 & 0 & 0 \\
\hline & Development of innovation technologies & 619,990 & 9,673 & 629,663 & 619,990 & 0 & 619,990 & $-9,673$ \\
\hline & 2012 & 741 & 4,644 & 5,385 & & 0 & 741 & 4,644 \\
\hline & 2013 & 109 & 2,515 & 2,623 & & 0 & 109 & 2,515 \\
\hline 6.3.11. & 2014 & 109 & 2,515 & 2,623 & & 0 & 109 & 2,515 \\
\hline & Foreign economic policy/relations & 74,227 & 0 & 74,227 & 35,566 & 0 & 35,566 & $-38,661$ \\
\hline & 2012 & 23,322 & 0 & 23,322 & & 0 & 13,413 & 9,909 \\
\hline & 2013 & 24,840 & 0 & 24,840 & & 0 & 14,470 & 10,370 \\
\hline 6.3.12. & 2014 & 26,065 & 0 & 26,065 & & 0 & 15,246 & 10,818 \\
\hline 6.4 . & Social development: & & & & & & & \\
\hline & Education & $49,592,600$ & 485,209 & $50,077,809$ & $22,344,494$ & 410,303 & $22,754,797$ & $-27,323,012$ \\
\hline & 2012 & $15,079,391$ & 138,322 & $15,217,713$ & & 120,166 & $14,967,900$ & 249,812 \\
\hline & 2013 & $16,532,879$ & 196,716 & $16,729,595$ & & 164,453 & $16,402,950$ & 326,645 \\
\hline 6.4.1. & 2014 & $17,980,330$ & 150,171 & $18,130,501$ & & 125,684 & $17,598,644$ & 531,857 \\
\hline & Health care & $31,193,838$ & 398,095 & $31,591,933$ & $31,193,838$ & 165,775 & $31,359,613$ & $-232,320$ \\
\hline & 2012 & $6,633,125$ & 398,095 & $7,031,220$ & & 165,775 & 165,775 & $6,865,445$ \\
\hline & 2013 & $6,962,632$ & 0 & $6,962,632$ & & 0 & 0 & $6,962,632$ \\
\hline 6.4.2 & 2014 & $7,186,747$ & 0 & $7,186,747$ & & 0 & 0 & $7,186,747$ \\
\hline & Social protection system & $14,026,540$ & 0 & $14,026,540$ & $13,495,384$ & 36,000 & $13,531,384$ & $-495,156$ \\
\hline & 2012 & $3,860,930$ & 0 & $3,860,930$ & & 12,000 & $3,784,830$ & 76,100 \\
\hline & 2013 & $4,632,650$ & 0 & $4,632,650$ & & 12,000 & $4,534,650$ & 98,000 \\
\hline 6.4.3. & 2014 & $5,532,960$ & 0 & $5,532,960$ & & 12,000 & $5,423,960$ & 109,000 \\
\hline & Social insurance system & $108,299,955$ & 0 & $108,299,955$ & $108,299,955$ & 0 & $108,299,955$ & $\mathbf{0}$ \\
\hline & 2012 & $28,440,183$ & 0 & $28,440,183$ & & 0 & $28,440,183$ & 0 \\
\hline & 2013 & $33,019,079$ & 0 & $33,019,079$ & & 0 & $33,019,079$ & 0 \\
\hline 6.4.4. & 2014 & $38,547,474$ & 0 & $38,547,474$ & & 0 & $38,547,474$ & 0 \\
\hline & Labor market and employment & $4,486,946$ & 670,696 & $5,157,642$ & $3,650,330$ & 174,786 & $3,825,116$ & $-1,332,527$ \\
\hline & 2012 & $1,421,382$ & 233,794 & $1,655,176$ & & 80,262 & $1,371,341$ & 290,935 \\
\hline & 2013 & $1,501,441$ & 215,551 & $1,716,992$ & & 47,262 & $1,407,792$ & 309,200 \\
\hline 6.4.5. & 2014 & $1,545,673$ & 221,351 & $1,767,024$ & & 47,262 & $1,444,784$ & 327,690 \\
\hline & Culture and religion & $5,036,139$ & 8,790 & $5,044,929$ & $5,036,139$ & 2,695 & $5,038,834$ & $-6,095$ \\
\hline & 2012 & $1,683,790$ & 2,780 & $1,686,570$ & & 965 & 28,777 & $1,657,793$ \\
\hline & 2013 & $1,579,134$ & 3,780 & $1,582,914$ & & 965 & 28,887 & $1,554,027$ \\
\hline 6.4.6. & 2014 & $1,577,778$ & 2,230 & $1,580,008$ & & 765 & 28,501 & $1,551,507$ \\
\hline & Development of physical culture and sport & 823,260 & 226,800 & $1,050,060$ & 482,160 & 0 & 482,160 & $-567,900$ \\
\hline & 2012 & 274,420 & 75,600 & 350,020 & & 0 & 160,720 & 189,300 \\
\hline & 2013 & 274,420 & 75,600 & 350,020 & & 0 & 160,720 & 189,300 \\
\hline 6.4.7. & 2014 & 274,420 & 75,600 & 350,020 & & 0 & 160,720 & 189,300 \\
\hline 6.5 . & Environmental protection: & & & & & & & \\
\hline & Environmental safety & $1,332,313$ & 494,995 & $1,827,308$ & $1,332,313$ & 194,755 & $1,527,068$ & $-300,240$ \\
\hline & 2012 & 223,398 & 186,053 & 409,451 & & 109,253 & 332,651 & 76,800 \\
\hline & 2013 & 225,181 & 170,088 & 395,269 & & 67,848 & 293,029 & 102,240 \\
\hline 6.5.1. & 2014 & 227,555 & 138,854 & 366,409 & & 17,654 & 245,209 & 121,200 \\
\hline & $\begin{array}{l}\text { Safety measures for protecting the population from natural } \\
\text { disasters and catastrophes }\end{array}$ & $4,197,989$ & 802,138 & $5,000,126$ & $4,197,989$ & 408,938 & $4,606,926$ & $-393,200$ \\
\hline & 2012 & 685,359 & 258,712 & 944,071 & & 119,270 & 650,078 & 293,993 \\
\hline & 2013 & 728,507 & 268,977 & 997,484 & & 142,173 & 680,273 & 317,211 \\
\hline 6.5.2. & 2014 & 851,170 & 274,448 & $1,125,619$ & & 147,494 & 743,096 & 382,522 \\
\hline & & & Required & & & Available & & \\
\hline & & $\begin{array}{c}\text { Internal } \\
\text { sources thou. } \\
\text { soms }\end{array}$ & $\begin{array}{c}\text { External } \\
\text { sources } \\
\text { thou. soms }\end{array}$ & Total & $\begin{array}{c}\text { Internal } \\
\text { sources } \\
\text { thou. soms }\end{array}$ & \begin{tabular}{|c|}
$\begin{array}{c}\text { External } \\
\text { sources thou. } \\
\text { soms }\end{array}$ \\
\end{tabular} & Total & Financing gap \\
\hline & Total: (thou. soms) & $392,987,751$ & $79,724,881$ & $472,712,632$ & $344,081,847$ & $62,081,139$ & $406,162,987$ & $-66,549,646$ \\
\hline & Total: (thou. dollars) & $8,187,245$ & $1,660,935$ & $9,848,180$ & $7,168,372$ & $1,293,357$ & $8,461,729$ & $-1,386,451$ \\
\hline
\end{tabular}


Budget of national projects

\begin{tabular}{|c|c|c|c|c|c|c|c|c|}
\hline \multirow[t]{2}{*}{ № } & \multirow[t]{2}{*}{ Sector } & \multicolumn{3}{|c|}{ Required } & \multicolumn{3}{|c|}{ Available } & \multirow[t]{2}{*}{ Financing gap } \\
\hline & & $\begin{array}{l}\text { Internal sources } \\
\text { thou. soms }\end{array}$ & $\begin{array}{l}\text { External sources } \\
\text { thou. soms }\end{array}$ & Total & $\begin{array}{l}\text { Internal sources, } \\
\text { thou. soms }\end{array}$ & $\begin{array}{c}\text { External sources, thou. } \\
\text { soms }\end{array}$ & Total & \\
\hline & Communications 7 & $489,662.58$ & $1,631,100.00$ & $2,120,762.58$ & $257,962.58$ & $296,100.00$ & $554,062.58$ & $1,566,700.00$ \\
\hline 1 & \begin{tabular}{|l|} 
Development of High Technology Park (PVT) \\
\end{tabular} & $2,500.00$ & & $2,500.00$ & & & & $2,500.00$ \\
\hline 2 & $\begin{array}{l}\text { Implementation and development of infrastructure for Electronic } \\
\text { Government }\end{array}$ & $264,200.00$ & $60,000.00$ & $324,200.00$ & $35,000.00$ & & $35,000.00$ & $289,200.00$ \\
\hline 3 & Program of transition to digital broadcasting in the Kyrgyz Republic & & $1,275,000.00$ & $1,275,000.00$ & & - & - & $1,275,000.00$ \\
\hline 4 & $\begin{array}{l}\text { Program of modernization and development of postal service in the } \\
\text { Kyrgyz Republic }\end{array}$ & & $296,100.00$ & $296,100.00$ & & $296,100.00$ & $296,100.00$ & - \\
\hline 5 & Development of radio monitoring system & $222,962.58$ & & $222,962.58$ & $222,962.58$ & & $222,962.58$ & - \\
\hline 6 & Information security 1 & $120,480.00$ & - & $120,480.00$ & - & - & - & $120,480.00$ \\
\hline 7 & $\begin{array}{l}\text { Development of information security and unification of information } \\
\text { resources of the KR }\end{array}$ & $120,480.00$ & & $120,480.00$ & & & - & $120,480.00$ \\
\hline & Energy 8 & & $136,238,896.20$ & $136,238,896.20$ & - & $25,493,070.60$ & $25,493,070.60$ & - $\quad 110,745,825.60$ \\
\hline 8 & $\begin{array}{l}\text { Modernization of power transmission lines in the south of Kyrgyzstan: } \\
\text { construction of new } 500 \mathrm{~kW} \text { TS «Datka» and } 220 \mathrm{~kW} \text { HV line in the } \\
\text { south of the country }\end{array}$ & & $8,006,400.00$ & $8,006,400.00$ & - & $7,718,400.00$ & $7,718,400.00$ & $288,000.00$ \\
\hline 9 & $\begin{array}{l}\text { Construction of } 500 \mathrm{~kW} \text { HV line «Datka-Kemin» and } 500 \mathrm{~kW} \text { TS } \\
\text { «Kemin» }\end{array}$ & & $17,774,670.60$ & $17,774,670.60$ & & $17,774,670.60$ & $17,774,670.60$ & - \\
\hline 10 & Start of exploitation of second hydro-aggregate Kambartinska HES-2 & & $4,819,200.00$ & $4,819,200.00$ & & & - & $4,819,200.00$ \\
\hline 11 & Construction of Kambartinska HES-1 & & $40,800,000.00$ & $40,800,000.00$ & & & - & - $\quad 40,800,000.00$ \\
\hline 12 & Construction of top-priority HES in upper reaches of river Naryn & & $3,982,305.60$ & $3,982,305.60$ & & & - & $3,982,305.60$ \\
\hline 13 & \begin{tabular}{|l|} 
Construction of $4 \mathrm{small}$ HES \\
\end{tabular} & & $1,893,120.00$ & $1,893,120.00$ & & & - & $1,893,120.00$ \\
\hline 14 & \begin{tabular}{|l|} 
Construction of Kara-Kechin thermal power plant \\
\end{tabular} & & $55,200,000.00$ & $55,200,000.00$ & & & - & $-\quad 55,200,000.00$ \\
\hline 15 & 《CASA-1000» & & $3,763,200.00$ & $3,763,200.00$ & & & - & $3,763,200.00$ \\
\hline & Road and transport infrastructure 10 & $1,550,400.00$ & $123,374,600.30$ & $124,925,000.30$ & $1,573,166.70$ & $16,447,673.60$ & $18,020,840.30$ & - $106,904,160.00$ \\
\hline 16 & Construction project of rail-road line «China-Kyrgyzstan-Uzbekistan» & & $96,240,000.00$ & $96,240,000.00$ & & & - & $-\quad 96,240,000.00$ \\
\hline 17 & $\begin{array}{l}\text { Construction project of rail-road line «Balykchy-Kochkor-Kara-Keche- } \\
\text { Arpa» }\end{array}$ & & $264,000.00$ & $264,000.00$ & & & - & $264,000.00$ \\
\hline 18 & $\mid$ Project «Modernization of air navigation equipment» & $1,550,400.00$ & $1,440,000.00$ & $2,990,400.00$ & $123,840.00$ & $1,440,000.00$ & $1,563,840.00$ & $1,426,560.00$ \\
\hline 19 & Project of reconstruction of international airport «Osh» & & $5,666,400.00$ & $5,666,400.00$ & & & - & $5,666,400.00$ \\
\hline 20 & Project of reconstruction of international airport «Issyk-Kul» & & $3,307,200.00$ & $3,307,200.00$ & & & - & $3,307,200.00$ \\
\hline 21 & $\begin{array}{l}\text { Osh - Sary-Tash-Irkeshtam, from } 123 \text { to } 240 \mathrm{~km} \text { and Sary-Tash- } \\
\text { Karamyk, from 0-136 km, Project CARES: regional corridor }\end{array}$ & & $1,015,918.60$ & $1,015,918.60$ & $242,834.40$ & $773,084.20$ & $1,015,918.60$ & - \\
\hline 22 & Bishkek-Naryn-Torugart, from 9 to $539 \mathrm{~km}$ & & $10,903,809.80$ & $10,903,809.80$ & $784,028.10$ & $10,119,781.70$ & $10,903,809.80$ & - \\
\hline 23 & $\begin{array}{l}\text { Osh-Batken-Isfana, } \\
\text { from } 123 \text { to } 220 \mathrm{~km}\end{array}$ & & $3,414,635.10$ & $3,414,635.10$ & $288,246.80$ & $3,126,388.30$ & $3,414,635.10$ & - \\
\hline 24 & $\begin{array}{l}\text { Talas-Taraz-Suusamyr, } \\
\text { from } 75 \text { to } 199 \mathrm{~km}\end{array}$ & & $1,122,636.80$ & $1,122,636.80$ & $134,217.40$ & $988,419.40$ & $1,122,636.80$ & - \\
\hline
\end{tabular}




\begin{tabular}{|c|c|c|c|c|c|c|c|c|}
\hline & Agriculture 5 & $6,138,912.00$ & $691,200.00$ & $6,830,112.00$ & $1,500,000.00$ & - & $1,500,000.00$ & $5,330,112.00$ \\
\hline 25 & Creation of network of agricultural cooperatives & $1,632.00$ & & $1,632.00$ & & - & - & $1,632.00$ \\
\hline 26 & Creation of seven - nine seed farms & & $\mathbf{3 5 5 , 2 0 0 . 0 0}$ & $355,200.00$ & & & - & $355,200.00$ \\
\hline 27 & Creation of seven - nine breeding farms & $65,280.00$ & $336,000.00$ & $401,280.00$ & & - & - & $401,280.00$ \\
\hline 28 & Development of lending system in the area of APK & $3,216,000.00$ & & $3,216,000.00$ & $1,500,000.00$ & - & $1,500,000.00$ & $1,716,000.00$ \\
\hline 29 & $\begin{array}{l}\text { Available agricultural technology (creation of leasing company for } \\
\text { agricultural technology) }\end{array}$ & $2,856,000.00$ & & $2,856,000.00$ & & & - & $2,856,000.00$ \\
\hline & Irrigation 6 & $9,936,000.00$ & $1,440,000.00$ & $11,376,000.00$ & - & - & - & $11,376,000.00$ \\
\hline 30 & $\begin{array}{l}\text { Development of new irrigated land in Suzak rayon in Dzhalal-Abad } \\
\text { oblast and Uzgen rayon in Osh oblast from the river Yassa system }\end{array}$ & $3,840,000.00$ & & $3,840,000.00$ & & & - & $3,840,000.00$ \\
\hline 31 & $\begin{array}{l}\text { Development of new irrigated land in Kara-Suyrayon in Osh oblast } \\
\text { from the river Kurshab system }\end{array}$ & $4,800,000.00$ & & $4,800,000.00$ & & - & - & $4,800,000.00$ \\
\hline 32 & $\begin{array}{l}\text { Construction of aqueduct in Maksat Leilek rayon in Batken oblast } \\
\text { with water supply to Arkin Massif }\end{array}$ & & $1,440,000.00$ & $1,440,000.00$ & & & - & $1,440,000.00$ \\
\hline 33 & $\begin{array}{l}\text { Development of land in Burgandin Massif in Kadamdzhai rayon of } \\
\text { Batken oblast }\end{array}$ & $432,000.00$ & & $432,000.00$ & & - & - & $432,000.00$ \\
\hline 34 & Construction of canal Ak-Terek Aksiy rayon in Dzhalal-Abad oblast & $480,000.00$ & & $480,000.00$ & & - & - & $480,000.00$ \\
\hline 35 & $\begin{array}{l}\text { Construction of Karimberdi canal in village community "Yntynak" } \\
\text { Nookat rayon in Osh oblast }\end{array}$ & $384,000.00$ & & $384,000.00$ & & & - & $384,000.00$ \\
\hline & Construction 1 & $2,250,000.00$ & - & $2,250,000.00$ & - & - & - & $2,250,000.00$ \\
\hline 36 & \begin{tabular}{|l|}
$\begin{array}{l}\text { Affordable social housing } \\
\text { (mortgage lending) }\end{array}$ \\
\end{tabular} & $2,250,000.00$ & & $2,250,000.00$ & & & - & $2,250,000.00$ \\
\hline & Mining 4 & - & $29,251,200.00$ & $29,251,200.00$ & - & $19,411,200.00$ & $19,411,200.00$ & $9,840,000.00$ \\
\hline 37 & Development of gold deposits Ishtamberdy & & $3,667,200.00$ & $3,667,200.00$ & & $3,667,200.00$ & $3,667,200.00$ & - \\
\hline 38 & Development of gold and copper deposits «Bozymchak» & & $7,872,000.00$ & $7,872,000.00$ & & $7,872,000.00$ & $7,872,000.00$ & - \\
\hline 39 & Development of gold deposits «Dzherui» & & $9,840,000.00$ & $\mathbf{9 , 8 4 0 , 0 0 0 . 0 0}$ & & & - & $\mathbf{9 , 8 4 0 , 0 0 0 . 0 0}$ \\
\hline 40 & Development of gold deposits «Taldy-Bulak Levoberezhniy» & & $7,872,000.00$ & $7,872,000.00$ & & $7,872,000.00$ & $7,872,000.00$ & - \\
\hline & & Required & & & Available & & & Financing gap \\
\hline & & $\begin{array}{c}\text { Internal sources } \\
\text { thou. soms }\end{array}$ & $\begin{array}{c}\begin{array}{c}\text { External sources } \\
\text { thou. soms }\end{array} \\
\end{array}$ & Total & $\begin{array}{c}\text { Internal sources } \\
\text { thou. soms }\end{array}$ & $\begin{array}{c}\begin{array}{c}\text { External sources } \\
\text { thou. soms }\end{array} \\
\end{array}$ & Total & \\
\hline & Total: (thou. soms) & $20,485,454.58$ & $292,626,996.50$ & $313,112,451.08$ & $3,331,129.28$ & $61,648,044.20$ & $64,979,173.48$ & $248,133,277.60$ \\
\hline & Total: ( thou. US dollars) & $426,780.30$ & $6,096,395.76$ & $6,523,176.06$ & $69,398.53$ & $1,284,334.25$ & $1,353,732.78$ & $5,169,443.28$ \\
\hline
\end{tabular}

